\title{
A daily process analysis of short -term physical activity goal pursuits in midlife: Changes in goal processes, physical activity, and subjective well -being
}

\author{
Eric A. Goedereis \\ West Virginia University
}

Follow this and additional works at: https://researchrepository.wvu.edu/etd

\footnotetext{
Recommended Citation

Goedereis, Eric A., "A daily process analysis of short -term physical activity goal pursuits in midlife: Changes in goal processes, physical activity, and subjective well -being" (2009). Graduate Theses, Dissertations, and Problem Reports. 2921. https://researchrepository.wvu.edu/etd/2921

This Dissertation is protected by copyright and/or related rights. It has been brought to you by the The Research Repository @ WVU with permission from the rights-holder(s). You are free to use this Dissertation in any way that is permitted by the copyright and related rights legislation that applies to your use. For other uses you must obtain permission from the rights-holder(s) directly, unless additional rights are indicated by a Creative Commons license in the record and/ or on the work itself. This Dissertation has been accepted for inclusion in WVU Graduate Theses, Dissertations, and Problem Reports collection by an authorized administrator of The Research Repository @ WVU. For more information, please contact researchrepository@mail.wvu.edu.
} 
A Daily Process Analysis of Short-term Physical Activity Goal Pursuits in Midlife: Changes in Goal Processes, Physical Activity, and Subjective Well-being

Eric A. Goedereis, M. S.

\author{
Dissertation submitted to the \\ College of Arts and Sciences at \\ West Virginia University \\ in partial fulfillment of the requirements \\ for the degree of
}

Doctor of Philosophy
in
Psychology

Julie Hicks Patrick, Ph.D.

Stanley Cohen, Ph.D.

Kevin Larkin, Ph.D.

Barry Edelstein, Ph.D.

Guyton Hornsby, Ph.D.

\title{
Department of Psychology \\ Morgantown, West Virginia 2009
}

Keywords: daily diary design, physical activity, goals, midlife, well-being, hand-held computers 


\begin{abstract}
A Daily Process Analysis of Short-term Physical Activity Goal Pursuits in Midlife: Changes in Goal Processes, Physical Activity, and Subjective Well-being
\end{abstract}

Eric A. Goedereis

The prevalence of obesity in the United States increases with age, with the highest rates corresponding to midlife. Midlife health behaviors may play a contributing role in many of the health problems commonly associated with advanced age. Health psychologists who have embraced a life-span developmental perspective argue that it is important to consider the individual developmental trajectories of health and successful aging. Goal-setting has been shown to account for significant variance in physical activity, which has a variety of healthpromoting benefits. In order to investigate individual variability in the daily processes of physical activity goal pursuit within a sample of middle-aged adults who were obese or overweight and actively trying to lose weight, data from 35 adults between the ages of 35 and 60 were collected three times per day for six days via Palm ${ }^{\circledR}$ handheld computers. Results from within-person correlation coefficients with repeated measures revealed a number of significant findings: (1) increases in perceived control were associated with increases in goal-directed effort $(r=0.17)$, perceived progress $(r=0.21)$, positive affect $(r=0.25)$, and life satisfaction $(r=$ $0.21)$; (2) decreases in control $(r=-0.22)$ and perceived progress $(r=-0.13)$ were associated with increases in negative affect; (3) increases in goal-directed effort $(r=0.19)$ and perceived progress $(r=0.60)$ were associated with increases in physical activity; and (4) increases in physical activity were associated with increases in positive affect $(r=0.14)$, all $\mathrm{p}<.05$. Although follow-up analyses using weighted correlations generally mirrored these findings, results suggest that group-level associations are not always consistent with individual-level experiences of personal goal pursuits. Findings from this study contribute to life-span perspectives in health and aging by considering the daily variability of overweight and obesity, as well as the psychological processes and consequences associated with physical activity goal pursuit during midlife. Results from this study provide information that might be used to develop interventions targeted at how middle-aged adults can most effectively pursue their physical activity goals in light of personal goal appraisals and how such pursuit are associated with various aspects of subjective well-being. 


\section{DEDICATION}

This dissertation is dedicated to my living grandparents, Dr. and Mrs. Merle Crossland and Marilyn Menn, whose influence is largely responsible for my interest in health and successful aging. May you continue to age well. 


\section{ACKNOWLEDGEMENTS}

I would like to acknowledge my graduate advisor and dissertation chair, Dr. Julie Hicks Patrick, for her flexibility and support. Second, I would like to thank the members of my dissertation committee: Drs. Stan Cohen, Barry Edelstein, Guy Hornsby, and Kevin Larkin. Their thoughtful suggestions, incredible patience, and guidance throughout this project are greatly appreciated. Third, in addition to my dissertation committee, I am indebted to Dr. Sean Meegan, who initially stimulated my interest in developmental psychology and has provided invaluable encouragement, advice, and friendship throughout my own development. Fourth, I would like to thank Deana Everrett for her assistance on this project. Of course, I am incredibly grateful to the individuals who participated in this study for their willingness to allow me access to their personal goal pursuits.

Next, I would like to thank Brian Ayotte, who has proven to be a great mentor and friend since I have known him. I would also like to extend a special thank you to Sam Insana, who has been a constant source of support and friendship during my four years at West Virginia University. Likewise, I am particularly grateful to my friends and colleagues at WVU, including Drs. Melinda Spencer and Clare Mehta, Alisa O'Riley, and Sarah Stahl, whose supportive behaviors are too numerous and broad to list, as well as the Sunday Morning Basketball group, for helping make my time during graduate school enjoyable.

Finally, I would not be where I am if not for the people who have supported me in everything I have pursued. The Green House seems like such a long time ago and I am eternally grateful to a truly unique group of individuals for their enduring friendship. Thank you to the best neighbors imaginable: Michael Balistreri, Rachael Detlor, David Hannum, and Alisa O'Riley. Thank you to my family, particularly my parents Mark Goedereis and Mary Wiewel, for your constant patience and encouragement, to my brothers, Adam and Markus Goedereis, for your loyalty and brotherly love, and to the most supportive in-laws one could imagine Jim, Karen, Kalyn, and Kelli Jones, for welcoming me into your family.

A special thank you is reserved for Mia, who has managed to be a surprising rock of support, love, and happiness and a good reminder for me to keep things in perspective. Finally, I would not have the opportunity to pursue my own personal goals if not for the love, endurance, humor, strong will, dedication, and optimism of my wife Kristina. Thank you all. 


\section{TABLE OF CONTENTS}

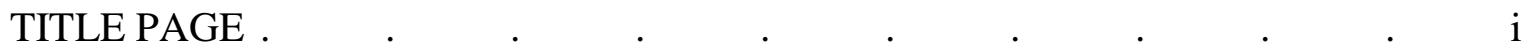

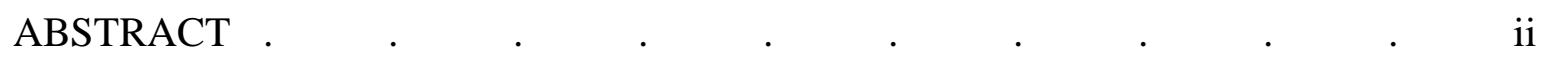

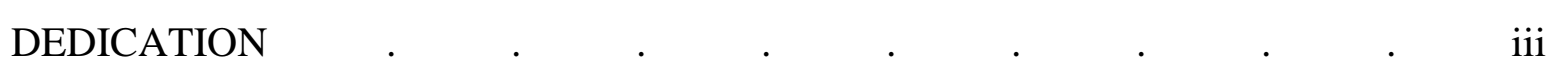

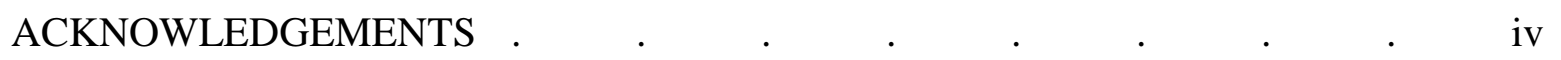

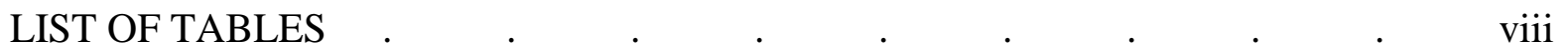

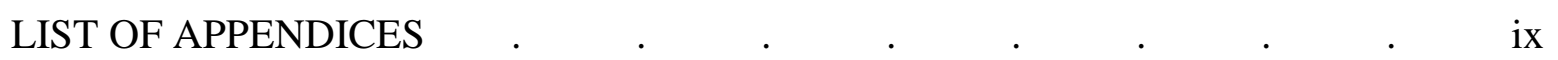

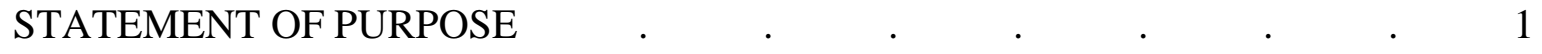

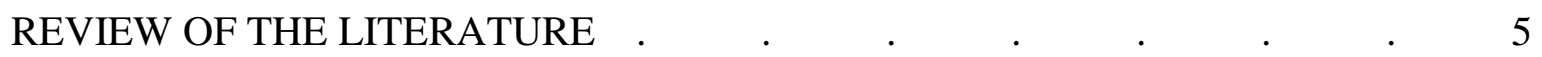

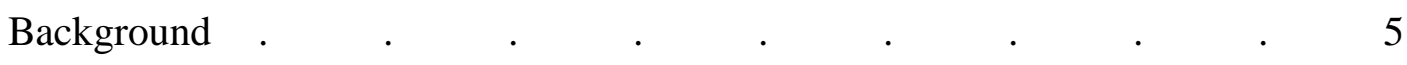

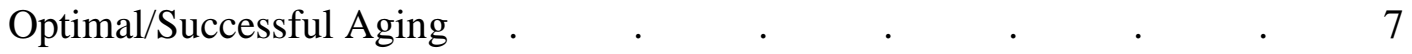

A Life-span Developmental Perspective $\quad . \quad$. $\quad . \quad$. $\quad . \quad 11$

Obesity and Overweight in Health and Aging. $\quad . \quad$. $\quad . \quad$. $\quad 14$

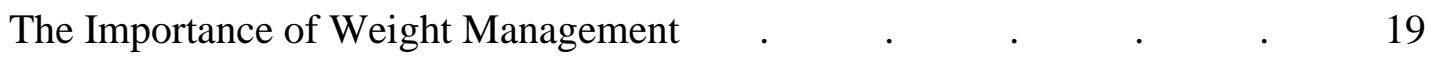

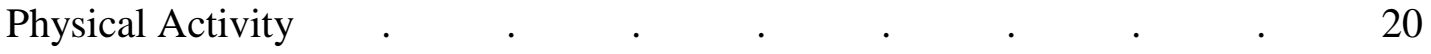

The Role of Personal Goals in Life-span Development

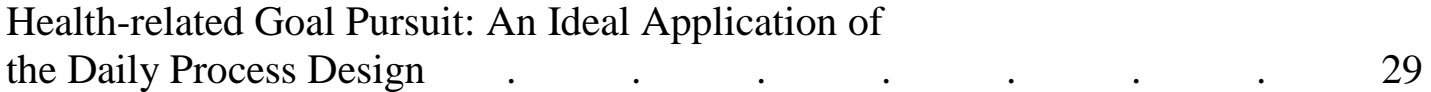

Summary and Rationale for the Present Study. $\quad . \quad \ldots \quad \ldots \quad$. $\quad . \quad$. $\quad$. 33

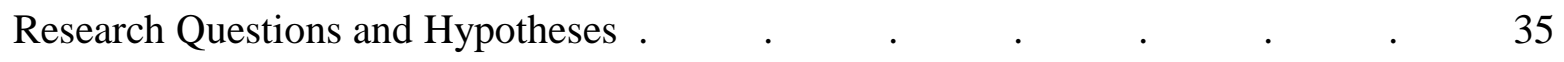

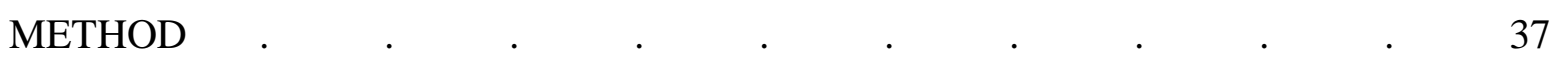

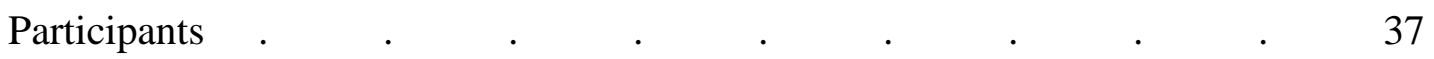

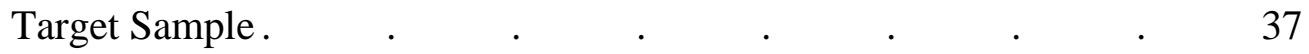


$\begin{array}{lllllll}\text { Screening Procedure and Selection Criteria . } & \text {. } & \text {. } & 37\end{array}$

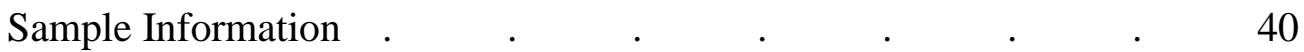

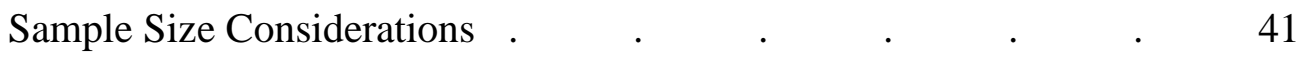

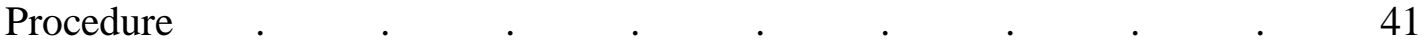

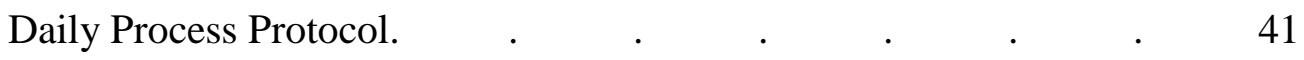

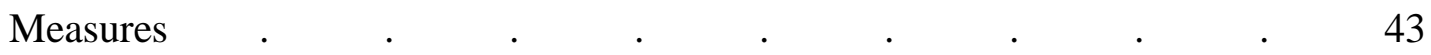

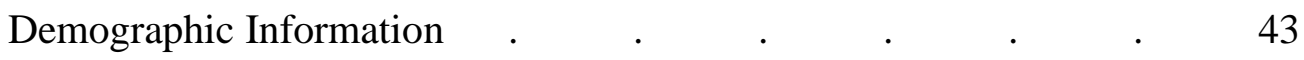

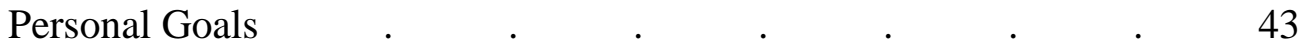

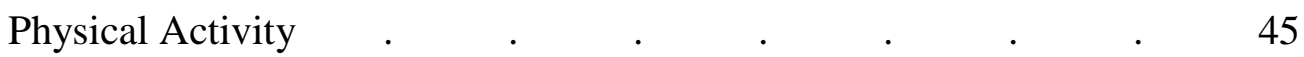

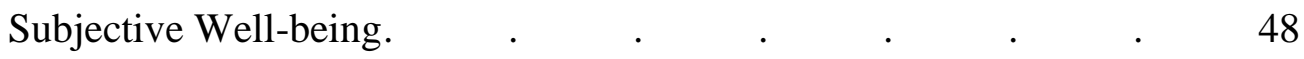

Analytical Approach: Overview of Within-person

$\begin{array}{llllllllll}\text { correlation with Repeated Measures } & . & \text {. } & \text {. } & \text {. } & \text {. } & 49\end{array}$

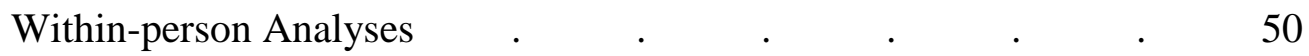

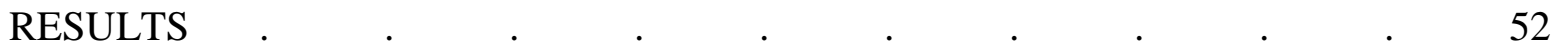

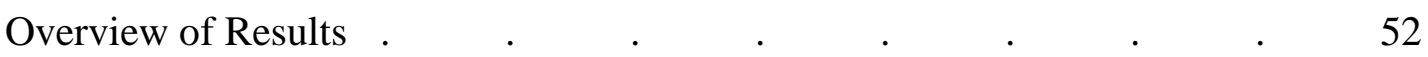

Data Management and Preliminary Analyses . $\quad . \quad$. $\quad . \quad$. $\quad 52$

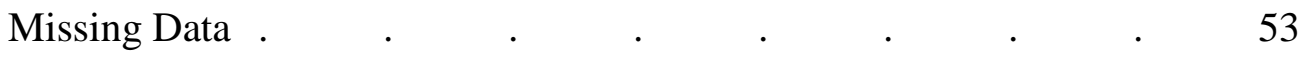

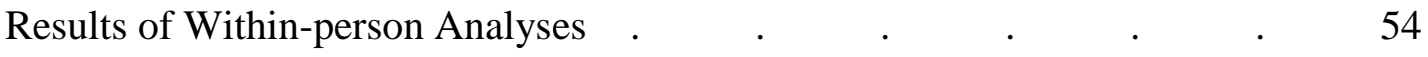

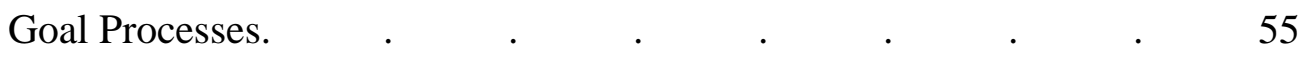

Goal Processes and Physical Activity. $\quad . \quad$. $\quad . \quad$. $\quad$. 56

Goal Processes and Subjective Well-being . $\quad . \quad$. $\quad . \quad 58$

Physical Activity and Subjective Well-being . $\quad$. $\quad$. 62

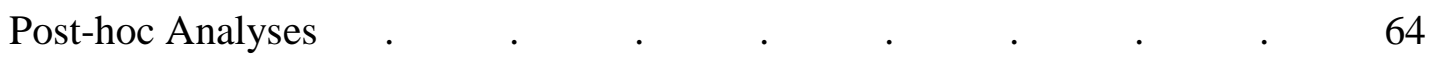


Overview of Sample-level Analyses of Repeated Measures . $\quad$. $\quad 65$

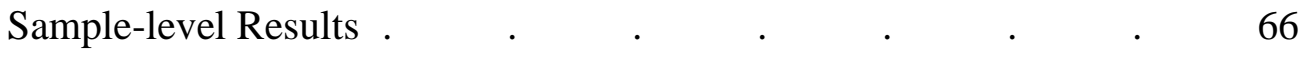

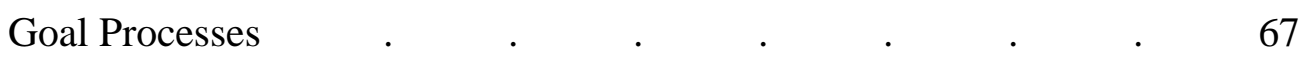

Goal Processes and Physical Activity. $\quad . \quad$. $\quad$. $\quad$. 67

Goal Processes and Subjective Well-being _ . $\quad . \quad$. $\quad 67$

Physical Activity and Subjective Well-being . $\quad . \quad$. $\quad$. 68

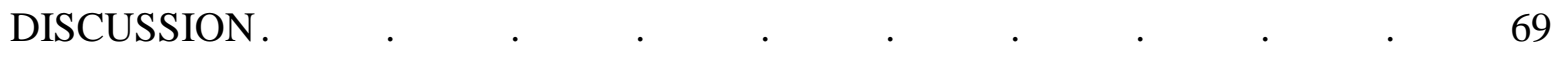

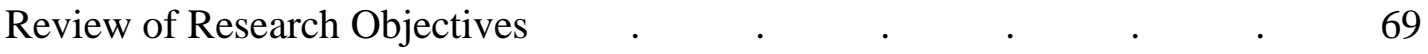

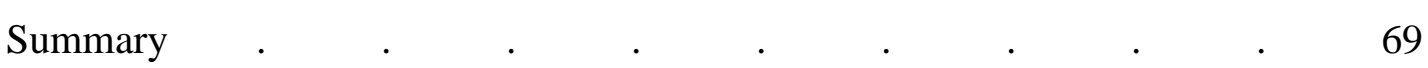

Review of Study Findings and Association with Previous Research . $\quad$ 70

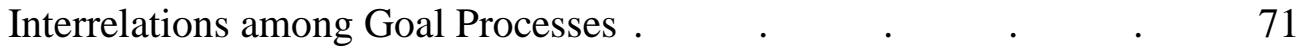

Associations between Goal Processes and Physical Activity. $\quad$. 72

Associations between Goal Processes and Subjective Well-being . 74

Associations between Physical Activity and Subjective Well-being . 78

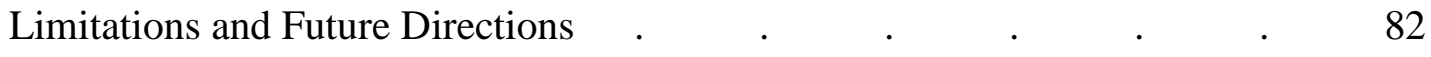

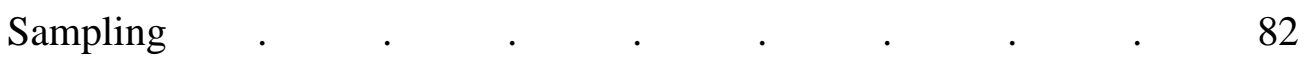

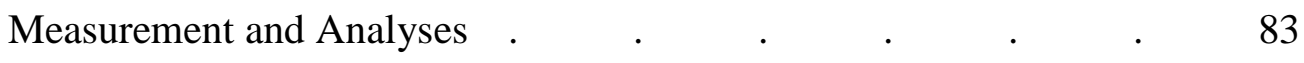

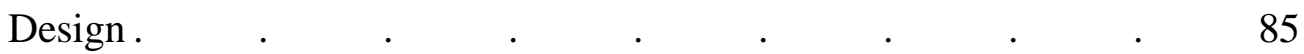

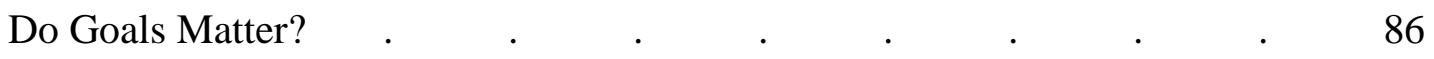

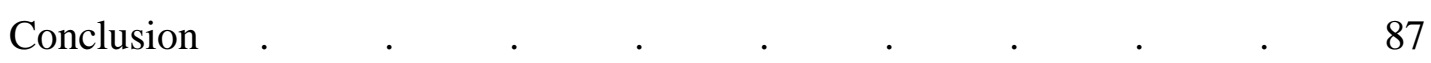

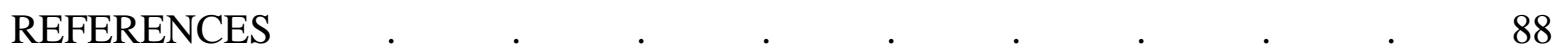




\section{LIST OF TABLES}

1. Sample Characteristics for Total Sample, and Women and Men . .

2. Intercorrelations among Participant Characteristics, Baseline Goal Appraisals,

Individual-level Subjective Well-being and Physical Activity.

3. Summary of Constructs and Measures

4. Physical Activity Goals and Corresponding Strategies Nominated by

Study Participants

5. CHAMPS (Physical Activity) and Baseline Goal Appraisals for Total Sample .

6. CHAMPS and Baseline Goal Appraisals for Total Sample and Low And High Missing Data

7. Standardized Regression Coefficients for Within-person Predictors And Final Model Fit .

8. Sample-level Weighted Correlation Coefficients Among Goal Processes .

9. Sample-level Weighted Correlation Coefficients Among Goal Processes and Physical Activity .

10. Sample-level Weighted Correlation Coefficients for Goal Processes and Subjective Well-being Indices

11. Sample-level Weighted Correlation Coefficients for Physical Activity And Subjective Well-being Indices

12. Summary of Within-person and Sample-level Findings . . . 
LIST OF APPENDICES

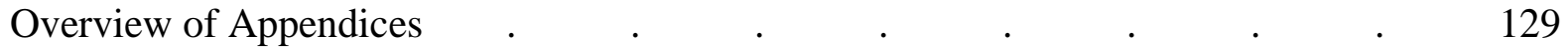

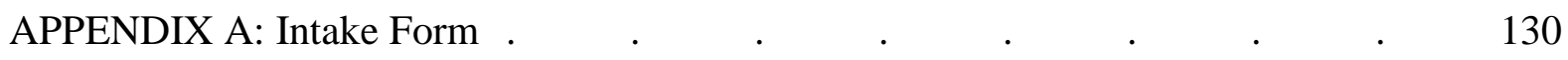

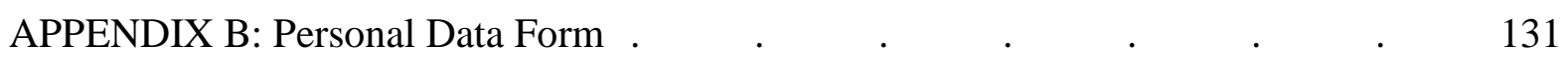

APPENDIX C: CHAMPS Physical Activity Questionnaire . _ . . . . 141

APPENDIX D: Paffenbarger Activity Questionnaire $\quad$. $\quad$. $\quad$. $\quad$. 145

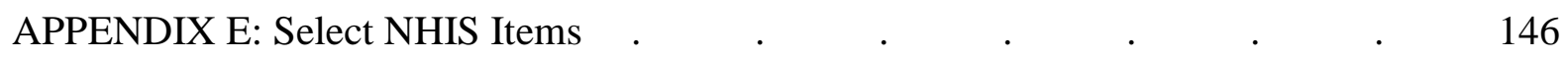

APPENDIX F: Positive and Negative Affect Scales . $\quad . \quad$. $\quad . \quad$. $\quad 147$

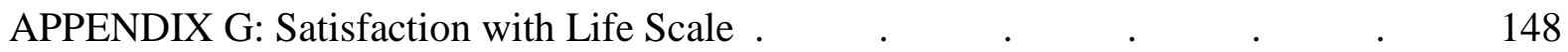

APPENDIX H: Goal Screening and Daily Goal Process Journal 149

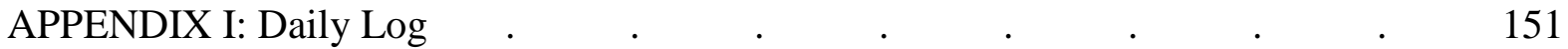




\section{Statement of Purpose}

Recent estimates indicate that the worldwide population of individuals aged 60 and over will grow to 1.2 billion by 2025 and potentially to 2 billion in 2050 (World Health Organization [WHO], 2008). Although this increased life expectancy reflects advances in the quality of health care, it represents important challenges given the increased likelihood of health issues associated with growing older (Ory \& Cox, 1994).

One commonly accepted model of health and successful aging is that advanced by Rowe and Kahn (1997, 1998), which suggests that individuals who age successfully can be identified according to three criteria: (1) the absence of disease, disability, and associated risk factors; (2) maintenance of physical and mental functioning; and (3) active engagement with life. Further, Rowe and Kahn (1998) highlight the importance of perceived control over the aging process. Similarly, other conceptualizations of health and successful aging have focused on the broad construct of subjective well-being (e.g., Baltes \& Baltes, 1990; Freund \& Baltes, 1998), which refers to the broad range of information regarding the variety of factors associated with the way individuals evaluate their own lives, including positive and negative mood, as well as life satisfaction (Diener, Suh, \& Oishi, 1997). Taken together, these perspectives suggest that the concept of successful aging is multidimensional.

Health psychologists who have embraced a life-span developmental perspective (e.g., Spiro, 2001) suggest that it is necessary to move beyond aging as an outcome and instead consider the developmental trajectories of health and aging. Such a framework highlights the importance of studying the processes associated with health and aging across the life span and subsequently shifts the focus from older adulthood to other age periods. One such period, midlife, is a time when a variety of health-related concerns become increasingly salient (Hooker 
$\&$ Kaus, 1994). The prevalence of obesity (Body Mass Index $[\mathrm{BMI}] \geq 30.0$ ) in the United States increases with age, with the highest obesity prevalence rates corresponding to midlife (Centers for Disease Control and Prevention [CDC], 2007). The association of BMI and age with health problems suggests that midlife body weight (and weight gain) may play a contributing role in many of the health problems and functional limitations commonly associated with advanced age (e.g., type 2 diabetes, coronary heart disease, high blood pressure, high cholesterol, and osteoarthritis) (CDC, 2006).

Midlife provides a fruitful context for the study of health-promoting behaviors that might guard against the onset of obesity and thus increase the likelihood of aging successfully. One of the most effective strategies for weight management and improving one's health is to engage in physical activity (for review, see U.S. Department of Health \& Human Services, 2008). With respect to Rowe and Kahn's $(1997,1998)$ model of successful aging, active lifestyles during midlife are longitudinally associated with better physical (Hillsdon, Brunner, Guralnik, \& Marmot, 2005; Lang, Guralnik, \& Melzer, 2007) and mental (Kramer, Hahn, \& McAuley, 2000; Singh-Manoux, Hillsdon, Brunner, \& Marmot, 2005) functioning, as well as higher scores on various indicators of subjective well-being ( (Arent, Landers, \& Etnier, 2000) in older adulthood.

One potential avenue by which an individual might engage in regular activity in order to effectively manage his or her weight is through the formulation and pursuit of personal healthrelated goals. Goal-setting has been shown to account for significant variance in a variety of health-promoting behaviors, including physical activity (for review, see Shilts, Horowitz, \& Townsend, 2004).

Although personal goals provide individuals with structure and meaning for their daily behaviors, the way individuals evaluate their goals may have important consequences for goal 
pursuit, as well as health behaviors and various indices of subjective well-being. The Theory of Planned Behavior (TPB; Ajzen, 1985) provides a useful framework for examining personal goals and goal appraisals and has been extensively applied to studies of physical activity. According to the TPB, behavior is determined by the combination of attitudes, subjective norms, perceived behavioral control, and intention, with results from meta-analyses suggesting that perceived control and behavioral intentions are most strongly associated with exercise and that TPB may operate differently based on the specific behavior and age of the study sample (Symons \& Hausenblaus, 2005). These findings lend support to the life-span perspective, which suggests that it is important to examine the processes and determinants of health-promoting behaviors across the life span.

Consistent with the propositions of the TPB and relevant to the present study, perceived control is thought to influence one's behavioral intentions, which are often articulated in the form of short-term personal goals, which then help individuals manage their action and effort (Bandura, 2004). Thus, it becomes important to assess how an individual evaluates his or her intentions to engage in a physical activity in order to gain a better understanding of the psychological processes associated with goal pursuit. Daily process studies involve multiple daily (and often within-day) measurements of key variables over time and allow researchers to examine dynamic associations between variables of interest, as well as the variability that may occur during short periods of time (Tennen, Affleck, \& Armeli, 2003). Such designs provide a useful method of inquiry by which to further examine the processes associated with healthrelated behavior, including psychological factors as they relate to physical activity goal pursuit (e.g., Tennen et al., 2003).

The present study employed a daily process design in order to examine in detail one 
specific behavior - the pursuit of one's physical activity goals for weight loss - and how individual variability in physical activity goal pursuit is associated with changes in physical activity and various indices of subjective well-being in non-sedentary, middle-aged individuals who were either overweight or obese and actively trying to lose weight. This study contributes to life-span perspectives in health and aging by considering the developmental trajectories of overweight and obesity, as well as the psychological processes and consequences associated with physical activity goal pursuit during midlife.

Specifically, data on physical activity, positive and negative mood, life satisfaction, and appraisals of one's physical activity goal pursuits using variables outlined in the Theory of Planned Behavior (Ajzen, 1986) were collected at three time points during the day for six consecutive days. Although daily process studies have examined a variety of health-related topics, (e.g., daily experiences of illness, Larsen \& Kasimatis, 1991; health/fitness goals, Affleck et al., 1998), the present study is the first to specifically apply this method within a sample of middle-aged individuals who are either overweight or obese and actively trying to lose weight. In addition, experience sampling via the use of a handheld computer for data collection provides a more "in the moment" evaluation of participants' goal pursuits and affect, which expands upon previous literature in this area. Results from this study provide valuable information that might be used to develop interventions targeted at how middle-aged adults can effectively pursue their physical activity goals in light of personal goal appraisals and how such pursuits may impact various aspects of subjective well-being. 


\section{Introduction (Parts I - VII)}

This chapter is divided into two sections. The first section (Parts I-III) provides an introduction to various conceptual and theoretical issues underlying the rationale of the current study. The second part (Parts IV - VII) presents a review of the literature with respect to obesity, physical activity, and personal goal processes, with a specific focus on midlife.

\section{Part I: Background}

Changing demographics. The average life expectancy for a person born in the United States (U.S.) in 1970 was 70.8 years (U.S. National Center for Health Statistics, [NCHS], 2008). By 2010, this figure is expected to increase to 78.3 years and by 2020 , U.S.-born individuals might reasonably anticipate living to nearly 80 (NCHS). The addition of nearly 10 years of average life expectancy within a span of just 50 years is clearly an impressive achievement.

With this increased life expectancy comes a corresponding increase in the number of older adults within the population. The World Health Organization (WHO) estimates that over 600 million individuals worldwide are age 60 or above. Further, this figure is expected to grow to 1.2 billion by 2025 and to over 2 billion by 2050 (WHO, 2008). At the national level, census data indicate that $17.1 \%$ of the US population are age 60 or above (U.S. Census Bureau, 2005). Clearly, individuals today are living longer than in previous years. Given these data, it becomes important to examine the factors associated with health and illness during this period of the life span.

When does health become a concern? Increasing age is associated with an increased risk of developing one or more chronic conditions. For example, the risk of developing arthritis and hypertension is quite high during midlife, with prevalence rates (per 1,000 individuals) estimated to be as high as 214.8 (for hypertension) in this population (NCHS, 1996). Other research 
suggests that the risk of developing both cancer (Greenlee, Murray, Bolden, \& Wingo, 2000) and coronary heart disease (Lloyd-Jones, Larson, Beiser, \& Levy, 1999) increases with age such that risks are significant and present during midlife, yet greatly increase from midlife to older adulthood.

Consequently, death rates attributed to such chronic conditions also increase with age. For example, in 2005, death rates due to specific chronic conditions, including heart disease, cancer, stroke, diabetes, and chronic obstructive pulmonary disease (COPD) steadily increased between the first and second decades of midlife (i.e., 35-44 and 45-54) and increased dramatically after age 55 (NCHS, 2008). More generally, all-cause mortality rates increase with age, with 199.6 (35-44 years), 423.5 (45-54 years), 1,030.7 (55-64 years), and 2,495.1 (65-74 years) deaths per 100,000 individuals (National Vital Statistics System [NVSS], 2000).

Perhaps not surprisingly, adults evaluate their health differently across the life span. For example, approximately $73 \%$ of men and $68 \%$ of women between the ages of 25 and 44 rate their health as either "excellent" or "very good," yet later into midlife (age 45-64), only 58\% of men and $53 \%$ of women do so, while just $39 \%$ of men and women have such favorable views of their own health after age 65 (NCHS, 1999). Given the data, it should not be surprising that for many adults, midlife is a time when a variety of health-related concerns become increasingly salient (Hooker \& Kaus, 1994).

In addition to the chronic conditions discussed thus far, one of the most important health threats facing industrialized nations today is overweight and obesity. Some estimates suggest that obesity (as indicated by a Body Mass Index [BMI] of 30.0 or above) prevalence rates are highest during the middle-age years (Ferraro, Thorpe, \& Wilkinson, 2003; Flegal, Carroll, Ogden, \& Johnson, 2002; Hedley et al., 2004) and that BMI tends to increase for individuals during midlife 
(Cornoni-Huntley et al., 1991). These data are particularly troubling in light of the generally negative impact of obesity and overweight on health status.

Taken together, these data highlight the importance of considering the developmental trajectories of health and illness across the life span. Given the changing demographics in the United States, with the number of older adults representing increasingly larger proportions of the population, coupled with data suggesting that BMI increases with age, it becomes imperative to examine the role of body weight on health across the life span. Considering the societal costs associated with chronic health conditions associated with obesity and overweight, a cohesive framework is needed in order to steer efforts aimed at meeting the health needs of this population.

\section{Part II: Optimal/Successful Aging}

Health and illness. One common way to view health is the absence of disease, disability, or impairment such that an individual is either healthy or is not. However, considerable variability exists with respect to health status and this is particularly true in older adulthood. Thus, an alternative conceptualization is to view health and illness as opposite ends of a continuum (George, 2001; Sarafino, 1994). Influencing where a person is situated along this continuum are a variety of interacting biological (e.g., chronic illness, genotype), environmental (e.g., social networks, access to healthcare), and psychological (e.g., perceived control, depression) factors. These factors and their impact on health vary across the life span.

Models of successful aging. In examining the health and illness continuum, scholars have advanced various concepts of successful, optimal, or healthy aging (e.g., Gingold, 1999; Fries, 2002; Rowe \& Kahn, 1997; for discussion on and summary of these topics, see Bowling, 2007) in order to examine how individuals effectively manage the aging process. Central to many of 
the ideas of successful aging is the assumption that many of the negative effects of aging have been overestimated and that many of the declines and issues commonly associated negatively with the aging process can be minimized through lifestyle behaviors such as physical activity (e.g., Rowe \& Kahn, 1997; Vaillant, 2002). Although there has been an increased focus on examining behaviors that might promote successful aging, there is much variability in terms of scholars' conceptualizations of what it means to age successfully (for review, see Bowling, 2007).

Biomedical models. Physical and mental functioning are primary considerations for researchers studying successful aging within a biomedical model (e.g., Gingold, 1999; Glass, Seeman, Herzog, Kahn, \& Berkman, 1995; Rowe \& Kahn, 1987). The biomedical paradigm dominated much of the literature on successful aging and focused on the role of infectious disease, genotype hormonal abnormalities, or medical treatments in determining health status and ultimately who aged successfully. Although this approach was highly effective in stimulating much research, it has been criticized for its neglect of psychological and environmental influences on health, as well as its implicit definition that health is marked by the absence of disease or illness as opposed to something that could be advanced through lifestyle behaviors (Whitman, 1999).

Environmental models. Environmental models emphasize the contribution of one's physical environment, as well as one's social networks, to health status. Physical environmental determinants include neighborhood and access to health care; social environmental determinants include one's coworkers, spouse, and peer networks. Several models of successful aging incorporate environmental influences (e.g., Fisher, Day, \& Collier, 1992; Grundy \& Bowling, 1999; Rowe \& Kahn, 1987, 1997). 
Psychological models and the importance of subjective well-being. Behavioral and social scientists often adopt psychological models, which recognize the role of factors such as subjective well-being (e.g., Freund \& Baltes, 1998) and life satisfaction (e.g., Vaillant, 1990) as indicators of health status and successful aging.

Subjective well-being (SWB) is a broad construct that provides a range of information regarding the variety of factors associated with the way individuals evaluate their own lives. Individuals high in SWB may demonstrate high levels of positive mood, low levels of negative mood, and high levels of life satisfaction (Diener, Suh, \& Oishi, 1997). Further, various health indicators, including the presence of chronic illnesses, as well as both functional and subjective health, have been found to longitudinally account for significant amounts of variance in various domains of SWB, as well as various indicators of active engagement with one's life (Smith, Borchelt, Maier, \& Jopp, 2002). Thus, SWB may provide a useful conceptualization of successful aging (e.g., Baltes \& Baltes, 1990).

Likewise, psychological variables such as feelings of control (e.g., Brandstadter \& Baltes-Gotz, 1990; Freund \& Baltes, 1998), self-efficacy (e.g., Seeman, Unger, McAvay, \& Mendes de Leon, 1999), and motivation (e.g., Freund \& Riediger, 2003) have all been incorporated into psychological models of successful aging. Social functioning also contributes to successful aging within psychological models (e.g., Strawbridge, Cohen, Shema, \& Kaplan, 1996) as well as biomedical models (e.g., Rowe \& Kahn, 1987). Finally, psychological models emphasize lifestyle behaviors such as physical activity as important determinants of health and illness. From this perspective and contrary to biomedical models, much of the focus is on preventing illness and how people might promote their own health through personal lifestyle choices (Whitman, 1999). 
Interestingly, although many of the traditional biomedical, environmental, and psychological models of successful aging might suggest otherwise, many older adults believe themselves to have aged quite successfully (Bowling \& Dieppe, 2005), leading to the question of who should define what it means to age successfully (e.g., Bowling, 2007; Golub \& Langer, 2007). Despite such inconsistencies, models of successful aging have generated a great deal of research aimed at adding "life to years" (Havinghurst, 1961) and are thus useful for providing a conceptual framework for continued investigation. Taken together, a multidimensional conceptualization of successful aging that incorporates physical and mental health, subjective well-being, social functioning, and individuals' perceptions of their own health and aging appears most comprehensive and appropriate.

Rowe and Kahn's model of successful aging. One of the most widely known conceptualizations is Rowe and Kahn's $(1987,1997,1998)$ model of successful aging, which incorporates biological, environmental, and psychological components into its definition. Originally, Rowe and Kahn (1987) distinguished between normal aging, which is characterized by declines and diseases, and successful aging, which was characterized by the absence (or very few) of these declines. In summarizing the data, Rowe and Kahn argued that individuals who aged successfully could be identified according to three criteria: (1) the absence of disease, disability, and risk factors, (2) maintenance of physical and mental functioning, and (3) active engagement with life (Rowe \& Kahn, 1997, 1998). Further, Rowe and Kahn (1998) highlight the importance of psychological factors, such as perceived control over the aging process, as important to successful aging.

Within the context of Rowe and Kahn's model, the task is to identify the determinants of their criteria for successful aging. As previously discussed, one's place on the continuum of 
health and illness is influenced by biological, environmental, and psychological factors. Thus, researchers working within Rowe and Kahn's model who are interested in promoting many of the physical aspects of successful aging might ask: How might biological factors such as BMI contribute to functional impairment? How might psychological variables such as perceived control over or effort towards regular physical activity affect physical and cognitive functioning? How might environmental factors such as one's social network promote or inhibit an active engagement with life? Similarly, researchers more interested in the SWB aspects of successful aging might ask: How might BMI contribute to positive or negative moods? How might one's own personal feelings of control affect his or her overall outlook on life? How might support from others contribute to an individual's life satisfaction? The life-span developmental perspective (Baltes, 1987) provides a useful conceptual framework in which to systematically examine such research questions and how these and other factors contribute to successful aging across the life span.

\section{Part III: A Life-span Developmental Perspective}

Overview. The life-span perspective (Baltes, 1987; Baltes, Lindenberger, \& Staudinger, 1998) is a contextual metatheory that guides a variety of developmental approaches within this perspective. Life-span developmental psychologists view development as an interaction between an individual and his or her environment. From this perspective, people are active agents in their development, placing themselves into a variety of contexts, while learning how to react and adapt to these contexts and circumstances across the life span.

Considering health within a life-span developmental framework. One way to integrate the health and aging literatures is through a life-span developmental perspective. Health psychologists who have embraced a lifespan developmental perspective (e.g., Spiro, 2001) 
suggest that biological, environmental, and psychological influences on health may operate differently at various points of the life span. When examining health, it is important to consider the various propositions of a life-span perspective. Four of these tenets: (1) development occurs within a sociohistorical context, (2) development is a lifelong process, (3) development is multidimensional, and (4) development involves individual differences are particularly relevant to the present study.

First, it is essential to recognize that all development occurs within a given sociohistorical context, as this is one of the core propositions of the life-span perspective. Across the life span, development is influenced by a variety of age- and history-graded normative and non-normative life events. Consider the impact of obesity on health. The average life expectancy for a person born in the U.S. in 2005 is nearly 77 years. This estimate is explicitly tied to one's sociohistorical context, as individuals born in 1990 were likely to live just over 75 years. Similarly, the prevalence of obesity in today's U.S. population (see Part IV) could potentially contribute to a lower average life expectancy and increased frequency of health problems during midlife and older adulthood (Aldwin, Spiro, \& Park, 2006).

A second, related proposition is that development is a lifelong process. For example, compared to those who have a profile of higher risk of cardiovascular disease (e.g., high cholesterol, smoker) in midlife, adults who exhibited lower risk profiles during midlife had lower risks for heart disease, cardiovascular disease, stroke, cancer, and mortality several years later (Stamler et al., 1999). Similarly, Britton and colleagues demonstrated that various early-life (e.g., education, father's social class) and midlife (e.g., socioeconomic status, smoking behavior, diet, and exercise) factors were associated with the absence of disease and maintenance of physical functioning in old age (Britton, Shipley, Singh-Manous, \& Marmot, 2008). 
Third, as previously discussed, health in general, and successful aging in particular, is multidimensional. This is particularly important within the context of the current study, as health is but one dimension of lifelong development. Specifically, it is not enough to simply observe whether or not someone exhibits a disease or impairment. Certainly biological indicators such as BMI are important dimensions of health. However, it is also important to consider how one evaluates his or her life, as well as both positive and negative affect. These aspects of subjective well-being contribute to optimal development and are consistent with the World Health Organization's (1946) definition of health as "a state of complete physical, mental, and social well-being and not only the absence of diseases and infirmity" (p. 100).

Fourth, a life-span perspective recognizes the potential for a variety of developmental trajectories within and across domains. Thus, researchers who study development within a lifespan perspective appreciate and are interested in individual differences in developmental processes and outcomes. This assumption requires methods that allow researchers to examine not only between-person averages, but also within-person changes in a given phenomenon. Such an approach is particularly important with respect to health. For example, scholars have recognized the importance of examining within-person variability in physical activity (Atienza, Oliveira, Fogg, \& King, 2006), recurring stress (Kamarck, Shiffman, Smithline, Goodie, \& Jong, 1998), and coping with chronic pain (Tennen, Affleck, Armeli, \& Carney, 2000).

Given these propositions, from a life-span perspective, optimal or successful development is an ongoing process of the various dynamic interactions between a person and his or her environment that maximize gains and minimize losses. This approach focuses on how individuals strive toward their desired outcomes and how this changes with age. For optimal development, it is necessary to strike a balance between one's needs and environmental demands 
on one's resources. What this means for researchers is that it is necessary to move beyond aging as an outcome and instead consider the developmental trajectories of health and aging. Such a framework highlights the importance of studying the dynamic processes associated with health and aging across the life span and subsequently shifts the focus from older adulthood to other age periods such as midlife.

Having reviewed the conceptual and theoretical issues underlying the rationale of the current study, I will now discuss the key study variables (i.e., overweight, obesity, physical activity, and personal goal processes) with respect to aging in general and midlife in particular. Part IV: Obesity and Overweight in Health and Aging.

Defining overweight and obesity. Before discussing the possible relation between body weight, health, and aging, it is important to clarify what is meant by the terms "overweight" and “obese.” According to an expert panel report of the National Heart, Lung, and Blood Institute (NHLBI), the term "obesity" is used to denote medical or health risk associated with excess body fat (NHLBI, 2002). Obesity can be determined using the Body Mass Index (BMI), which is calculated by either of the following two methods: (1) weight $(\mathrm{kg})$ divided by height (in meters squared), or (2) weight (in lbs) divided by height (in inches squared), multiplied by a scaling factor of 703. Based on these calculations, the NHLBI defines four primary categories: (1) underweight, which consists of a BMI less than 18.5, (2) normal weight, which consists of a BMI between 18.5 and 24.9, (3) overweight, which consists of a BMI between 25.0 and 29.9, and (4) obesity, which consists of a BMI greater than 30 (NHLBI, 2002). Although BMI is not a diagnostic tool, it is often used as a screening tool to identify potential weight problems in adults (CDC, 2006) and has been shown to correlate well with other measures of body fat (Mei et al., 2002; Willett, Dietz, \& Colditz, 1999) 
Prevalence rates in the Unites States. Recent estimates indicate that the prevalence of overweight $(\mathrm{BMI}=25.0-29.9)$ in the United States increases with age with approximately $37 \%$ of 35-44 year-olds, 38\% of 45-54 year-olds, and nearly 40\% of 55-64 year-olds in America classified as overweight. Similarly, data drawn from the Behavioral Risk Factor Surveillance System (BRFSS) indicate that approximately $28 \%$ of $35-44$ year-olds, $31 \%$ of $45-54$ year-olds, and $32 \%$ of $55-64$ year-olds are classified as obese $(\mathrm{BMI} \geq 30.0)$ (Centers for Disease Control and Prevention [CDC], no date). As previously discussed, obesity prevalence rates may be highest during midlife (Ferraro et al., 2003; Flegal et al., 2002; Hedley et al., 2004). Further, BMI tends to increase for individuals during their middle-age years (Cornoni-Huntley et al., 1991). Given current patterns of health and lifestyle behaviors in the U.S., Wang and colleagues estimated that by 2030 , over $86 \%$ of U.S. adults will be either overweight or obese (Wang, Beydoun, Liang, Caballero, \& Kumanyika, 2008). These data are particularly troubling in light of the generally negative impact of obesity and overweight on health status.

Overweight, obesity and mortality. Aging does not occur in isolation; biological, psychological, and environmental factors contribute to the aging process. With respect to the present study, much research indicates that one biological factor in particular, body weight, is specifically associated with mortality. Longitudinal data such as those from the Framingham Heart Study indicate that adults who were obese at 40 died approximately 6 years earlier than their normal-weight peers (Peeters et al., 2003). Similarly, Willcox and colleagues reported that men who avoided overweight during midlife were more likely to survive to age 85 than men who were overweight during their middle-aged years (Willcox, He, Chen et al., 2006). Other research further highlights the role of obesity during young adulthood and its impact on mortality. In a review of several national survey data sets, Fontaine and colleagues found that men who were 
severely obese (i.e., BMI > 45) in their twenties died at least 13 years earlier than their counterparts. Similarly, women in this age group who were severely obese died eight years earlier than their normal-weight peers (Fontaine, Redden, Wang, Westfall, \& Allison, 2003).

Overweight, obesity, health, and successful aging. Ultimately, research suggests a positive association between BMI and age (until age 75), as well as a positive association between BMI and health problems (Stevens et al., 1998). Although overweight individuals are at an increased risk for certain health problems, it is those individuals who are obese who are at a greater risk (CDC, 2006).

Adults who are obese are at an increased risk of developing a variety of chronic health conditions, including type 2 diabetes, coronary heart disease, high blood pressure, high cholesterol, and osteoarthritis (CDC, 2006). Using national survey data from the Third National Health and Nutrition Examination Survey (NHANES III), higher BMI was associated with an increased prevalence of chronic conditions and the likelihood of having two or more chronic conditions was highest for obese, followed by overweight, individuals compared to normal weight individuals (Must et al., 1999). In fact, based on trends from national survey data, by 2030, overweight and obesity-related healthcare costs are estimated to make up as much as $18 \%$ of the total healthcare expenditures in the U.S. (Wang et al., 2008). Further, research suggests that both women and men who were either overweight or obese during midlife accumulated more Medicare expenditures in later adulthood compared to nonoverweight individuals. Specifically, both women and men spent significantly more annually if they were overweight ( $\$ 7,653$ and $\$ 8,390$, respectively) or obese $(\$ 9,612$ and $\$ 10,128$, respectively) at midlife than nonoverweight women $(\$ 6,224)$ and men $(\$ 7,205)$ (Daviglus, Liu, Yan et al., 2004).

Similarly, obesity is generally associated with an increased risk of functional impairment 
among community-dwelling older adults, with general physical functioning suffering with increased BMI (Apovian, Frey, Rogers, McDermott, \& Jensen, 1996). With respect to functional mobility, both overweight and obese older adults report more impairment than do their normal weight peers (Hubert, Block, \& Fries, 1993; Jenkins, 2004; Launer, Harris, Rumpel, \& Madans, 1994). Using data from the Health, Aging, and Body Composition (Health ABC) Study, Penninx and colleagues found that the highest risk of mobility limitations was in those individuals with the highest amounts of abdominal obesity in particular (Penninx et al., 2009).

In addition, BMI also predicts future disability (Davison, Ford, Cogswell, \& Dietz, 2002; Jensen \& Friedmann, 2002). Using longitudinal data on over 30,000 young and middle aged adults, Rissanen and associates found that the risk of work disability was strongly and positively associated to BMI, with women with BMIs greater than 30.0 being twice as likely and men with BMIs greater than 30.0 being 1.5 times as likely to report work disability than normal weight adults (Rissanen, Heliovaara, Knekt, Reunanen, \& Maatela, 1990).

Overweight, obesity and subjective well-being. In addition to an increased risk of functional impairment, research suggests that overweight and obesity negatively impact various indices of subjective well-being. For example, Fine and colleagues found that obesity was negatively associated with women's health-related quality of life (Fine et al., 1999). Similarly, in a longitudinal study which followed over 6,700 individuals from midlife to older adulthood, Daviglus and associates found body mass index at baseline (i.e., during the middle-age years) to be negatively associated with health-related quality of life scores 26 years later (Daviglus, Liu, Yan et al., 2003). Further, Lean, Han, and Seidell (1998) demonstrated that young and middleaged adults who had higher amounts of abdominal obesity were twice as likely to report difficulties in daily activities as their normal weight counterparts. Using longitudinal data from 
the National Health and Nutrition Examination Survey (NHNES), Rumpel and colleagues found that over the course of a 10 -year follow-up, women who gained 11 pounds or more were 1.5 times more likely to report lower subjective well-being, more negative affect, and lower positive affect than women who did not (Rumpel et al., 1994).

The developmental trajectory of obesity. Although overweight and obesity are clearly associated with an increased risk of developing various chronic conditions, as well as various decreases in SWB, the developmental trajectory of becoming overweight or obese is also important. Given the linear association between BMI and age in terms of health problems, research suggests that midlife body weight (and weight gain) may play a contributing role in many of the health problems and functional limitations commonly associated with advanced age (Stevens et al., 1998). For example, Yan and colleagues reported that individuals who were obese during midlife were more likely to be hospitalized for coronary heart disease, cardiovascular disease, and diabetes than middle-aged individuals who were normal weight (Yan et al., 2006). Similarly, Harris and associates found that older adults who had histories of being overweight since age 50 had higher rates of coronary heart disease than older adults who became overweight later in life (Harris, Launer, Madans, \& Feldman, 1997). In a longitudinal study of nearly 20,000 Finnish adults, obesity was associated with an increased risk of work disability, heart disease, and medication use than their normal-weight peers over a 15 year period (Visscher et al., 2004).

Given recent declines in obesity-related deaths, coupled with an increasing number of older adults within the population, as well as a younger age of obesity onset, these data suggest the potential for an increased burden associated with functional impairments within a population of older adults who are obese (Alley \& Chang, 2007). Taken together, these findings underscore 
the importance of examining the role of midlife overweight and obesity in the aging process.

Cumulative lifetime experiences are also important in determining health status. Certain lifestyle behaviors such as regular physical activity have been shown to be effective for weight management and thus protect against some of the declines commonly associated with aging. The next section reviews the importance of weight management with respect to promoting healthy aging.

Part V: The Importance of Weight Management

Benefits of weight management. Given the increased risks of mortality, chronic health conditions, functional impairment, and decreased quality of life and well-being associated with overweight and obesity, it becomes important to examine how to guard against the onset of obesity. Research suggests that individuals who lose even a modest amount of weight (e.g., 10\% of initial body weight) are likely to experience a host of health improvements (Zamboni et al., 2005), including lower blood pressure, reduced cholesterol levels (Goldstein, 1992), and a lower risk of coronary heart disease (Bales \& Buhr, 2008).

The benefits of weight loss also extend to physical functioning (Lee, Chang, Loiu, \& Chang, 2006), including fewer symptoms of osteoarthritis (Bales \& Buhr, 2008), as well as mental functioning (Wing, Epstein, Marcus, \& Kupfer, 1984). Taken together, as summarized in a review of obesity treatments in older adulthood, McTigue and colleagues conclude that interventions aimed at diagnosing and treating obesity are effective at reducing the health complications associated with obesity in older adulthood (McTigue, Hess, \& Ziouras, 2006).

Further, research has shown that individuals who participate in weight control programs are also likely to report improvements in SWB (Wadden, Womble, Stunkard, \& Anderson, 2002). For example, Villareal and colleagues implemented a weight loss intervention within a 
sample of obese older adults. Participants in the treatment group, which consisted of three days/week of regular exercise as well as weekly behavioral counseling, lost more weight and improved their physical performance compared to those older adults in the control condition (Villareal, Banks, Sinacore, Siener, \& Klein, 2006). Further, the American Society for Nutrition and The Obesity Society agree that weight-loss treatments are effective for adults suffering functional limitations and complications due to overweight and obesity (Villareal, Apovian, Kushner, \& Klein, 2005)

Given the risks associated with overweight and obesity, many of which can preclude aging successfully and decrease SWB, it is clear that most individuals would do well to engage in behaviors that minimize their chances of becoming overweight or obese. One promising and largely modifiable behavior that has shown promise for reducing the risk of overweight and obesity is regular physical activity.

\section{Part V: Physical Activity}

Benefits of physical activity. Research suggests that one of the most effective strategies for weight management and improving one's health is to engage in physical activity (for review, see U.S. Department of Health \& Human Services, 2008). In order to receive the healthpromoting benefits of physical activity, adults should engage in vigorous physical activity 3 or more days per week for 20 (or more) minutes per session or moderate physical activity 5 or more days per week for 30 (or more) minutes per occasion (Haskell, Lee, Pate et al., 2007).

Regular physical activity has been shown to be effective in reducing health complications in both middle-aged (Lang, Guralnik, \& Melzer, 2007) and older adults (Berg, 2003; Stevens, Cai, Evenson, \& Thomas, 2002). With respect to physical functioning, older adults who engage in physical activity are better able to perform routine tasks of daily living (Buckwalter, 1997), 
and demonstrate better mobility (National Institute on Aging, 2006) and range of motion (Klein, Stone, Phillips, Gangi, \& Hartman, 2002) compared to sedentary older adults. The benefits of physical activity also extend to mental functioning, including improvements in performance on fluid intelligence (Sing-Manoux, Hillsdon, Brunner, \& Marmot, 2005) and various task planning and working memory tasks (Kramer, Hahn, \& McAuley, 2000).

Physical activity and subjective well-being. Additionally, physical activity appears to be associated with various indicators of SWB. Qualitative research suggests that physical activity contributes to a variety of indices of SWB, including positive attitudes, increased mental alertness, stress avoidance, and maintenance of an active lifestyle (Stathi, Fox, \& McKenna, 2002). In terms of longitudinal, quantitative evidence, Elavsky (2005) found that increases in physical activity over a 4-year period were associated with gains in both self-esteem and positive mood, and that such increases in positive mood subsequently predicted increases in quality of life. Using a daily diary design that permitted the tracking of within- and across-day change, Steele (2004) found a positive relation between physical activity and positive mood over a six day period in a sample of older, community-dwelling women, which illustrates the dynamic association between physical activity and SWB. With respect to older adulthood in particular, the results of a recent meta-analysis of 32 empirical studies underscore these findings and indicate that exercise is associated with greater positive affect and decreased negative affect (Arent, Landers, \& Etnier, 2000).

Epidemiological evidence suggests that physical activity is positively related to SWB and lower levels of anxiety and depression over a 10-year period (Stephens, 1988). Interventions aimed at increasing physical activity have also been shown to improve the symptoms of anxiety in middle-age adults (King, Taylor, \& Haskell, 1993), as well as depressive symptoms in both 
middle-age (Fremont \& Craighead, 1987) and older adults (McNeil, LeBlanc, \& Joyner, 1991). In a study of clinically depressed middle-aged and older adults, Khatri and associates demonstrated that individuals who completed four months in an aerobic exercise condition reported greater improvements in tests of memory and executive functioning compared to those in a control condition (Khatri et al., 2001). Similarly, Nelson and colleagues found that middleaged women who incorporated a brisk walk into their daily routines reported lower levels of stress, anxiety, and depression compared to women who engaged in less activity (Nelson et al., 2007). Supporting these studies is a recent meta-analysis which found exercise to be associated with greater positive affect and decreased negative affect across 32 studies of older adults (Arent et al., 2000).

To summarize, physical activity is an effective strategy for weight management and may help to protect against the onset of overweight and obesity and thus promote healthy aging. Individuals who engage in regular physical activity are less likely to experience obesity-related disease, disability, or impairment. Physically active individuals also exhibit better physical and mental functioning, and remain actively engaged in their lives compared to sedentary individuals. With respect to successful aging, one important area of inquiry involves the examination of the psychological processes associated with physical activity pursuit in order to identify potential targets for increasing the level of regular physical activity at the populationlevel. One potential avenue by which an individual might effectively manage his or her weight and thus enhance his or her SWB, as well as facilitate aging successfully, is through the formulation and pursuit of personal physical activity goals. 


\section{Part VI: The Role of Personal Goals in Life-span Development and Successful Aging}

Recall that one assumption of the life-span perspective is that individuals are active agents in their development. One way an individual plays an active role in his or her development is through the formulation and pursuit of personal goals, which can be defined in terms of the "desired states that people seek to obtain, maintain, or avoid" (Emmons, 1996, p. 314), and theoretically, are thought to impose structure and personal salience to an individual's daily behaviors (Klinger, 1975; Lazarus \& DeLongis, 1983), Similarly, the concept of possible selves (Markus \& Nurius, 1986), which refers to the way individuals describe themselves and how they think about their futures, has been used to study goal-related cognitions. Taken together, personal goals and possible selves refer to goal-related constructs important to the individual, which serve to help manage action and effort. From this perspective, individuals are motivated to engage in a variety of behaviors designed to achieve their goals, which, in turn, will impact various interactions between individuals and their environmental contexts over the course of their lives (Brandtstadter, 1998).

Whether referring to personal goals or possible selves, from a life-span developmental perspective, it is important to note that individuals may pursue different types of each across the life span. For example, different goals have been associated with different life transitions (e.g., to college, college-to-work, to parenthood, to retirement) (Cross \& Markus, 1991). With respect to health, individuals may formulate personal goals in order to achieve or avoid specific healthrelated possible selves associated with aging. For example, Hooker and Kaus (1994) have shown that health-related concerns become predominant during middle age, with health concerns making up a larger proportion of middle-age individuals' self-reported possible selves compared to young adults'. Thus, the formulation and adjustment aspects of personal goal pursuit are 
theorized to provide individuals with a sense of control and a means of managing the various gains and losses one encounters across the life span.

Personal goals and health-promoting behaviors. Broadly speaking and across the life span, individuals who form specific health-related personal goals, including goals for physical activity, are more likely to pursue and achieve their goals compared to individuals who do not specify such goals. For example, Scholz and colleagues found that individuals between the ages of 31-86 years assigned to a goal-setting intervention during cardiac rehabilitation engaged in more physical activity at both four months and one year follow-ups (Scholz, Knoll, Sniehotta, \& Schwarzer, 2006) than those in a control group. Similarly, young adults who form intentions which are often articulated in the form of personal goals - to implement specific behavioral strategies in order to address their health-related goals are more likely to engage in physical activity (Milne, Orbell, \& Sheeran, 2002), while goal-directed behaviors (as well as other social cognitive factors) predicted vigorous physical activity in a sample of young adults (Lingyak, Suminski, \& Hortz, 2003).

From a life-span perspective, midlife is a time when adults must increasingly manage a variety of the gains and losses associated with life-span development (Baltes \& Baltes, 1990), given that midlife is a time when many health-related concerns become increasingly salient (Hooker \& Kaus, 1994). During midlife, research suggests that the number of self-reported goaloriented activities in which an individual engages predicts physical activity and other healthpromoting behaviors (Hooker \& Kaus, 1992). Using data from the study of Midlife in the United States (MIDUS), Wethington (2003) found that self-reports of health problems were related to participants' desires to change behaviors that they felt were responsible for their health issues. With respect to older adults, participants who set their own activity goals as part of a physical 
activity intervention reported increased independence in activities of daily living, improved mobility, and improved psychological well-being (Taylor et al., 2003).

In comparing predictors of physical activity in a sample of young adults, Lutz and colleagues identified the planning, monitoring, and pursuit dimensions of participants' exercise goals accounted for the majority of the variance on exercise attributed to self-determination scores (i.e., reasons for exercising) (Lutz, Karoly, \& Okun, 2008). These results suggest that although individuals may be motivated to engage in physical activity, their actual physical activity behavior is better predicted by certain aspects of goal processes rather than the need fulfillment aspects of behavior posited by self-determination theorists (e.g., Deci \& Ryan, 2000). Given such findings, it should be clear that across the life span, those individuals who adopt and pursue specific health-related goals, particularly goals for physical activity, are more likely to engage in health-promoting behaviors than individuals who do not. Further, these results highlight the importance of studying systematically the various aspects of goal pursuit.

Goal appraisals and the importance of perceived control. Although personal goals provide individuals with structure and meaning for their daily behaviors, the way individuals appraise their goals may have important consequences for goal pursuit. Goal appraisals refer to the ways individuals evaluate their personal goals and include a variety of dimensions, including perceived difficulty, importance, and value (i.e., how good or bad, useful or useless, harmful or beneficial an individual believes his or her goal to be), as well as the amount of perceived effort and progress one has made toward one's goals. Such appraisals also hold important implications for predicting certain health behaviors and various indices of SWB. For example, Lawton and colleagues demonstrated that, for older adults, positive evaluations of personal projects are associated with positive affect and life satisfaction (Lawton, Moss, Winter, \& Hoffman, 2002). 
Similarly, Rapkin and Fischer (1992) found that specific factors associated with personal goals, including goals for active lifestyles and increased social engagement, were positively related to life satisfaction.

Although various aspects of goal appraisals are important in predicting behavior, most relevant to the present study is perceived control. Various theoretical models highlight the importance of perceived control in predicting behavioral intentions, often articulated in the form of personal goals, and ultimately, goal-directed behavior. For example, the Model of Goaldirected Behaviour (MGB) (Perugini \& Bagozzi, 2001) suggests that individuals’ perceived control predicts desire, behavioral intentions, and effort, which ultimately predict goal-directed behaviors. Similarly, the Lifespan Theory of Control (LTC) (Heckhausen \& Schulz, 1995; Schulz \& Heckhausen, 1996) posits that individuals engage in various behaviors in an effort to exert control over their environments. Thus, from a life-span developmental perspective, shortterm goal formation and adjustment processes may actually contribute to an individual's sense of control over his or her development, which may be associated with SWB (Brandtstadter, Wentura, \& Rothermund, 1999).

Perceived control and health. The ability to adopt behavioral strategies within domains in which one still feels that he or she can exert some control could be taken as an adaptive process which may facilitate aging successfully (Baltes \& Baltes, 1990). Although many theoretical conceptualizations of control exist, various research suggests that control does indeed lend a predictive value to health behaviors in general, which may also have important consequences for SWB across the life span (for a review of the association between various conceptualizations of control and SWB in older adulthood, see Jacelon, 2007).

Compared to adults who report low levels of control, adults who feel that they exert more 
control over their lives are more likely to endorse a variety of strategies, including goal-setting, in order to engage in health-promoting behaviors (Lachman, 2006). With respect to exercise, Lucidi and colleagues found that perceived behavioral control, as well as self-efficacy, was the strongest predictor of exercise attendance in a sample of older adults (Lucidi, Grano, Barbaranelli, \& Violani, 2006). The role of perceived behavioral control in predicting readiness for physical activity behavioral change in older adults (Courneya, 1995) further highlights the importance of control with respect to physical activity.

Data from the MIDUS study suggest that those middle-aged adults who feel a sense of control report better health and SWB (Lachman \& Firth, 2004). The results of a recent metaanalysis demonstrated that individuals who have perceived control over various health conditions report higher levels of positive affect, higher social functioning and engagement, as well as lower levels of negative affect and illness (Hagger \& Orbell, 2003). Similarly, in a diary study of older adults who reported feelings of control randomly throughout the day, Larson (1989) found that days characterized by higher average control were positively related to days with higher average happiness. Given the well-documented importance of perceived control within the context of the personal goal literature, as well as the role of perceived control in promoting optimal development and successful aging, it becomes useful to adopt a theoretical framework which allows for the application of perceived control to the pursuit of specific health-related goals during midlife.

The Theory of Planned Behavior. One theoretical model that has gained wide empirical support in its specification of the interrelations between various aspects of goal pursuit is the Theory of Planned Behavior (TPB; Ajzen, 1985). According to the TPB, one's behavior is determined by the combination of one's attitudes (e.g., "It is very important that I exercise" or 
"Exercise is very difficult for me"), subjective norms (e.g., "My spouse thinks I should exercise" or "I should lose weight"), perceived behavioral control (e.g., "I have complete control over whether I exercise" or "There are too many barriers today for me to exercise"), and intention (e.g., "My goal is to walk 20 minutes during lunch" or "I plan to go to the gym three days per week"). Attitudes, subjective norms, and perceived behavioral control are theorized to individually and interactively lead to the formulation of behavioral intentions, which, relevant to the present study, are often articulated in the form of personal goals. Such intentions, then, are theorized to lead to behavior (Ajzen).

$T P B$ and physical activity. Azjen's TPB has been utilized extensively as a framework for examining and explaining exercise behavior. Within the framework of TPB and with respect to physical activity, attitude and perceived behavioral control are often the strongest predictors of one's intention to exercise (Godin \& Kok, 1996; Symons Downs, \& Hausenblaus, 2005).

Consistent with the TPB, two separate meta-analyses of published exercise studies examining TPB constructs concluded that actual exercise behavior could be predicted most strongly by intentions and behavioral control. In addition, behavioral intention was most closely related to attitude. Finally, one's intentions predicted actual exercise behavior, whereas attitudes and perceived behavioral control predicted behavioral intention (Hagger, Chatziaratis, \& Biddle, 2002; Symons Downs \& Hausenblaus, 2005).

In addition to supporting the role of TPB constructs on predicting physical activity, these meta-analyses supported the assertion that the TPB determinants may operate differently based on the specific behavior and population (Ajzen, 1991). These findings lend support to opting for a life-span perspective and consequently, researchers have examined TPB constructs on exercise in various age groups, including middle-age and older adulthood. For example, Benjamin, 
Edwards, and Bharti (2005) found a strong intention to maintain regular exercise levels, as well as positive attitudes toward exercising, characterized older adults who reported high levels of physical activity compared to those who report low levels of activity. More generally, Andrykowski and colleagues found that for a sample of middle-aged adults, attitudes, subjective norms, and behavioral control accounted for significant amounts of the variance in behavioral intentions for both physical (e.g., physical exercise) and psychosocial (e.g., spend time with friends) health behaviors (Andrykowski, Beacham, Schmidt, \& Harper, 2008).

Taken together, research examining various personal goal dimensions highlights the importance of examining the dynamic association between personal goal processes, SWB, and health behaviors such as physical activity in contributing to successful aging. Consistent with the propositions of the TPB and relevant to the present study, perceived control is thought to influence one's behavioral intentions and such intentions are often articulated in the form of short-term personal goals, which help individuals manage their action and effort (Bandura, 2004).

Given the role of personal goal pursuit processes, particularly the importance of perceived control, in life-span development and successful aging, it is then useful to examine systematically the association between health-related goal pursuits and their consequences for health-promoting behaviors such as regular physical activity. Further, given research suggesting the positive impact of goal pursuits, as well as regular physical activity, on various indices of subjective well-being, it becomes important to investigate the psychological consequences of health-related goal pursuit as individuals strive towards their own personally salient goals. Part VII: Health-related Goal Pursuit: An Ideal Application of a Daily Process Design Whether termed daily diary studies (e.g., Feldman, Downey, \& Shaffer-Neitz, 1999), 
experience sampling studies (e.g., Steiger, Gauvin, Jabalpurwala, Seguin, \& Stotland, 1999), or ecological momentary assessment studies (e.g., Marco, Neale, Schwartz, Shiffman, \& Stone, 1999), these daily process designs share an interest in the repeated assessment of variables that are thought to vary in meaningful ways, either from day to day or within the same day. Daily process studies involve multiple daily (and often within-day) measurements of key variables over time. These designs are useful in that they allow researchers to examine the dynamic association between certain variables of interest, as well as the variability that occurs when certain variables change from day-to-day or within a day (Tennen, Affleck, \& Armeli, 2003).

Perhaps the most useful advantage afforded by the daily process approach involves the ability to differentiate between-person relations from within-person relations. The well-known limitations of cross-sectional designs highlight the need for multiple times of measurement if one hopes to understand how a given phenomenon unfolds over time for a specific person and whether that process is similar across individuals. Similarly, other research has demonstrated that across-person and within-person associations may differ in strength as well as direction, while significant between-person relations can occur despite no single significant within-person correlations within the sample (Kenny, Kashy, \& Bolger, 1997; Tennen \& Affleck, 1996).

Next, because daily process designs can capture changes in key variables closer in time to their actual occurrence, such procedures are particularly useful for examining the dynamic psychological processes such as goal pursuit and SWB. Daily process designs have been shown to reduce recall error compared to retrospective reporting methods (Stone et al., 1998), thus minimizing one of the common limitations of self-report research.

Daily processes and health. Daily process studies are a useful method of inquiry by which to further examine the dynamic processes associated with health-related behavior (e.g., 
Tennen et al., 2003). Relevant to the proposed study, theory and research suggest that much of our daily lives are devoted to pursuing personal goals. Daily process studies of college students illustrate the important role of goals and consequences for SWB. For example, Cantor and colleagues reported that personal goals were closely related to students' interpretation of and emotional involvement in routine daily activities (Cantor et al., 1991). Further, young adults who nominated intimacy-focused personal strivings reported more within-day emotional variability as a result of various daily interpersonal interactions (Emmons, 1991).

Similarly, research suggests that daily variability in goal pursuits holds important implications for health. Using samples of approximately 50 women suffering from fibromyalgia, Henricksson and colleagues found that most women reported that both daily pain and fatigue impacted their ability to achieve their personal goals (Henriksson, 1995; Henriksson, Gundmark, Bengtsson, \& Ek, 1992). Affleck and colleagues have used the daily process design to break new ground in the prospective measurement of goal pursuit and attainment. Interested in mediumrange health goals (e.g., eating a low fat diet, following an exercise routine), the authors used a daily diary design to examine goal processes, pain, fatigue, sleep, and mood in 50 women who met the diagnosis for primary fibromyalgia syndrome. Using the daily process approach, the authors were able to obtain a rich data set which permitted them to conclude that women who reported a poor night's sleep also reported less effort to accomplish health-related goals the following day, as well as the perception that goal progress was hindered on days that corresponded with higher reported pain and fatigue. In addition, women who felt that they made progress on an interpersonal goal were likely to exhibit higher levels of positive mood during that day (Affleck et al., 1998). 
Experience sampling methods and self-monitoring. Previous research has demonstrated the utility of data collection using Palm ${ }^{\circledR}$ handheld organizers and various electronic sampling diary programs. For example, Steele (2004) asked a sample of community-dwelling, older women to complete measures of physical activity and affect four times per day for 6 days and found adherence to the study protocol to be quite strong.

With respect to health, research highlights the positive impact of various self-monitoring techniques on health-promoting behaviors. For example, Glanz and colleagues asked 33 middleaged and older women to use a hand-held computer during a dietary intervention program. Results indicated that participants who used the electronic diary system were more likely to adhere to their dietary goals (Glanz, Murphy, Moylan, Evensen, \& Curb, 2006). Results from diary studies of physical activity highlight the efficacy of self-monitoring approaches in understanding within-person fluctuations in exercise behaviors and attitudes. For example, Carels and colleagues measured activity levels and perceived difficulties within a sample of 40 obese adults participating in a weight loss intervention. Participants who perceived more difficulties with physical activity during certain weeks engaged in less physical activity during these weeks than when perceiving fewer difficulties. Further, increased self-monitoring was associated with increased physical activity and greater weight loss (Carels et al., 2005).

Advantages of experience sampling methods in psychological studies of health. Developments in widely-available software such as Barrett and Barrett's Experience Sampling Program (ESP; Barrett \& Barrett, 2003) offer certain advantages over traditional self-report methods (e.g., paper-and-pencil questionnaires) when applied to daily process data. First, in contrast to laboratory assessments, ESP allows for the completion of all daily process measures with (presumably) less intrusion into the daily lives of participants, thus minimizing threats to 
ecological validity (Shiffman \& Stone, 1998). Second, ESP allows the researcher to determine the duration of a study period (i.e., the beginning and end of each day under investigation), as well as the total duration of the study. Third, as described above, ESP can be programmed to notify participants (via a pre-programmed alarm) when it is time to complete a trial. Fourth, researchers using ESP can control the number of trials during a given day, as well as the amount of time available for participants to answer questions. Fifth, ESP records response times for each item. Finally, ESP can be programmed to prohibit participants from retrospectively answering questions. Such a feature is particularly advantageous and important for the present study, given the emphasis on moment-to-moment reports of goal processes, SWB, and physical activity. Summary and Rationale for the Present Study

Although research suggests that regular physical activity is a useful strategy for weight management, over $40 \%$ of adults, including over half of middle-age adults do not achieve the recommended levels of either moderate or vigorous physical activity on a regular basis (CDC, 2006). Given the high degree of frequency, as well as the increased saliency of health-related concerns during midlife, the middle-age years appear to be a particularly important period of the life span in which to concentrate health promotion research.

Evidence emerging from a variety of approaches suggests that one potential method by which an individual might adhere to a regular exercise program involves personal goals. However, many existing approaches simply assume that an individual has and is working towards a health-related goal. Additionally, most studies to date have examined health-related goals in general, but have not examined specific, yet similar goals within the same sample. Thus, it is important to not only screen for personal goals in order to confirm one actually nominates a goal, but it is also important to examine health-related goal pursuit in a sample of individuals 
who likely hold similar goals.

Further, although the existing literature in this area includes both small- and large-scale cross-sectional and longitudinal studies, there is a lack of emphasis on the daily processes associated with healthy goal pursuit. Although research suggests that perceived control in particular is an important predictor of personal goals, the daily variability between important goal process variables remains unknown. Daily process designs provide an innovative opportunity to examine daily health pursuits, yet no single daily process study reviewed has directly examined how certain goal processes (e.g., perceived control) were related to both participants' physical activity and SWB levels while actively trying to lose weight. Consequently, the present study adopted a daily process study in order to address such limitations by examining within a sample of middle-aged individuals the within-person variability of the psychological processes associated with the pursuit of physical activity goals, as well as the dynamic relation between changes in goal pursuits and SWB while trying to lose weight.

The present study had four primary research objectives. The four within-person (i.e., individual-level) research objectives were to examine: (1) the association of daily variability in perceived control over physical activity-related goals with daily changes in perceived goal effort and progress, and (2) the association of daily variability in these goal process variables with daily physical activity, (3) the association of daily variability in these goal process variables with daily SWB, and (4) whether daily variability in physical activity is associated with daily changes in SWB. As described below, these research objectives were examined at the individual-level by capitalizing on the within-person structure of the data and treated the daily observations as within-person repeated measures of goal processes, physical activity, and SWB. This allowed for 
the testing of the hypotheses at the individual-level and to determine whether increases or decreases in one variable were associated with increases or decreases in another variable for individuals over time.

\section{Research Questions and Hypotheses}

The research questions and hypotheses for the present study are based on the four primary objectives of the research.

RQ1. At the individual-level, what is the association between daily perceived control over one's physical activity goal and daily perceived goal effort and progress?

H1. It was expected that there would be a significant and positive association between perceived control and daily goal effort toward physical activity goals.

H2. It was expected that there would be a significant and positive association between perceived control and daily goal progress toward physical activity goals.

RQ2. At the individual-level, what is the association between daily variability goal processes and daily physical activity?

H3. It was expected that there would be a significant and positive association between perceived control and total daily minutes of physical activity.

H4. It was expected that there would be a significant and positive association between daily effort and total daily minutes of physical activity.

H5. It was expected that there would be a significant and positive association between daily progress and total daily minutes of physical activity.

RQ3a. At the individual-level, what is the association between daily variability in goal processes and daily positive affect?

H6. It was expected that there would be a significant and positive association between perceived control and daily positive affect.

H7. It was expected that there would be a significant and positive association between goal effort and daily positive affect. 
H8. It was expected that there would be a significant and positive association between goal progress and daily positive affect.

RQ3b. At the individual-level, what is the association between daily variability in goal processes and daily negative affect?

H9. It was expected that there would be a significant and negative association between perceived control and daily negative affect.

H10. It was expected that there would be a significant and negative association between goal effort and daily negative affect.

H11. It was expected that there would be a significant and negative association between goal progress daily negative affect.

RQ3c. At the individual-level, what is the association between daily variability in goal processes and daily life satisfaction?

H12. It was expected that there would be a significant and positive association between perceived control and daily life satisfaction.

H13. It was expected that there would be a significant and positive association between goal effort and daily life satisfaction.

H14. It was expected that there would be a significant and positive association between goal progress and daily life satisfaction.

RQ4. At the individual-level, what is the association between daily physical activity and daily subjective well-being?

H15. It was expected that there would be a significant and positive association between physical activity and positive affect.

H16. It was expected that there would be a significant and negative association between physical activity and negative affect. 
H17. It was expected that there would be a significant and positive association between physical activity and life satisfaction.

\section{Method}

\section{Participants}

\section{Target Sample}

The present study sought to enroll 40 community-dwelling, middle-aged adults who met the screening criteria (described below). A variety of sampling methods were used in order to obtain a representative sample of community-dwelling, middle-aged individuals who were either overweight or obese and actively trying to lose weight. Advertising for the study took the form of flyers posted at various locations, electronic announcements (e.g., West Virginia University [WVU] Employee Wellness listserv, WVU E-News), and word-of-mouth referrals. Screening Procedure and Selection Criteria

The author contacted each potential participant via telephone or email in order to ensure that he or she met the initial criteria required for study participation. During this initial contact, each participant provided his or her age, self-reported height and weight (for determining BMI), and at least one physical activity goal to facilitate weight loss. Participants who met the initial screening criteria participated in a secondary in-person intake and orientation session in order to assess sensory and reading criteria and a brief training session designed to familiarize participants with their Palm ${ }^{\circledR}$ devices, as well as the daily process protocol of the study. These criteria, as well as the rationale for selection, are described below in greater detail.

Middle-age. As previously discussed, midlife is a time when health-related concerns become increasingly salient (Hooker \& Kaus, 1992, 1994). The ages of 35 - 64 years have been used elsewhere to define midlife (e.g., Lachman \& James, 1997; Spiro, 2001). Prospective 
participants who were not between the ages of 35 and 64 years at the time of the data collection were placed on a waiting list in the event that the inclusion criteria were expanded. No data were collected from anyone outside of the ages of 35-64 years.

Overweight or obese. Because the primary focus of the present study was to examine the processes associated with physical activity goal pursuit specifically within a sample of individuals who are overweight or obese, participants were asked to self-report their height and weight in order to calculate and determine BMI prior to participation. Using the NHLBI (2002) guidelines, prospective participants with BMI $\geq 30.0$ (obese) and those with BMI between 25 and 29.9 (overweight) were eligible for participation.

Two prospective participants chose not to provide either height or weight information (both necessary for the calculation of BMI) during the initial interview and were subsequently allowed to participate in the study, given that they met other eligibility requirements. BMI for these two participants was calculated following their participation using self-reported height and weight information from the participant demographic questionnaire. Subsequent calculations indicated that BMI values for these two individuals were 24.6 and 24.9. A decision was made to include these two individuals in the analyses because (1) these two individuals were on the high end of the NHLBI (2002) normal weight classification and (2) all participants in the current study responded to advertisements seeking individuals who were trying to lose weight. Thus, it seemed reasonable to characterize even these two normal weight individuals (per BMI status) as eligible for participation, provided they meet other screening criteria. Outside of these two individuals, prospective participants with BMI values in the NHLBI normal weight or underweight ranges were placed on a waiting list in the event that the inclusion criteria were expanded; no data were collected on wait-listed individuals. 
Physical activity goal. Prospective participants were asked to nominate a physical activity goal, as well as strategies for achieving this goal, during an initial contact with the author. Because the primary aim of the study was to examine the association between key variables during physical activity goal pursuit, it was necessary that participants endorsed at least one physical activity goal. Although participants' goals differed qualitatively, all prospective participants nominated at least one physical activity goal.

Capacity for moderate physical activity. Prospective participants completed the physical activity survey items from the Community Healthy Activities Model Program for Seniors (CHAMPS; Stewart et al., 2001, described below). Using the CHAMPS questionnaire as a screening tool in the present study ensured that potential participants had the physical ability to engage in at least light physical activity. No prospective participants were excluded based on a lack of capacity for moderate physical activity.

Sensory, reading, and employment requirements. Because the study involved data collection via Palm ${ }^{\circledR}$ handheld computers (described below), it was necessary that prospective participants possessed the minimum sensory and reading abilities required to complete the protocol.

During an orientation and intake session, participants completed a mock trial. The purpose of this trial was to ensure that participants could see and read the various survey items displayed on the screen of the training Palm ${ }^{\circledR}$ and to demonstrate how to answer each type of question using the device. The trial also allowed the participants to hear the "beep" alert from the Palm $^{\circledR}$. Further, given the multiple within-day assessments in the proposed design, prospective participants were asked about a typical day so they might determine if they could reasonably incorporate the multiple daily assessment protocol into their daily routines and work demands. 
Any individual who (1) could not see the questions displayed on the screen, (2) could not read the questions displayed on the screen, (3) was not comfortable operating the Palm ${ }^{\circledR},(4)$ could not hear the alert, or (5) reported regular fluctuations within his or her daily routine was excluded from the study. No prospective participants were excluded due to sensory, reading, or employment criteria.

\section{Sample Information}

Participants were recruited from a variety of sources. Data were collected from 40 individuals who met the above screening criteria. Four participants were excluded from the analyses because they did not provide at least two data points per day for at least three of the six days. A fifth participant withdrew from the study because the multiple daily assessments interfered with her work schedule. Electronic advertising proved to be highly effective at soliciting interest, as $80 \%$ of the eventual sample were recruited through announcements sent via the WVU Employee Wellness Newsletter and WVU E-News. Six additional participants (17\%) were recruited via participant referrals, while one participant responded to a flyer posted at a local health center.

Demographic characteristics for the 35 (4 males, 31 females) eligible participants included in the analyses are presented in Table 1. Participants generally identified themselves as Caucasian/White $(94.3 \%)$ and ranged in age from $35-60$ years $(M=48.97, S D=7.76)$. On average, participants reported $15.65(S D=2.56)$ years of education and the majority $(60 \%)$ reported household incomes over $\$ 50,000$. The average BMI (based on self-reported height and weight) for the sample was 33.95, which lies in the obese range (NHBLI, 2002). The majority of participants considered themselves to be in "very good" or "good" physical (51.4\%) and mental $(65.7 \%)$ health. In general, participants were fairly healthy, active, and reported few functional 
impairments $(M=0.31, S D=0.72)$. Intercorrelations among participant characteristics, baseline goal appraisals and average daily reports of subjective well-being and physical activity are depicted in Table 2.

\section{Sample Size Considerations}

Previous daily process studies (e.g., Affleck et al., 1998; Henriksson et al., 1992;

Henriksson, 1995; Steele, 2004; Vansteelandt, Rijmen, Pieters, Probst, \& Vanderlinden, 2007) targeting small, well-defined populations have demonstrated the feasibility of such a sample size. Previous research (e.g., Steele, 2004) using an identical duration was able to detect significant relations between SWB and physical activity, suggesting that such a period should provide a sufficient timeframe within which to detect significant associations in individual-level variability among the variables of interest.

\section{Procedure}

Once deemed eligible for participation, the author reviewed Informed Consent and Health Insurance Portability and Accountability Act (HIPAA) forms with participants, answered any additional questions regarding the procedures, and obtained signatures necessary for participation. Initial participant and tracking information were obtained using the Intake Form (see Appendix A). In addition to the Palm ${ }^{\circledR}$ (described below) for use in the study, each participant received a packet containing additional measures (e.g., participant demographic information), as well as a Daily Log (see Appendix I). The Daily Log was included in an effort to monitor any technical issues related to the $\mathrm{Palm}^{\circledR}$ operation. Participants were also asked to record on the Daily Log any missed trials.

\section{Daily Process Protocol}

Participants completed measures of goal processes, physical activity, and SWB (i.e., 
positive and negative affect, satisfaction with life) at three fixed times per day for six days. Thus, the daily process protocol used in the present study yielded overall within-person data, with the resulting data structure consisting of individual-level goal process data, as well as individuallevel daily data for physical activity and SWB, for 630 possible times of measurement (3 times/day X 6 days/week per participant X 35 participants).

Upon completion of the study, participants were debriefed and given compensation for their participation. Participants received $\$ 2$ for each day of usable data provided, with a day consisting of responses to at least two of the three possible assessment trials within a given day. Participants who provided usable data for six days received a $\$ 3$ bonus for a potential total of $\$ 15$. Twenty-two participants received the full $\$ 15$ for providing six days, nine participants provided data for five days and received $\$ 10$, and four participants provided data for 4 days and received \$8. Finally, although they were compensated for their participation, five individuals were excluded from the analyses because they provided either only two (two individuals) or three (three individuals) days of useable data.

Palm ${ }^{\circledR} 22$ handheld computer. Each participant completed all daily protocol measures using a Palm ${ }^{\circledR} \mathrm{z} 22$ handheld computer. The Palm ${ }^{\circledR} \mathrm{z} 22$ model weighs approximately three ounces. Additional details can be found at http://store.palm.com/sm-palm-z22-handheld--pi2113008.html.

Experience Sampling Program. Scale items were programmed into each Palm ${ }^{\circledR}$ by the author using the most recent version of the Experience Sampling Program (ESP 4.0, Barrett \& Barrett, 2003). ESP is accessible as free downloadable software from the following link: http://www.experience-sampling.org/.

The ESP program allows participants to enter their responses to a variety of questions 
directly into the Palm ${ }^{\circledR}$. Additionally, ESP allows the researcher to designate the fixed sampling interval necessary for the present study. Participants in the present study received an audible alert (via their Palm ${ }^{\circledR}$ ) at the same time each day, three times per day, for the duration of the study (i.e., 6 days). The fixed sampling procedure was used for two reasons. First, completing the survey measures at the same time each day is likely to contribute to a daily routine, thus minimizing the likelihood of participants missing a trial. Second, a fixed sampling interval for all participants permits the examination of the variability between key study variables over the course of a day across individuals. Trials were completed at approximately 0930, 1430, and 1800 each day for six consecutive days (Monday - Saturday).

\section{Measures}

Participants completed measures designed to assess four primary areas: demographic information, personal goals, physical activity, and subjective well-being. Table 3 contains a summary of the constructs examined and measures used in the present study.

\section{Demographic Information}

Participants completed a demographic questionnaire (see Appendix B) in order to obtain data on age, sex, height, weight, self-rated health (physical and mental), highest level of education, income, marital status, occupation, and functional impairments (i.e., instrumental activities of daily living; Pfeffer, Kurosaki, Harrah, Chance, \& Filos, 1982). These data were used for descriptive purposes only and were not included in subsequent analyses.

\section{Personal Goals}

Screening and baseline goals appraisals. Before beginning the study, participants were interviewed as part of a goal elicitation task in order to determine whether or not they endorsed at least one physical activity goal. Based on previous evidence that suggests certain goal 
constructs may elicit different goals than others (Goedereis, 2005), the definition for a personal goal for the proposed study was modeled after Klinger's (1975) "current concerns" construct in order to capture short-term health-related goals (see Appendix H). Table 4 illustrates the range of physical activity goals nominated by study participants. Participants also completed a variety of goal appraisal items in order to obtain baseline data of various dimensions of participants' physical activity goal pursuits.

Daily goal appraisals. Participants completed a variety of information about their physical activity goals using the Daily Goal Process Journal (DGPJ) (see Appendix H) three times per day via the Palm $^{\circledR}$ as part of the daily process protocol. Items included in the DGPJ assessed constructs outlined in the Theory of Planned Behavior. (Ajzen, 1985) (i.e., perceived control, attitudes, and subjective norms) with respect to participants' personal physical activity goals (i.e., behavioral intentions). All items were drawn from previous studies of TPB and exercise (e.g., Ajzen \& Madden, 1986; Brenes, Strube, \& Storandt, 1998; Dean, Ferrell, Kelley, Taylor, \& Rhodes, 2006).

Unless otherwise noted, all items were rated on a scale of $0-10$, with items coded such that higher scores corresponded to higher values of the variable. In the present study, the TPB construct of behavioral intentions was represented by the personal goals nominated by participants. Intentions were further assessed by examining separately participants' goal-directed effort and perceived progress toward their physical activity goals.

With respect to the TPB, the primary focus of the current study was perceived control as it related to goal-directed effort, perceived progress, and actual behavior. Perceived control was measured by a single rating of how much control participants felt they had over their physical activity goals up to that point in the day, as well as the level of difficulty $(1=$ very difficult, $10=$ 
very easy) associated with working towards their goals. Similar to previous research (e.g., Dean et al., 2006), these two items were examined for their appropriateness in creating an aggregated value of perceived control. In the present study, the two items were not significantly correlated $(r$ $=.20$ ) and the consistency of these items as an aggregated scale was low $(\alpha=.33)$ (cf. $\alpha=.76$, Dean et al.). Given the focus of the present study, only the perceived control item was retained for use in subsequent analyses.

Although not included in the present study, four items were used to assess participants' attitudes toward their physical activity goals (useless to useful, harmful to beneficial, very bad to very good, not at all important to very important). Internal consistency was acceptable at $\alpha=$ 0.83. An attitude summary variable for each session was created using the mean of these four items. Two items were used to examine subjective norms. Internal consistency was acceptable at $\alpha=0.87$. A subjective norm summary variable for each session was created using the mean of these two items. The values are comparable to those reported in published research using similar scales (e.g., Dean et al., 2006; $\alpha_{\text {attitudes }}=.93$ and $\alpha_{\text {attitudes }}=.85$ ). Given the current study's objectives with respect to determining the association between the goal process variables of perceived control, goal-directed effort, and perceived progress, there were no hypothesized associations for the association between attitudes and subjective norms with respect to goal pursuit.

Physical Activity

Screening and baseline physical activity. Prior to participation, prospective participants completed physical activity survey items from the CHAMPS (Stewart et al., 2001) using paperand-pencil in order to determine capacity for physical activity and subsequent eligibility (as described above). The CHAMPS questionnaire takes approximately 10-15 minutes to complete. 
Participants reported whether or not they engaged in 40 specific activities (as well as one openended "other" item), as well as how many times and total hours per week they do so "in a typical week during the past four weeks." The frequency of activities per week, as well as the estimated caloric expenditures for each individual activity, for moderate-intensity activities, and for the total week can then be computed by collapsing responses to the individual items and then using published conversion formulae (Stewart et al.).

The CHAMPS questionnaire has been shown to demonstrate acceptable test-retest reliability (Stewart et al., 2001). Although the CHAMPS questionnaire was originally developed for use with older adults, recent research has used the CHAMPS in a multisite study of physical activity during adulthood (King et al., 2006), including midlife. In addition to serving as a screening tool in the present study, the CHAMPS provided a baseline approximation of participants' average weekly physical activity in order to assess the construct validity of daily physical activity measures.

Daily physical activity. Because adults are more likely to engage in walking than any other type of physical activity (Siegel, Brackbill, \& Heath, 1995), day-specific measures assessed the frequency and duration of walking and other physically-active behaviors. Specifically, participants completed the Paffenbarger Physical Activity Questionnaire (PAQ; Paffenbarger, Wing, \& Hyde, 1978) (see Appendix D), as well as two additional items adopted from the National Health Interview Survey (NHIS; USDHHS, 2005) (see Appendix E) via Palm ${ }^{\circledR}$ three times per day for the duration of the study.

The PAQ was specifically designed to assess leisure-time physical activity. Previous research suggests that the PAQ exhibits reasonable test-retest reliability $(r=.58$ to .73 ; LaPorte et al., 1983; Washburn, Smith, Goldfield, \& McKinlay, 1991). Additionally, the PAQ has been 
shown to correlate positively $(r=.60)$ with maximum oxygen uptake (Ainsworth, Leon, Richardson, Jacobs, \& Paffenbarger, 1993), suggesting that the PAQ is a valid measure of physical activity. The two items from the NHIS (USDHHS, 2005) have been shown to correlate positively with prospective diary reporting of walking (Johnson, Sallis, \& Hovell, 2000).

To summarize these measures, at each testing session, participants provided an estimate of (a) the number of stairs climbed since the last testing session (3 times/day), (b) the number of blocks walked since the last testing session ( 3 times/day), and (c) a list of other physical activities performed since the last testing session, as well as an estimate of the total amount of minutes spent in these activities (3 times/day).

In order to assess the construct validity of these items, data for the number of stairs climbed and blocks walked were compared to participants' baseline CHAMPS data for their average weekly frequency of all physical activities. The correlation between total stairs climbed per day $(M=86.49, S D=295.02)$ and CHAMPS average weekly frequency of all physical activities $(M=21.17, S D=10.32)$ was not significant, $r(191)=-.01, p=.89$. However, the correlation between total blocks walked per day $(M=17.97, S D=21.96)$ and CHAMPS average weekly frequency of all physical activities was significant, $r(192)=.19, p<.05$. These inconsistencies between daily measures of stairs climbed and blocks walked and their respective association with baseline frequency of physical activities suggested the need for a more accurate measure of daily physical activity. Consequently, items that asked participants to report duration of time spent in a given activity were aggregated to create a summary score of total minutes of physical activity per session. These aggregated values per session were then averaged to create a summary score for total minutes of physical activity per day. This score of total minutes of activity $(M=107.60, S D=147.12)$ demonstrated significant and positive correlations with 
measures of activity for the frequency of both total $(r=.33, p<.01)$ and moderate intensity $(r=$ $.22, p<.05)$ activities obtained from the CHAMPS measure. Thus, the total minutes of physical activity index values were a more appropriate measure of physical activity and were used in subsequent analyses.

Subjective Well-being

Participants completed two measures designed to address three specific components of subjective well-being: positive affect, negative affect, and life satisfaction. Participants completed the Positive and Negative Affect Scales (PANAS; Watson, Clark, \& Tellegen, 1988) (see Appendix F) three times per day as part of the daily process protocol in order to assess the within-person variability in two components (i.e., positive and negative mood) of SWB. The PANAS consists of 20 mood descriptors. Participants rated each item based on the extent to which they felt a particular way $(1=$ very slightly/not at all, $5=$ extremely/completely $)$. The PANAS has been shown to correlate well with other measures of mood, including the Hopkins Symptom Checklist (Derogatis, Lipman, Rickels, Uhlenhuth, \& Covi, 1974) ( $r=-.19-.74)$, the Beck Depression Inventory (Beck, Ward, Mendelson, Mock, \& Erbaugh, 1961) ( $r=-.35$ - .58), and the STAI Anxiety Scale (Spielberger, Gorsuch, \& Lushene, 1970) $(r=-.35-.51)$, suggesting acceptable external validity. Additional psychometric properties, including internal consistency ( $\alpha=.86-.90$ for positive affect, $\alpha=.84-.87$ for negative affect) and test-retest reliability over one week ( $r=.87$ for positive affect, $r=.78$ for negative affect) of the PANAS are well-documented (Watson et al.). In the present study, both the positive $(\alpha=.94)$ and negative $(\alpha=.88)$ affect scales demonstrated acceptable internal consistency. Scores for the positive (possible range $=10-50)$ and negative $($ possible range $=10-50)$ items were summed in order to create separate indices of positive and negative mood for each testing session. 
The Satisfaction With Life Scale (SWLS; Diener, Emmons, Larsen, \& Griffin, 1985) (see Appendix G) was used in order to measure participants' life satisfaction, a third component of SWB. Participants responded to each of five descriptive statements designed to tap an individual's overall satisfaction with his or her life three times per day using a 7 -point scale $(1=$ strongly disagree, $7=$ strongly agree). Responses to each of the five statements are summed to determine an individual's overall life satisfaction score. The SWLS has been shown to correlate well with other measures of subjective well-being, including the Self-Anchoring Ladder (Cantril, 1965) $(r=.62-.66)$, the Differential Personality Questionnaire (Campbell, Converse, \& Rodgers, 1976) $(r=.68)$, as well as the Bradburn Positive $(r=.50-.51)$ and Negative $(r=-.37$ - -.32) Affect Scale (Bradburn, 1969), suggesting acceptable external validity. Diener and colleagues reported strong test-retest correlations over one month within samples of undergraduates $(r=.82, \alpha=.87)$ and acceptable item-total correlations $(r=.61-.81)$ for each of the five items in a sample of older adults $(M=75$ years). In the present study, scale items exhibited strong inter-item correlations $(r=.70-.92)$ and strong internal consistency $(\alpha=.96)$. Scores for participants' corresponding values to each statement are then summed to determine an individual's overall life satisfaction score for a given testing session, with scores ranging from 5 (indicating low satisfaction) to 35 (indicating high satisfaction).

\section{Analytical Approach: Overview of Within-person Correlation with Repeated Observations}

The research objectives focused on the individual-level associations among daily variability of goal processes, physical activity, and subjective well-being over the duration of the study. Because the hypotheses are primarily focused on testing the associations between changes in one variable (e.g., physical activity) with changes in another variable (e.g., life satisfaction) at the person-level, it is necessary to isolate the within-person variance by removing any 
differences attributed to between-person factors. Consequently, the appropriate analysis must account for the within-person repeated measures of the data structure.

Within-person Analyses

Bland and Altman (1995a) detail an approach to such research questions. The first step involves creating dummy variables which allow individuals to be treated as a categorical predictor variable within a multiple regression framework. In order to assess the extent to which an outcome variable of interest varies with increases or decreases in a predictor, all dummycoded subject factors are entered into the first-step of a multiple regression and treated as categorical predictor variables. Next, the predictor of interest is entered into the second-step of the regression. This technique removes variance attributed to individuals (first-step in the model), with the remaining variance in the outcome due to within-person changes in the predictor. Mathematically, this approach is expressed as the following equation: $\mathrm{SS}_{\text {predictor }}$ / $\left(\mathrm{SS}_{\text {predictor }}+\mathrm{SS}_{\text {residual }}\right)$.

The magnitude of the within-person correlation coefficient is then calculated by taking the square root of the above equation. The significance and direction (i.e., positive or negative) is the same as the resulting regression coefficient (i.e., beta weight) for the predictor variable (Bland \& Altman, 1995a), which in this case would be interpreted as within-person changes in an outcome attributable to the predictor entered in the second step. Model fit improvement (i.e., $\Delta R^{2}, \Delta F$ ) is assessed and the $p$ - value for the resulting within-person correlation coefficient is determined by the $t$-test of the associated regression slope.

As an illustration, consider the hypothesized association between physical activity and life satisfaction. One could simply calculate the coefficient for the entire sample, which in this case would be $r(593)=0.24, p<.001$. This would seem to suggest that total minutes of physical 
activity in a session $(M=25.54, S D=60.96)$ was positively associated with life satisfaction ( $M$ $=21.91, S D=7.87)$. However, this analysis ignores the fact that these pairs of repeated observations were made on the same 35 individuals. In addition to violating the assumption of independence of observations, this approach reveals nothing about the within-person variability over time, which is the primary focus of this study.

More accurately, applying the within-person correlation analysis detailed above indicates that at the individual-level, variability in physical activity was not significantly associated with life satisfaction. Specifically, the between-person factors (i.e., dummy variables) entered at Step 1 of the model accounted for approximately $90 \%$ of the variance in physical activity, $F(34,466)$ $=124.10, p<.001$. Such a large portion of the variance attributable to differences betweenpersons leaves little in the way of remaining variance within participants. The addition of physical activity did not add to the variance explained $\left(\Delta R^{2}=.00, \Delta F=.89, p=.35\right)$. The final model consisting of the between-person factors (i.e., dummy variables) and within-person variability in physical activity accounted for $90 \%$ of the variance in life satisfaction, $F(35,466)$ $=120.55, p<.001$. The standardized beta of physical activity was not significant, thus indicating that after accounting for the between-person variance, physical activity was not related to life satisfaction. Using the outlined formula, the resulting within-person association between physical activity and life satisfaction was not significant $(r=.04, p=.35)$ and consequently, Hypothesis 17 would not be supported.

This example illustrates how accounting for inter-person variation allows the researcher to isolate remaining variance due to individual variability in a predictor of interest. In this example, the within-person correlation found that daily variability in physical activity was not associated with variability in life satisfaction, although the initial group-level correlation 
suggested a significant association. Similarly, Bland and Altman (1995a) have demonstrated the efficacy of this technique for identifying an association not detected by the initial analysis. Thus, the within-person analysis provides a more accurate test of the individual-level research hypotheses by removing the variance due to the sample and specifically examining the withinperson prospective variability of the predictor on corresponding variability in the outcome.

Results

\section{Overview of Results}

The results are reported in three sections: (1) data management and preliminary analyses, (2) within-person analyses of repeated measures with dummy variables, and (3) post-hoc samplelevel analyses of repeated measures with weighted correlations.

\section{Data Management and Preliminary Analyses}

Individual daily process data from the Palms ${ }^{\circledR}$ were uploaded to a laboratory computer for management and analysis. The author and trained research assistants completed data entry for all non-Palm® items.

Baseline goal appraisals and CHAMPS data are presented in Table 5. Participants in the present study reported engaging in at least some type of physical activity between three and 52 times over the past week, which is similar to other samples (e.g., range $=0-51$; Stewart et al., 2001). Data from the CHAMPS questionnaire suggest that the sample of middle-aged adults in the present study were fairly active. Specifically, participants in the current study reported engaging in an average of 21.17 physical activities ( $M$ caloric expenditure/week $=4,442$ ) and 10.39 moderate intensity physical activities $(M$ caloric expenditure/week $=2,900)$ per week. For comparison, Stewart et al. (2001) reported an average of 13.52 physical activities ( $M$ caloric expenditure/week $=2,116)$ and just 5.27 moderate intensity physical activities $(M$ caloric 
expenditure/week = 1,163) per week for their "somewhat active" participants who set aside regular time for exercise but did not meet the guidelines for engaging in 20 minutes of moderateintensity activity at least three days per week.

\section{Missing Data}

Daily process data from Palms ${ }^{\circledR}$ that were used in the primary analyses were examined for missing data. Given the nature of the daily process protocol, which consisted of multiple daily assessments across several days, the potential for missing data would exist for a variety of reasons. However, Palms ${ }^{\circledR}$ were programmed such that participants had to respond to an alert within a specific time frame (20 minutes) in order to access the questions in a given testing session. Thus, any missing data indicated that a participant missed an entire trial, as there were no missing data on individual items.

Palms ${ }^{\circledR}$ were programmed for three trials per day for six days, for a total of 18 possible trials per participant. Thirty-four of the 35 participants missed at least one trial. However, adherence to the protocol was fairly strong, with the majority of participants $(n=32,91.4 \%)$ missing five or fewer sessions $(M=2.94, S D=1.89)$. An examination of the Daily Logs suggested that in general, participants were aware of missed trials.

Approximately half ( $n=18,51.4 \%$ ) of the sample missed zero, one, or two trials; these individuals were classified as low missing and compared to the remainder of the sample who missed three or more trials (high missing) on demographic and baseline goal characteristics in order to examine whether participants who reported better adherence (i.e., fewer missed trials) systematically differed from participants who missed more trials overall.

Demographic and baseline goal characteristics for participants who reported data classified as low missing, participants who reported data classified as high missing, as well as the 
difference test statistics between the missing groups are presented in Table 6. To summarize, results from a one-way analysis of variance (ANOVA) indicated that there were no differences between the groups on age, education, years of marriage, BMI, physical health, mental health, and functional impairments (all $F(1,33) \leq 1.48$, all $p=$ n. s.), suggesting that data were missing completely at random. In addition, other than baseline differences in perceived difficulty, there were no differences in baseline goal characteristics between participants with low missing data and those with high missing data. Participants with data classified as high missing reported greater baseline difficulty working towards their exercise goals $(M=4.94, S D=2.15)$ than those with low missing data $(M=6.79, S D=2.16), F(1,33)=5.41, p<.05$. Given the number of observations, as well as the results from the above analyses suggesting data were missing completely at random, data were not imputed for missing cases and thus missing values were treated in analyses using the listwise deletion procedure within SPSS.

\section{Results of within-person analyses}

Participants completed all measures three times per day for six days, resulting in an overall within-person repeated measures data structure with 18 times of measurement. In order to test the hypotheses at the individual-level, dummy variables were created for each "level" of the participants variable. Thirty-five dummy variables were created and entered into the first-step of each regression model. As described above, this method treats individuals as categorical predictors. The predictor of interest was entered into the second step of each individual regression. Thus, the results report the model fit statistics predicting the outcome from the set of dummy variables in the first step (i.e., the inter-person variation in the outcome), as well as the model change statistics when the predictor to be tested was added to the model. Final model fit statistics are also reported. The method of calculating the magnitude and direction of the within- 
person correlation coefficient for each analysis was identical to that described above. Results are grouped by topic: (1) goal processes (i.e., perceived control and behavioral intentions), (2) goal processes and physical activity, (3) goal processes and subjective well-being, and (4) physical activity and subjective well-being. Standardized regression coefficients for all predictors, change statistics, and final model fit for all analyses are summarized in Table 7.

\section{Goal Processes}

The first research objective was to examine at the individual-level the association between variability in perceived control and goal-directed effort and perceived progress.

Results from a multiple regression analysis with between-person dummy variables entered as the first-step indicated that inter-person variation accounted for $48 \%$ of the variance in effort, $F(34,474)=12.77, p<.001$. The addition of perceived control explained an additional $2 \%$ of the variance in effort, $\left(\Delta R^{2}=.02 ; \Delta F=14.30, \mathrm{p}<.001\right)$. The final model consisting of the between-person factors and within-person variability in perceived control accounted for 50\% of the variance in goal-directed effort, $F(35,466)=47.81, p<.001$. The standardized beta of perceived control was significant and positive, thus indicating that after accounting for the between-person variance, an increase in perceived control was related to an increase in goaldirected effort. Using the outlined formula, the resulting within-person correlation between perceived control and effort was significant and positive, $(r=0.17, p=<.001)$, thus indicating that as perceived control increases, there is a corresponding increase in goal-directed effort, supporting Hypothesis 1.

A similar procedure was used in order to test the hypothesis that increases in perceived control would be associated with increases in daily perceived goal progress (H2) at the individual-level. Step 1 of the model accounted for $64 \%$ of the variance in individuals' goal 
progress, $F(34,474)=24.81, p<.001$. The addition of perceived control significantly improved the model fit $\left(\Delta R^{2}=.02 ;, F=21.94, p<.001\right)$. The final model consisting of the between-person factors and within-person control accounted for $66 \%$ of the total variance in perceived goal progress, $F(35,473)=25.79, p<.001$. The standardized beta of perceived control was significant and positive, thus indicating that after accounting for the between-person variance, an increase in perceived control was related to an increase in perceived progress on one's goals. Using the outlined formula, the resulting within-person correlation between perceived control and perceived progress was significant and positive, $(r=.21, p<.001)$, thus indicating that as individuals' experience increasing perceived control, they also experience a corresponding increase in perceived progress toward their goal. This finding supports Hypothesis 2.

\section{Goal Processes and Physical Activity}

The focus of the second research objective was to examine individual variability in perceived control, goal-directed effort, and perceived progress and their relation to variability in total physical activity. Similar procedures were used in order to test the hypotheses that increases in perceived control (H3), goal effort (H4), and perceived goal progress (H5) were associated with increases in physical activity at the individual-level. For all three models, the initial step of between-person dummy variables accounted for $37 \%$ of the variance in physical activity, all $F$ $(34,474)=8.11$, all $p<.001$. This value serves as a baseline for comparing the fit of subsequent models.

Participants' reports of perceived control did not significantly improve the model fit, $\left(\Delta R^{2}=.001 ; \Delta F=.96, p=.33\right)$. The final model consisting of the inter-person variation and within-person variability in perceived control accounted for $37 \%$ of the variance in physical activity, $F(35,473)=7.90, p<.001$. The standardized beta of perceived control was not 
significant, thus indicating that after accounting for the between-person variance, an increase in perceived control was not related to variability in physical activity. Using the outlined formula, the resulting within-person association between perceived control and physical activity was not significant $(r=.05, p=.33)$ and consequently, Hypothesis 3 was not supported.

Using similar procedures, the hypothesis that increases in goal-directed effort and increases in physical activity were examined at the individual-level (H4). Participants' reports of their effort significantly improved the model fit, $\left(\Delta R^{2}=.02 ; \Delta F=16.70, p<.001\right)$. The final model consisting of inter-person variance and effort accounted for 39\% of the variance in physical activity, $F(35,473)=8.61, p<.001$. The standardized beta of goal-directed effort was significant and positive, thus indicating that after accounting for between-person variance, an increase in effort was associated with an increase in minutes of physical activity. Using the outlined formula, the resulting within-person correlation between goal-directed effort and physical activity was significant and positive, $(r=.19, p<.001)$, thus indicating that as individuals experienced increasing effort toward their physical activity goals, they also experienced a corresponding increase in physical activity, supporting Hypothesis 4.

The relation between the behavioral intention measure of perceived goal progress and physical activity (Hypothesis 5) was also examined at the individual-level. Participants' reports of their perceived progress improved the model fit, $\left(\Delta R^{2}=.02 ; \Delta F=17.27, p=<.001\right)$. The final model consisting of inter-person variance and perceived progress accounted for 39\% of the variance in physical activity, $F(35,473)=8.64, p<.001$. The standardized beta of perceived goal progress was significant and positive, thus indicating that after accounting for betweenperson variance, an increase in perceived progress was associated with an increase in physical activity over the study period. In support of Hypothesis 5, an examination of the within-person 
correlation coefficient indicated a positive association between participants' reports of their perceived goal progress and physical activity $(r=.60, p<.001)$, thus suggesting that as individuals' perceptions of their perceived progress increased, they experienced a corresponding increase in physical activity.

Goal Processes and Subjective Well-being.

The third research objective was to examine the association between the goal process variables (perceived control, effort, and perceived progress) and three aspects of subjective wellbeing. These results are organized in three sections: positive affect, negative affect, and life satisfaction.

Positive affect. Multiple regression analyses similar to those previously reported were conducted in order to test the hypotheses that increases in perceived control (H6), goal effort (H7), and perceived goal progress (H8) were associated with increases in positive affect over the study period. Results from a multiple regression analysis with between-person factors dummy variables entered as the first-step are reported below. For all three models, the initial step of including the between-person factors accounted for $71 \%$ of the variance in positive affect, all $F \mathrm{~s}$ $(34,465)=34.16$, all $p$ s $<.001$. This value serves as a baseline for comparing the fit of subsequent models.

Perceived control significantly improved the model fit $\left(\Delta R^{2}=.02 ; \Delta F=31.33, p<.001\right)$, with the final model consisting of inter-person variation and within-person variability in perceived control accounting for $73 \%$ of the variance in positive affect, $F(35,464)=36.25, p<$ .001 . The beta for perceived control was positive and significant and thus indicated that after accounting for between-person variance, an increase in perceived control was associated with a corresponding increase in positive affect. The within-person correlation coefficient between 
perceived control and positive affect was positive, $(r=.25, p<.001)$, thus indicating that as individuals experience increasing levels of perceived control, they also report a corresponding increase in positive affect, supporting Hypothesis 6.

When participant reports of goal-directed effort were added to the initial step of the multiple regression (i.e., after accounting for between-person associations), the model fit improved $\left(\Delta R^{2}=.003 ; \Delta F=5.05, p<.001\right)$, with the final model consisting of between-person associations and goal-related effort accounting for $72 \%$ of the variance in positive affect, $F$ (35, $464)=33.62, p<.001$. The beta for effort was significant and positive, thus indicating that after accounting for between person variance, an increase in effort was associated with an increase in positive affect. Using the formula above, the within-person correlation coefficient between effort and positive affect was positive $(r=.10, p<.05)$, indicating that as participants reported increasing effort, they also experienced an increase in positive affect.

Similarly, the model improved when individuals' reports of their perceived goal progress were added at the second step of the multiple regression, $\left(\Delta R^{2}=.02 ; \Delta F=30.48, p<.001\right)$, with the final model consisting of between-person associations and perceived progress accounting for $73 \%$ of the variance in positive affect, $F(35,464)=36.16, p<.001$. An examination of the beta for perceived progress revealed a positive and significant association between perceived progress and positive affect after accounting for between person variance of the study period. The withinperson correlation coefficient between perceived progress and positive affect was significant $(r=$ $.25, p<.001$ ) and supported Hypothesis 8. As participants' ratings of perceived goal progress increased, they experienced corresponding increases in positive affect.

Negative affect. Multiple regression analyses similar to those previously reported were conducted in order to test the hypotheses that decreases in perceived control (H9), goal effort 
(H10), and perceived goal progress (H11) were negatively associated with negative affect at the within-person level over the duration of the study. Results from a multiple regression analysis with between-person dummy variables entered as the first-step are reported below. For all three models, the initial step that included the between person variance accounted for $47 \%$ of the variance in negative affect, all $F \mathrm{~s}(34,466)=12.10$, all $p \mathrm{~s}<.001$. This value serves as a baseline for comparing the fit of subsequent models.

Perceived control improved the model $\left(\Delta R^{2}=.03 ; \Delta F=23.98, p<.001\right)$, with the final model accounting for $50 \%$ of the variance in negative affect, $F(35,465)=13.02, p<.001$. The beta weight for control was negative and significant, thus indicating that after accounting for the between person variance, a decrease in control was associated with an increase in negative affect over the duration of the study. Using the outlined formula, the within-person correlation coefficient between perceived control and negative affect was significant $(r=-.22, p<.001)$, indicating that as individuals experienced decreases in perceived control, they experienced a corresponding increase in their negative affect, supporting Hypothesis 9.

The addition of participants' reports of their effort did not improve the model $\left(\Delta R^{2}=\right.$ $.001 ; \Delta F=.90, p=.34)$, with the final model including between-person factors and goaldirected effort accounting for $47 \%$ of the variance in negative affect, $F(35,464)=11.78, p<$ .001 . However, the beta for goal effort was not significant and thus suggested that there was no association between effort and negative affect over the course of the study. The within-person correlation between goal-directed effort and negative affect indicated a non-significant association between effort and negative affect $(r=-.04, p=.34)$ and thus Hypothesis 10 was not supported.

Participants' perceived progress on their physical activity goals since the last testing 
session improved the model $\left(\Delta R^{2}=.01 ; \Delta F=7.64, p<.001\right)$, with the final model accounting for $48 \%$ of the variance in negative affect, $F(35,465)=12.14, p<.001$. The beta for perceived goal progress was significant and negative, thus indicating that after accounting for the between person variance, a decrease in perceived progress was associated with an increase in negative affect. In support of Hypothesis 11, the within-person correlation coefficient between perceived progress and negative affect was negative and significant $(r=-.13, p<.05)$, thus as participants' progress toward their goals decreased, an increase in negative affect was observed.

Life satisfaction. Paralleling previous analyses, multiple regression analyses were conducted in order to test the hypotheses that increases in perceived control (H12), goal effort (H13), and perceived goal progress (H14) were associated with increases in life satisfaction at the within-person level. Consistent with previous sections, results from a multiple regression analysis with within-person dummy variables entered as the first-step are reported below. For all three models, the initial step of the between-person factors accounted for $90 \%$ of the variance in life satisfaction, all $F \mathrm{~s}(34,466)=124.10$, all $p \mathrm{~s}<.001$. This value serves as a baseline for comparing the fit of subsequent models.

Perceived control added a small but significant amount of predictive power to the model $\left(\Delta R^{2}=.01 ; \Delta F=22.23, p<.001\right)$, with the final model accounting for $91 \%$ of the variance in life satisfaction, $F(35,465)=126.68, p<.001$. The beta of perceived control was positive and significant, thus indicating that after accounting for inter-person variation, an increase in control was associated with an increase in life satisfaction over the course of the study. The withinperson correlation coefficient between perceived control and life satisfaction was positive $(r=$ $.21 p<.001)$, indicating that as participants experienced increased control over their physical activity goals they also experienced a corresponding increase in life satisfaction, supporting 
Hypothesis 12 .

The addition of participants' reports of their effort toward their physical activity goals did not improve the model $\left(\Delta R^{2}=.001 ; \Delta F=3.17, p=.08\right)$, with the final model consisting of between-person factors and within-person variability in goal-directed effort accounting for $90 \%$ of the variance in life satisfaction, $F(35,454)=121.21, p<.001$. The beta associated with effort was not significant, thus indicating that increases in effort were not associated with variability in life satisfaction. Using the defined formula, the within-person correlation coefficient between effort and life satisfaction was non-significant $(r=.08, p=.08)$ and consequently, Hypothesis 13 was not supported. Based on this analysis, variability in goal-related effort was not associated with variability in life satisfaction.

Participants' perceived progress on their physical activity goals since the last testing session slightly but significantly improved the model $\left(\Delta R^{2}=.002 ; \Delta F=8.00, p<.001\right)$, with the final model accounting for $90 \%$ of the variance in life satisfaction, $F(35,465)=122.59, p<$ .001. The corresponding beta for goal progress was significant and positive, thus indicating that after accounting for between person variance, increases in perceived progress were associated with increases in life satisfaction. The within-person correlation coefficient between perceived progress and life satisfaction was positive, $(r=.13, p<.05)$ and thus indicated that as participants' perceived progress toward their physical activity goals increased, they also experienced a corresponding increase in life satisfaction.

\section{Physical Activity and Subjective Well-being}

A final set of multiple regression analyses similar to those previously reported were conducted in order to test the hypotheses that increases in physical activity would be associated with increases in positive affect (H15) and life satisfaction (H17), while decreases in physical 
activity would be associated with increases in negative affect (H16) at the within-person level.

Results from a multiple regression analysis with within-person dummy variables entered as the first-step indicated that the between-person factors accounted for $71 \%$ of the variance in positive affect $F(34,466)=33.71, p<.001$. The addition of physical activity provided a slight but significant improvement, $\left(\Delta R^{2}=.01 ; \Delta F=9.73, p<.001\right)$, with the final model accounting for $72 \%$ of the variance in positive affect, $F(35,465)=33.64, p<.001$. The beta of physical activity was positive and significant, indicating that after accounting for between person variance, an increase in physical activity was related to an increase in positive affect over the study period. The within-person correlation coefficient between physical activity and positive affect was positive, $(r=.13, p<.05)$, supporting Hypothesis 15 . As participants engaged in increasing amounts of physical activity, they experienced corresponding increases in positive affect.

A model consisting of the between-person factors-only accounted for $47 \%$ of the variance in negative affect, $F(34,467)=12.17, p<.001$. The addition of physical activity did not significantly improve the model $\left(\Delta R^{2}=.003 ; \Delta F=2.63, p=.11\right)$. The beta for physical activity was not significant, indicating that after accounting for between person variations, physical activity was not associated with negative affect. The within-person correlation between physical activity and negative affect was not significant, $(r=.07, p=.11)$ and consequently, Hypothesis 16 was not supported.

A final model examining well-being and consisting of the between-person factors accounted for $90 \%$ of the variance in life satisfaction, $F(34,466)=124.10, p<.001$. The addition of physical activity did not significantly improve the model $\left(\Delta R^{2}=.00 ; \Delta F=.89, p=\right.$ $.35)$ and thus the final model consisting of between-person factors and physical activity 
accounted for $90 \%$ of the variance in life satisfaction. The beta for physical activity was positive but not significant, indicating that after inter-person variation is accounted for, increases in physical activity are not associated with life satisfaction. Thus, the within-person correlation coefficient between physical activity and life satisfaction was also not significant $(r=.04, p=$ .35 ) and consequently, Hypothesis 17 was not supported. For each model, adjusted $R^{2}$ values were similar to the non-adjusted $R^{2}$, suggesting the models derived from this sample are a good approximation to those drawn from the population.

\section{Post-hoc Analyses}

Of primary interest in the present study was the within-person variability that occurs as individuals pursue their physical activity goals within the context of their lives. Thus, the hypotheses tested and reported in the previous section focus on changes in measurements over time and whether increases (or decreases) in one variable were associated with increases (or decreases) in another variable at the individual-level after removing between-person differences. However, sample-level relations (i.e., whether on average, participants with higher or lower values on one variable also exhibited higher or lower values on another variable) may further inform the findings of the present study.

A second series of analyses were conducted in order to examine (1) goal processes, (2) goal processes and physical activity, (3) goal processes and subjective well-being, and (4) physical activity and subjective well-being at the sample-level The focus of these analyses was to investigate whether on average, participants with higher (or lower) values on one variable also exhibited higher (or lower) values on another variable. These follow-up analyses, when considered within the context of the individual-level analyses, contribute to a more complete understanding of the associations among study variables over time. 


\section{Overview of Sample-level Analyses of Repeated Measures}

Because participants in the present study reported on the variables of interest at multiple assessments, in order to examine any between-person associations among the variables of interest over the duration of the study, one could simply calculate participants' means for each of the variables of interest, and then calculate a between-subject correlation coefficient for the sample. This approach would involve aggregating all repeated observations on a single variable into a single mean score for each participant. Such an approach is straightforward and would involve calculating correlations between the means of the variables of interest and comparing the significance value for the appropriate number of comparisons (i.e., the total sample).

As an illustration, consider Hypothesis 1, which aimed to test whether increases in perceived control were associated with increases in goal effort at the individual-level. This hypothesis makes no predictions about sample-level associations between control and effort, yet this information is important to consider. A simple between-subjects comparison would indicate that participants' mean daily reports of perceived control $(M=8.19, S D=2.00)$ were positively associated with mean daily reports of effort $(M=6.11, S D=1.67), r(35)=.46, p<.01$. However, this analysis ignores the repeated measures that occurred within a day and across days. Aggregating participants' repeated responses in such a manner and calculating the correlation coefficient for a predictor variable on a similarly-created outcome variable for an entire sample can produce misleading results.

The appropriate analysis must take into account the within-person repeated measures of the data structure. As is common in repeated measures designs, participants often provide different numbers of assessments and thus it is necessary to person-center the data. Bland and Altman (1995b) provide a detailed description of how to calculate weighted correlation 
coefficients in order to account for differing numbers of assessments among participants. The number of observations provided serves as the weight in the analysis. Each participant's mean for all assessments of a given variable is used to replace the observed value for each of the repeated measures of the variable. Person-centering the data balances the data structure by assigning to each value a corresponding weight based on the number of total observations completed by each respective participant. Corresponding significance values and degrees of freedom for the correlations are based on the number of participants (i.e., $N=35$, df $=33$ ) and not the number of observations. This approach permits the examination of whether, on average, participants with high levels of a predictor (e.g. perceived control) also have high average values of an outcome variable (e.g., goal-directed effort).

\section{Sample-level Results}

Weighted correlations were calculated in order to test appropriately-modified versions of the research hypotheses at the between-person level. Specifically, the hypotheses were modified in order to examine the associations among variables at the sample-level, thus removing any predictions of within-person variability. As described above, each participant's number of responses served as weights in subsequent analyses. In order to person-center the data, each participant's mean was calculated for each of the variables to be tested. Similar to the withinperson results, results for the sample-level analyses are reported by topic: (1) goal processes, (2) goal processes and physical activity, (3) goal processes and subjective well-being, and (4) physical activity and subjective well-being. Although the relatively small sample size often precludes tests of statistical significance, the magnitude of the correlation coefficient is often useful. 


\section{Goal Processes}

Weighted correlation coefficients were calculated to test the hypotheses that at the sample-level, participants who report high levels of perceived control also report high levels of goal effort $(\mathrm{H} 1)$ and perceived goal progress $(\mathrm{H} 2)$. Results are summarized in Table 8. On average, participant ratings of perceived control $(M=8.21, S D=1.96)$ were positively associated with effort $(M=6.13, S D=1.65)(r=.44, p<.01)$ and perceived progress $(M=$ $5.66, S D=1.96)(r=.46, \mathrm{p}<.01)$.

\section{Goal Processes and Physical Activity}

Paralleling the previous analyses, weighted correlations were calculated to test at the group-level the hypothesized association between average perceived control (H3), effort (H4), and perceived progress (H5) with average levels of physical activity. Results are summarized in Table 9. Participants' reports of daily effort $(r=.40, p<.05)$ and perceived progress on their goals $(r=.37, p<.05)$ were positively associated with total minutes of physical activity $(M=$ 71.99, $S D=91.52$ ), supporting Hypotheses 4 and 5 at the sample-level. However, neither the magnitude nor significance test suggested a significant sample-level relation existed between physical activity and perceived control $(r=.05, p=.77)$.

\section{Goal Processes and Subjective Well-being}

Paralleling previous analyses, weighted correlations were calculated in order to test the hypothesis that at the sample-level, participants higher in perceived control would report higher positive affect (H6) and life satisfaction (H12) and lower levels of negative affect (H9). On average, perceived control was positively associated with session measures of positive affect ( $M$ $=30.41, S D=10.26)(r=.37, p<.05)$. Contrary to hypotheses, no significant association was found between perceived control and negative affect $(r=-.03, p=.87)$. Despite the magnitude of 
association, no significant associations were found between perceived control and life satisfaction $(r=.23 p=.18)$.

Similarly, weighted correlations were calculated in order to test the hypothesis that at the sample-level, participants who reported greater goal-directed effort would report higher levels of positive affect $(\mathrm{H} 7)$ and life satisfaction $(\mathrm{H} 13)$ and lower levels of negative affect (H10). On average, session reports of effort were positively associated with positive affect $(r=.62, \mathrm{p}<$ .001). However, effort was not significantly associated with either life satisfaction $(r=.31, p=$ $.07)$ or negative affect $(r=-.18, p=.29)$.

In order to test whether, on average, participants who reported greater perceived goal progress would report higher levels of positive affect (H8) and life satisfaction (H14) and lower levels of negative affect (H11), weighted correlations were calculated and examined for significance. On average, participant reports of perceived goal progress were positively associated with positive affect $(r=.65, p<.001)$ and life satisfaction $(r=.41, p<.05)$. However, participant reports of perceived goal progress were not significantly associated with negative affect at the between-person level $(r=-.20, p=.27)$. Results for all sample-level weighted correlations testing the association between goal processes and SWB are summarized in Table 10.

\section{Physical Activity and Subjective Well-being}

Paralleling previous analyses, weighted correlations were calculated in order to test the sample-level hypotheses that physical activity would be positively associated with positive affect (H15) and life satisfaction (H17) and negatively associated with negative affect (H16). Results are summarized in Table 11. Physical activity was positively associated with positive affect $(r=$ $.48, p<.05)$ and life satisfaction $(r=.36, p<.05)$. However, no association was found between 
physical activity and negative affect $(r=-.21, p=.23)$.

\section{Discussion}

\section{Review of Research Objectives}

The purpose of this study was to investigate individual variability in the daily processes of physical activity goal pursuit. Thirty-five individuals used Palm ${ }^{\circledR}$ handheld computers to complete daily diaries three times per day for six days in order to investigate four primary research objectives. In general, these objectives examined the within-person variability of specific goal process variables identified in the Theory of Planned Behavior (TPB; Ajzen, 1985) in a sample of middle-aged adults who were overweight or obese and actively trying to lose weight. Of further interest was the association between changes in these goal process variables (perceived control, goal-directed effort, and perceived progress) and both physical activity and subjective well-being, as well as the association between changes in physical activity and subjective well-being over time. The associated hypotheses were examined at the individuallevel by capitalizing on the within-person structure of the data. Follow-up analyses used weighted correlations to examine similar objectives at the sample-person level.

\section{Summary}

Table 12 provides a summary of the within-person and sample-level analyses in relation to the general study hypotheses. Results from within-person and sample-level analyses supported the positive association between perceived control with both goal-directed effort and perceived progress. Similarly, the positive association between goal-directed effort and perceived progress with physical activity was supported at the individual- and sample-level, however neither analysis identified an association between perceived control and physical activity. 
With respect to SWB, there was a positive association between perceived control and goal-directed effort with positive affect at both the individual- and sample-level. Further, increases in perceived goal progress were associated with increases in positive affect, although no significant association was detected at the sample-level. Although individual decreases in perceived control, effort, and perceived progress were each associated with increases in negative affect, results from the weighted correlation analyses did not identify any significant associations between goal-process variables and negative mood at the sample level.

Increases in perceived goal progress and perceived control were associated with increases in life satisfaction at the individual-level and at the sample-level for perceived progress only. No individual- or sample-level associations between goal-directed effort and life satisfaction with life satisfaction were detected. Finally, increases in physical activity were associated with positive affect at the individual-level. Physical activity was positively associated with positive affect and life satisfaction at the sample-level. No individual- or sample-level associations between physical and negative affect were detected.

The following discussion will: (1) review key study findings for the four primary research objectives at the individual level and provide possible explanations for each of the key findings within the context of previous research, and (2) identify limitations to the study and discuss possible future directions. Because the theoretical and conceptual foundations on which this study was based highlight the importance of goal processes in promoting successful aging, this section will discuss the study findings within a life-span developmental framework.

\section{Review of Study Findings and Association with Previous Research}

This section summarizes the major findings of the current study and is divided into four subsections corresponding to the four research objectives: (1) interrelationships among goal 
processes (i.e., perceived control, goal-directed effort, and perceived progress), (2) goal processes and physical activity, (3) goal processes and subjective well-being, and (4) physical activity and subjective well-being. Because the hypotheses were primarily interested in testing within-person variability, the discussion will focus on these findings, with consideration given to between-person findings of note.

\section{Interrelations among Goal Processes}

Building upon previous daily process studies (e.g., Affleck et al., 1998), the present study sought to examine the interrelations among the variability of the goal-process variables perceived control, goal effort, and goal progress within the context of the physical activity goal pursuits of middle-aged individuals who were overweight or obese and actively trying to lose weight. In addition to the specific sample under study, this research is innovative in that it screened participants such that having a physical activity goal was a requirement for participation.

The first research objective was to investigate the association between increases in perceived control as it relates to goal-directed effort and perceived progress. As hypothesized, as participants reported increased control over their physical activity goals, they experienced a corresponding increase in goal-directed effort and perceived progress. With respect to the question of average scores, results of the weighted correlations also indicated that perceived control was positively associated with effort and perceived progress. When viewed together, these results provide a detailed picture of goal pursuit and suggest that not only are there important between-person associations between perceived control with effort and perceived progress, but after accounting for the inter-person variation in effort and perceived progress separately, increases in control at the individual-level are associated with increases in goaldirected effort and progress. 
In the present study, participants articulated their behavioral intentions in the form of personal goals for physical activity. At three points per day for six days, participants were asked about their goal-directed effort and perceived progress toward these intentions. The findings that perceived control was positively associated with both goal-directed effort and perceived progress at both the individual and between-person levels are consistent with the TPB (Ajzen, 1985) and the Model of Goal-directed Behaviour (Perugini \& Bagozzi, 2001) in that perceived control is thought to be one of the strongest predictors of behavioral intentions. Perceived control has been shown to account for significant amounts of variance in behavioral intentions in studies of physical activity behavior (e.g., Godin \& Kok, 1996) and physical activity attendance (Lucidi et al., 2006), as well as midlife health behaviors in general (e.g., Andrykowski et al., 2008). These results are novel in that they point to positive associations among increases in perceived behavioral control and the corresponding increase in effort and perceived progress towards shortterm physical activity goal pursuits.

\section{Associations between Goal Processes and Physical Activity}

Previous studies of health during midlife have demonstrated the importance of goalrelated processes in predicting health-promoting behaviors (e.g., Hooker \& Kaus, 1992). Building from these findings, the second research objective investigated perceived control, goaldirected effort, and perceived progress as they relate to physical activity.

As hypothesized, increases in goal-directed effort and perceived progress were positively associated with increases in physical activity at the individual-level. Other studies of goal pursuit and health consistently highlight the positive association between behavioral intentions and behaviors such as physical activity (e.g., Benjamin et al., 2005; Symons \& Hausenblaus, 2005). Results from the sample-level analyses are consistent with this notion. However, after accounting 
for the inter-person variation in physical activity, the individual-level findings that increases in goal-directed effort and perceived progress were each associated with increases in total minutes of physical activity extend this body of research and point to the importance of considering the momentary association between goal constructs while individuals actively pursue their physical activity goals.

Perceived control is consistently associated with physical activity in meta-analytical studies of the psychological correlates of health behaviors (e.g., Hagger et al., 2002; Symons \& Hausenblaus, 2005); thus, it was somewhat surprising that the within-person analysis failed to detect a significant association between increases in perceived control and corresponding increases in physical activity (H3). Similarly, no significant association was detected between control and physical activity at the sample-level. Although unexpected, these non-significant findings are interesting and provide additional support to the notion that TPB constructs may operate differently in different contexts and within different populations (Ajzen, 1991).

Theoretically, the concept of perceived behavioral control was thought to add to the explanatory power of Ajzen's original Theory of Reasoned Action (Ajzen \& Fishbein, 1980) by providing a path to behavior when such a behavior is not under one's complete control. Such is the case with physical activity, as there are often a variety of perceived personal and environmental barriers to exercise behavior across adulthood (Booth, Bauman, \& Owen, 2002; Salmon, Owen, Crawford, Bauman, \& Sallis, 2003). Clearly, simply intending to exercise does not mean that one will necessarily follow through with this intention, as any number of barriers may impede actual exercise behavior. Within the context of the TPB then, perceived control provides a means of explaining instances where behavioral intentions do not predict actual behavior (Armitage \& Conner, 2001). 
The findings that increases in goal-directed effort and perceived progress were associated with increases in physical activity support this notion. Participants in the present study had already expressed their behavioral intentions in the form of their own personally salient goals for physical activity. Specifically, the non-significant finding for the association between increases of perceived control and physical activity may suggest that as participants put forth increased effort toward and perceive greater progress on their physical activity goals, they engaged in more physical activity. This behavior would likely result in a feedback loop to increase perceived control. If this were the case, it is possible then that the any conceptual association between individual-level variability between control and physical activity was attenuated over the course of the study. However, the present study did not speculate on potential covariates or multivariate associations among the variables, as the primary hypotheses were only interested in examining the within-person variability associated with physical activity goal pursuit.

\section{Associations between Goal Processes and Subjective Well-being}

The third objective of the research was to examine how increases in the goal process perceived control, goal-directed effort, and perceived progress relate to the three components of subjective well-being (SWB). As reviewed in the Introduction, the concept of SWB involves positive affect, the absence of negative affect, and overall satisfaction with life (Diener et al., 1997) and provides a useful proxy for successful aging. Further, from a life-span perspective one way that individuals are active agents in their own development involves the pursuit of personal goals. Findings in this section are organized by goal process (i.e., the individual-level predictor in the primary analyses).

Perceived control and SWB. As hypothesized, increases in perceived control over one's physical activity goals were associated with increases in life satisfaction at the individual-level. 
These findings were further confirmed at the sample-level. These findings are consistent with sample-level data from the MIDUS study in that middle-aged adults who reported greater control had higher life satisfaction (Lachman \& Firth, 2004). These findings are novel when considering the magnitude of the baseline model predicting life satisfaction. The between-person factors accounted for $90 \%$ of the variance in life satisfaction, leaving very little variance to explain. That perceived control significantly improved the model fit is informative and further highlights the utility of daily process studies in detecting even slight within-person variation in SWB.

As hypothesized, increases in perceived control were associated with increases in positive affect, while decreases in perceived control were associated with increase in negative affect at the individual level. The individual-level findings underscore findings from a meta-analysis that found greater control over one's health to be negatively associated with negative affect (Hagger \& Orbel, 2003). Similarly, although perceived control was significantly and positively associated with positive affect at the sample-level, it was not associated with negative affect. This divergence is particularly interesting in light of the between-person variance in affect. Returning to the baseline models, between-person factors accounted for $71 \%$ of the variance in positive affect, yet only $47 \%$ of the variance in negative affect. Given the remaining variance in negative affect not accounted for by between-person factors (i.e., 53\%), the non-significant findings are not entirely surprising. This sample-level association between perceived control and positive affect but not negative affect is intriguing and warrants further investigation.

Taken together, the associations between perceived control and SWB were consistent with previous research. From a life-span perspective, the goal formulation and adjustment processes of goal pursuit are a central task of optimal development, as one must continuously strive to strike a balance between one's needs and his or her resources, and thus are thought to 
provide individuals with a sense of control over their lives. This means of exercising control over development and managing one's actions and effort is theorized to be an important contributor to SWB. Findings from the present study provide further support for the association of perceived control with SWB and extend this literature to include middle-aged individuals who were overweight or obese and actively trying to lose weight. Thus, an increase in perceived control within the context of healthy behavioral pursuit appears to have generally positive associations with SWB. These findings are intriguing in light of additional findings and are further discussed in subsequent sections.

Goal effort, goal progress, and SWB. Contrary to hypotheses, there was no individuallevel association between increases in goal-directed effort and life satisfaction. However, perceived goal progress was positively associated with life satisfaction at both the individualand sample-level. However, on average, participant reports of perceived goal progress were positively associated with life satisfaction. When interpreted together, these results suggest that although there are sample-level associations between perceived goal progress and life satisfaction, such associations do not necessarily translate to participants' prospective experiences of their daily goal pursuits. As hypothesized, increases in goal effort and perceived progress were each associated with corresponding increases in positive affect at the individuallevel. However, with respect to negative affect, the within-person findings were mixed. As expected, decreases in perceived goal progress were associated with increases in negative affect, yet contrary to hypotheses, there was no association between increases in effort and withinperson changes in negative affect.

Few studies have examined specifically the association of goal-directed effort and perceived progress with mood. One study that examined these associations using a daily process 
design found no such association between morning-to-evening changes in either positive mood or negative mood and both goal-directed effort and perceived progress toward participants' health goals (Affleck et al., 1998). Findings from the present study extend this line of research in two ways. First, the non-significant findings for the within-person association between decreases in effort and increases in negative affect are consistent with those of Affleck and colleagues. However, contrary to Affleck et al., several significant within-person associations were detected. First, and perhaps most notably, increases in both goal-directed effort and perceived progress were each associated with corresponding increases in positive affect. Second, decreases in perceived goal progress were associated with increases in negative affect in the present study.

It is interesting to speculate as to the possible explanations for these discrepancies. Participants in the Affleck et al. (1998) study were middle-age women who receiving treatment for fibromyalgia. Over the course of 30 days of monitoring, individual-level changes in mood were not associated with effort or progress toward participants' health-related goals (Affleck et al.). In the present study, however, increases in both goal-directed effort and perceived progress were associated with increases in positive mood, while decreases in perceived progress only were associated with increases in negative affect. Results from Steele's (2004) daily process study among older women suggest that, at least in the short-term, significant within-person associations exist between physical activity and mood within community-dwelling, non-clinical samples. Thus, it is unclear if the non-significant findings reported by Affleck and colleagues are at least partially a function of the specific disease processes associated with the symptoms of fibromyalgia. Further, it is likely that individuals coping with the chronic pain symptoms associated with fibromyalgia hold qualitatively different health-related goals compared participants in the present study, which consisted of middle-aged individuals who were fairly 
active and reported themselves to be in fairly good health. Taken together, these findings point to the importance of explicitly examining participants' goals when investigating time-covarying associations between physical activity and affect. The association between both goal-directed effort and perceived progress and positive and negative mood within the daily processes of health-related goal pursuits remains an empirical question.

In the present study, increases in perceived control, effort, and perceived progress were associated with increased positive affect, while decreases in control and progress were associated with increases in negative affect at the individual-level. However, increases in goal-directed effort were not associated with negative affect. When considered within the context of other daily process research (e.g., Affleck et al., 1998), these findings allow for the possibility that within middle-aged individuals, the processes involved with physical activity goal pursuit are differentially associated with affect and more specifically, certain aspects of goal pursuit are more important for the positive rather than the negative aspects of affect. Associations between Physical Activity and Subjective Well-being

Research has demonstrated the positive associations between physical activity and various indices of SWB. When taken together, findings from qualitative (Stathi, 2002), shortterm daily process (Steele, 2004), longitudinal (Elavskiy, 2005), and meta-analytical (Arent et al., 2000) studies support the notion that physical activity is positively associated with positive affect and life satisfaction and negatively associated with various aspects of negative mood. Given the negative associations between obesity and SWB (Fine et al., 1999), the fourth research objective of this study was to examine the within-person relation between increases in physical activity and participants' corresponding experiences of the three indices of subjective well-being 
(positive affect, negative affect, and life satisfaction) specifically within a sample of middle-aged adults who were obese or overweight and actively trying to lose weight.

Physical activity and positive affect. As expected, increases in physical activity were associated with a corresponding increase in positive affect at the individual and sample-level. These results are consistent with those of Steele (2004), who identified a positive relation between physical activity and positive mood over a six-day reporting period for some participants, but not all. Similarly, Gauvin and colleagues found positive affect to be greater on days characterized by greater physical activity (Gauvin, Rejeski, \& Reboussin, 2000).

The findings of the present study that increases in physical activity are associated with increase in positive affect build upon these studies in a number of ways. First, compared to Steele's study of older women $(M=71.5$ years of age) recruited broadly from the community, the sample studied herein consisted of middle-aged adults $(M=49$ years $)$ who were obese or overweight and recruited specifically because they were actively trying to lose weight. Thus, findings provide support for within-person variability between physical activity and positive mood among middle-aged overweight and obese persons in particular. Second, although participants in the Gauvin et al. study were closer to midlife $(M=33.1$, range $=19-57$ years of age), they reported normal body fat (24\%). In the present study, although participants' body fat was not calculated, the average BMI for the sample $(M=33.64$, range $24.60-49.10)$ suggests that these middle-aged adults were considerably more obese than those in the Gauvin et al. study. Thus, these findings extend this body of research to include specifically middle-aged adults who are obese or overweight.

Physical activity and negative affect. Contrary to hypotheses, there was no association between physical activity and negative affect at either the individual- or sample-level. Although 
these non-significant findings were unexpected, they are consistent with those of Vendrig and Lousberg (1999), who found no within-person associations between physical activity and affect in a daily process study of chronic pain patients.

A recent intervention study conducted within middle-age cardiac rehabilitation patients provides some insight into the non-significant findings. Scholz and colleagues implemented a self-regulation intervention focused on planning and goal-setting for physical activity and found that after both four and twelve months, participants in the intervention group reported fewer depressive symptoms than those in the control group (Scholz, Knoll, Sniehotta, \& Schwarzer, 2006). However, the authors found no association between actual physical activity behavior and depressive symptoms. On the other hand, participant perceptions of their own exercise goal attainment were significantly related to the reduction in depressive symptoms (Scholz et al., 2006).

Physical activity and life satisfaction. As expected, the significance of the weighted correlation coefficient indicated a positive association between physical activity and life satisfaction at the sample-level. These results are consistent with previous research using pedometers to examine the association between physical activity and life satisfaction among older adults (Parker, Strath, \& Swartz, 2008) and extend these findings to include middle-aged adults who are obese or overweight and actively trying to lose weight. Similarly, these results are in line with findings from longitudinal studies of physical activity such as that of Schnohr and colleagues, who found increase in physical activity to be inversely associated with life dissatisfaction (Schnohr, Kristensen, Prescott, \& Scharling, 2005).

Contrary to hypotheses, increases in physical activity were not associated with life satisfaction at the individual-level. Although there were between-person associations between 
physical activity and life satisfaction, these associations do not necessarily translate to the participants' experiences of their goal pursuits. Returning to the within-person associations between the goal process variables, where increases in perceived control in particular were associated with increases in life satisfaction, consistent with Scholz et al. (2006), it is possible that any within-person associations between physical activity and life satisfaction are attenuated by goal process variables.

A further review of the literature yielded two studies of particular interest. First, one recent study that found physical activity, as assessed by pedometers and accelerometers, showed stronger associations with both the PANAS and SWLS than did self-reported measures of activity (Parker et al., 2008). Second, Cranford and colleagues contend that many of the instruments typically used to measure mood in daily process studies may need to be modified in order to demonstrate appropriate psychometric properties necessary for detecting subtle withinperson variability (Cranford et al., 2006). Taken together, the mixed findings between physical activity and various indices of SWB at both the individual- and sample-level could be at least partially attributed to the self-reported physical activity measure or to the reliability of the SWB measures for detecting subtle within-person changes in various indices of SWB. In order to encourage middle-aged and older adults to take more control over their functional and subjective well-being, and thus promote successful aging, we must improve our understanding of how these individuals actually live their lives. Future research should continue to apply daily process designs and within-person analytical techniques to studies of physical activity in order to determine the suitability of the measures for detecting meaningful within-person changes. 


\section{Limitations and Future Directions}

\section{Sampling}

The sample recruitment focused explicitly on middle-aged adults who currently held weight-loss goals and had chosen physical activity as a means to achieve that goal. For the present set of research objectives and corresponding hypotheses, the targeted sampling of this population was considered a strength of this study. However, it is unclear whether such findings would be replicated among other samples. Whereas the present study detected significant associations among a variety of variables of interest (e.g., between goal-directed effort and progress and positive mood), other research (e.g., Affleck et al., 1998) has failed to find such results. Future research should further investigate the nature of the interrelations between goal process variables, physical activity, and SWB to determine the significance and magnitude of such associations within various population sub-groups. In particular, it is unclear if these results would generalize to groups without stated goals or goals that were more ambiguous.

In addition, it is unclear if these findings are uniform for men and women. Similar daily process studies of physical activity and affect have focused exclusively on women (e.g., Affleck et al., 1998; Gauvin et al., 2000; Steele, 2004). The present study could not clarify this issue, as the sample consisted mostly of females (89\%). A recent cross-sectional study of 6,379 adults ( $M$ $=49.64$ years of age) found that older adults report greater perceived control over physical activity than middle-aged or young adults, but no significant associations between other TPB variables (e.g. behavioral intention, attitudes) across age and gender (Rhodes, Blanchard, \& Blacklock, 2008). The authors interpret these non-significant findings as evidence that TPB beliefs (other than perceived control) and exercise behavior are invariant across age and gender, yet this study only assessed between-person differences. 
The findings in the present study suggest that for certain variables, bivariate associations can be non-significant at the sample-level but be significant at the individual-level. Although the sample size was appropriate for addressing the within-person hypotheses which were of primary interest, power considerations prohibited between-group comparisons. Whether participants in this study differ from younger or older adults and whether the associations among goal processes, health behavior, and SWB differ for adults choosing other health-promotion goals or other means remains an empirical question to be addressed by future research.

\section{Measurement and Analyses}

The findings of this study and conclusions should be interpreted in light of certain measurement limitations. The measure of physical activity used in the analyses consisted of the total minutes of physical activity self-reported across a variety of activities. The items used to assess physical activity were drawn from a well-established measure of physical activity (PAQ; Paffenbarger et al., 1978), as well as those used in a national population survey (NHIS; USDHHS, 2005). Self-reports may not be as accurate as objective measures of physical activity, particularly with respect to their ability to detect associations between activity and various indices of SWB (Parker et al., 2008) and thus, the index of physical activity used in this study could be considered a limitation. However, with respect to the NHIS items, these are the criteria presented to the public and perhaps most appropriate for community-based interventions. Further, the inclusion of open-ended items (in order to allow for appropriate breadth in the variety of physical activities) and the daily recording procedures are consistent with recommendations of an expert panel for assessing physical activity in middle-aged women (Masse et al., 1998). 
The analyses used to test the univariate and bivariate hypotheses could be considered an additional limitation of the study. Because the primary hypotheses were only interested in examining the within-person variability associated with physical activity goal pursuit, the present study did not speculate on potential covariates or multivariate associations among the variables. Future research should build upon these findings in order to ascertain whether certain participant characteristics, such as social support, self-rated health, marital status, or physical impairments add further clarity to the research findings.

One potentially fruitful avenue for further inquiry involves spousal support for physical activity goals. Participants in the present study were married on average 24.33 years $(S D=$ 11.14) and reported fairly high baseline ratings of support from a significant other $(M=8.63, S D$ $=1.50$ on a 10-point scale). Interestingly, although participants reported strong support, their responses suggest that they had little desire to simply please their partners $(M=5.97, S D=$ 3.03). This descriptive finding is intriguing in light of the marital health literature. For example, in a review of 64 empirical studies, Kiecolt-Glazer and Newton (2001) highlight the impact of marital functioning on various health behaviors. In addition, results from a daily diary study of short- and long-term married couples suggest that shared life task appraisals are associated with greater spouse involvement in life task pursuits. Further, greater positive affect was observed on days where spouses were more involved in one another's life tasks (Meegan \& Goedereis, 2006). This descriptive finding is intriguing with respect to the daily processes associated with daily physical activity goal pursuit and warrants future investigation.

An additional limitation is that the analyses used in the present study do not permit causal inference. Emerging analytical strategies such as hierarchical linear modeling (Bryk \& Raudenbush, 1987) allow researchers to include within-person differences in both slopes and 
intercepts, which preserves the temporal sequence under study and allows for the modeling of causal relationships among the variables of interest. Further, as summarized by Tennen and Affleck (1996), West and Hepworth (1991) argue that meta-analytical techniques, where participants correspond to the number of studies and the number of observations serves as the sample size, are appropriate for daily process studies. Whether goal process variables exert a causal effect on one another, on physical activity, or on subjective well-being within the context of physical activity goal pursuit remains an open question to be addressed in future research. Design

Health behavioral change can be conceptualized as a process (e.g., the Transtheoretical Model Stages of Change, Prochaska \& DiClemente, 1983). Although the design utilized in the present study permitted the examination of within-person variability in physical activity goal pursuits, the six-day protocol only captures part of the process of physical activity goal pursuit. Although participants were screened for physical activity goals, the present study did not assess an individual's position within the process of behavioral change. The magnitude and significance of the findings in the present study may differ within samples of middle-aged adults within the same stage of behavioral change or over different assessment periods. Further, whether a longer period of assessment, which is more consistent with the slow and steady approach to weight loss (i.e., 1-2 pounds per week) recommended by the NHLBI would reveal a different pattern of results remains to be tested.

Finally, the field protocol placed daily demands on participants and may have served to strengthen their commitment to reaching their goals. A recent study of older adults found that participants assigned to monitor their physical activity using PDAs engaged in more physical activity than participants in a control condition (King, Ahn, Oliveira et al., 2008). Compliance 
rates suggest that individuals in the present sample were highly motivated to complete the protocol. However, whether the use of the handheld devices and the multiple, daily entries facilitated this function in the current sample remains unknown.

\section{Do Goals Matter?}

It is important to point out that participants in the present study responded to advertisements seeking middle-aged individuals who were trying to lose weight. Further, participants self-nominated at least one personal goal for physical activity prior to participation. This would be considered a self-set goal, as opposed to one that is assigned to them by a health professional or a personal trainer, for example.

In studies of the efficacy of goal-setting with respect to health-promoting behaviors, assigned goals (e.g., Duncan \& Pozehl, 2002) are most common, while self-set goals (e.g., Cobb, Stone, Anonsen, \& Klein, 2000) are less common. There seems to be some evidence that assigned goals are often more effective than self-set goals for behavior change. However, in a review of the literature, Schilts et al. (2004) argue that it is unclear which type of goal is more effective for behavior change and suggest that a variety of factors, including age, type of behavior, and readiness to change, may need to be considered in determining which type of goalsetting is most appropriate for a given individual or population.

The central objective of the present study was to begin to investigate such factors at the individual-level. The present study confined the study population to middle-aged adults who were obese or overweight in order to specifically examine goal pursuits within this critical period of the life span. Further, although readiness for change was not explicitly measured, all participants in the present study nominated and endorsed their own personal goals for physical activity. Findings from the present study suggest that in general, increases in goal processes held 
positive associations with behavior and subjective well-being at the individual-level. As such, the central objective was attained. Whether such within-person associations are stable over longer periods of time remains an empirical question to be addressed in future research.

\section{Conclusions}

To summarize, results from within-person correlation analyses revealed a number of findings: (1) increases in perceived control were associated with increases in goal-directed effort, perceived progress, positive affect, and life satisfaction; (2) decreases in control and perceived progress were associated with increases in negative affect; (3) increases in goal-directed effort and perceived progress were associated with increases in physical activity; and (4) increases in physical activity were associated with increases in positive affect. .Although follow-up analyses using weighted correlations generally mirrored these findings, results suggest that sample-level associations are not always consistent with individual-level experiences of personal goal pursuits.

Findings from this daily process study contribute to life-span perspectives in health and aging by considering the individual variability in middle-aged individuals' experiences of overweight and obesity, as well as the psychological processes and consequences associated with physical activity goal pursuit during midlife. Results from this study provide information that might be used to develop interventions targeted at how middle-aged adults can most effectively pursue their physical activity goals in light of personal goal appraisals and how such pursuits are associated with various aspects of subjective well-being. Researchers should continue to investigate the individual trajectories with health and illness in order to better understand the within-person factors that contribute to successful aging. 


\section{References}

Affleck, G., Tennen, H., Urrows, S., Higgins, P., Abeles, M., Karoly, P. et al. (1998).

Fibromyalgia and women's pursuit of personal goals: A daily process analysis. Health Psychology, 17, 40-47.

Ainsworth, B. E., Leon, A. S., Richardson, M. T., Jacobs, D. R., \& Paffenbarger, R. S. (1993). Accuracy of the College Alumnus Physical Activity Questionnaire. Journal of Clinical Epidemiology, 46, 1403 - 1411.

Ajzen, I. (1985). From intentions to actions: A theory of planned behavior. In J. Kugl \& J. Beckman (Eds.), Action-control: From cognition to behavior (pp. 11-39). Heidelberg: Springer.

Ajzen, I. (1991). The theory of planned behavior. Organizational Behavior and Human Decision Processes, 50, 179-211.

Ajzen, I., \& Fishbein, M. (1980). Understanding attitudes and predicting social behavior. Englewood Cliffs, NJ: Prentice-Hall.

Ajzen, I., \& Madden, T. J. (1986). Prediction of goal-directed behavior: Attitudes, intentions, and perceived behavioral control. Journal of Experimental Social Psychology, 22, 453-474.

Aldwin, C. M., Spiro, A., III, \& Park, C. L. (2006). Heath behavior and optimal aging: A lifespan developmental perspective. In J. Birren \& K. W. Schaie (Eds.), Handbook of the psychology of aging, sixth edition (pp. 85 - 104). San Diego: Academic Press.

Alley, D.E., \& Chang, V.W. (2007). The changing relationship of obesityand disability, 19882004. Journal of the American Medical Association, 298, 2020- 2027.

Andrykowski, M. A., Beacham, A. O., Schmidt, J. E., \& Harper, F. W. (2006). Application of the theory of planned behavior to understand intentions to engage in physical and 
psychosocial health behaviors after cancer diagnosis. Psycho-oncology, 15, $759-771$.

Armitage, C. J., Conner, M. (2001). Efficacy of the theory of planned behaviour: A metaanalytic review. British Journal of Social Psychology, 40, 471-499.

Apovian, C. M., Frey, C. M., Rogers, J. Z., McDermott, B., \& Jensen, G. L. (1996). Body mass index and physical function in obese older women. Journal of the American Geriatrics Society, 44, $1487-1488$.

Arent, S.M., Landers, D.M., \& Etnier,J.L. (2000). The effects of exercise on mood in older adults: A meta-analytic review. Journal of Aging and Physical Activity, 8, 407-430.

Atienza, A. A., Oliveira, B., Fogg, B. J., \& King, A. C. (2006). Using electronic diaries to examine physical activity and other health behaviors of adults age 50+. Journal of Aging and Physical Activity, 14, 192-202.

Bales, C. W., \& Buhr, G. (2008). Is obesity bad for older persons? A systematic review of the pros and cons of weight reduction in later life. Journal of the American Medical Association, 9, 302-312.

Baltes, P. B. (1987). Theoretical propositions of life-span developmental psychology: On the dynamics between growth and decline. Developmental Psychology, 23, 611-626.

Baltes, P. B., Lindenberger, U., \& Staudinger, U. M. (1998). Life-span theory in developmental psychology. In R. M. Lerner (Ed.), Handbook of child psychology, (Vol. 1: Theoretical models of human development, pp. 1029-1143). New York: Wiley.

Baltes, P. B., \& Baltes, M. M. (1990). Successful aging: Perspectives from the behavioral sciences. New York, NY: Cambridge University Press.

Bandura, A. (2004). Health promotion by social cognitive means. Health Education and Behavior, 31, 143-164. 
Barrett, L. F., \& Barrett, D. J. (2003). ESP: The Experience Sampling Program. Retrieved November 5, 2007 from http://www.experience-sampling.org/.

Beck, A. T., Ward, C. H., Mendelson, M., Mock, J., \& Erbaugh, J. (1961). An inventory for measuring depression. Archives of General Psychiatry, 4, 561 - 571.

Benjamin, K., Edwards, N. C., \& Bharti, V. K. (2005). Attitudinal, perceptual, and normative beliefs influencing the exercise decisions of community-dwelling physically frail seniors. Journal of Aging and Physical Activity, 13, 276 - 293.

Berg, A. O. (2003). U.S. Preventive services task force. Behavioral counseling in primary care to promote physical activity: Recommendations and rationale. The American Journal of Nursing, 103, $101-109$.

Bland, J. M., \& Altman, D. G. (1995a). Calculating correlation coefficients with repeated observations: Part 1 - correlation within subjects. British Medical Journal, 310, 633.

Bland, J. M., \& Altman, D. G. (1995b). Calculating correlation coefficients with repeated observations: Part 1 - correlation between subjects. British Medical Journal, 310, 446

Booth, M. L., Bauman, A., \& Owen, N. (2002). Perceived barriers to physical activity among older Australians. Journal of Aging and Physical Activity, 10, 271 - 280.

Bowling, A. (2007). Aspirations for older age in the $21^{\text {st }}$ century: What is successful aging? International Journal of Aging and Human Development, 64, 263-297.

Bowling, A., \& Dieppe, P. (2005). What is successful aging and who should define it? British Medical Journal, 331, 1548-1551.

Bradburn, N. M. (1969). The structure of psychological well-being. Chicago: Aldine.

Brandtstadter, J. (1998). Action perspectives on human development. In W. Damon (Series Ed.) \& R. M. Lerner (Vol. Ed.), Handbook of child psychology: Vol. 1. Theoretical models of 
human development $\left(5^{\text {th }}\right.$ ed., pp. $\left.807-863\right)$. New York: John Wiley.

Brandtstadter, J., \& Baltes-Gotz, B. (1990). Personal control over development and quality of life perspectives in adulthood. In P. B. Baltes \& M. M. Baltes (Eds.), Successful aging: Perspectives from the behavioral sciences (pp. 197-222). New York: Cambridge University Press.

Brandtstadter, J., Wentura, D., \& Rothermund, K. (1999) Intentional self-development through adulthood and later life: Tenacious pursuit and flexible adjustment of goals. In J. Brandtstadter \& R. M. Lerner (Eds.) Action \& self-development: Theory and research through the life span (pp. 373 - 400). Thousand Oaks, CA: Sage.

Brenes, G. A., Stube, M. J., \& Storandt, M. (1998). An application of the theory of planned behavior to exercise among older adults. Journal of Applied Social Psychology, 28, 22742290.

Britton, A., Shipley, M., Singh-Manoux, A., \& Marmot, M. G. (2008). Successful aging: The contribution of early-life and midlife risk factors. Journal of the American Geriatrics Society, 56, $1098-1105$.

Bryk, A. S., \& Raudenbush, S. W. (1987). Application of hierarchical models to assessing change. Psychological Bulletin, 101, $147-158$.

Buckwalter, J. (1997). Decreased mobility in the elderly: The exercise antidote. Physician and Sports Medicine, 25, $127-133$.

Campbell, A., Converse, P. E., \& Rodgers, W. L. (1976). The quality of American life. New York: Russell Sage.

Cantor, N., Norem, J., Langston, C., Zirkel, S., Fleeson, W., \& Cook-Flannagan, C. (1991). Life tasks and daily experience. Journal of Personality, 59, 425-452. 
Cantril, H. (1965). The patterns of human concern. New Brunswick, NJ: Rutgers University Press.

Carels, R. A., Darby, L. A., Rydin, S., Douglass, O. M., Cacciapaglia, H. M., \& O’Brien, W. H. The relationship between self-monitoring, outcome expectances, difficulties with eating and exercise, and physical activity and weight loss treatment outcomes. Annals of Behavioral Medicine, 30, $182-190$.

Centers for Disease Control and Prevention. (2006). Behavioral Risk Factor Surveillance System Survey Data. Atlanta, Georgia: U.S. Department of Health and Human Services, Centers for Disease Control and Prevention.

Centers for Disease Control and Prevention. (2007). Surveillance of certain health behaviors among states and selected local areas - United States, 2005. Morbidity and Mortality Weekly Report, 56, $1-160$.

Centers for Disease Control and Prevention. (2008). Behavioral Risk Factor Surveillance System Survey Data. Retrieved June 3, 2009 from http://apps.nccd.cdc.gov/brfss/age.asp?yr=2008\&state=UB\&qkey=4409\&grp=0

Cobb, L., Stone, W., Anonsen, L., \& Klein, D. (2000). The influence of goal setting on exercise adherence. Journal of Health Education, 31, 277 - 281.

Cornoni-Huntley, J. C., Harris, T. B., Everett, D. F., Albanes, D., Micozzi, M. S., Miles, T. P. et al. (1991). An overview of body weight of older persons, including the impact on mortality. The National Health and Nutrition Examination Survey I - Epidemiologic Follow-up Study. Journal of Clinical Epidemiology, 44, 743 - 753.

Cranford, J. A., Shrout, P. E., Iida, M., Rafaeli, E., Yip, T., \& Bolger, N. (2006). A procedure for evaluating sensitivity to within-person change: Can mood measures in diary studies 
detect change reliably? Personality and Social Psychology Bulletin, 32, 917 - 929.

Cross, S. \& Markus, H. (1991). Possible selves across the life span. Human Development 34, $230-255$

Courneya, K.S. (1995). Understanding readiness for regular physical activity in older individuals: An application of the theory of planned behavior. Health Psychology, 14, 8087.

Daviglus, M. L., Liu, K., Yan, L. L., Pirzada, A., Manheim, L., Manning, W. et al. (2004). Relation of body mass index in young adulthood and middle age to Medicare expenditures in older age. Journal of the American Medical Association, 292, 2743 2749.

Daviglus, M. L., Liu, K., Yan, L. L., Pirzada, A., Garside, D. B., Schiffer, L. et al. (2003). Body mass index in middle age and health-related quality of life in older age. Archives of Internal Medicine, 163, 2448 - 2455.

Davison, K. K., Ford, E. S., Cogswell, M. E., \& Dietz, W. H. Percentage of body fat and body mass index are associated with mobility limitations in people aged 70 and older from NHANES III. Journal of the American Geriatrics Society, 50, 1802-1809.

Dean, R. N., Farrell, J. M., Kelley, M. L., Taylor, M. J., \& Rhodes, R. E. (2006). Testing the efficacy of the theory of planned behavior to explain strength training in older adults. Journal of Aging and Physical Activity, 15, 1 - 12.

Deci, E. L., \& Ryan, R. M. (2000). The "what" and "why" of goal pursuits: human needs and the self-determination of behavior. Psychological Inquiry, 11, 227-268.

Derogatis, L., R., Lipman, R. S., Rickels, K., Uhlenhuth, E. H., \& Covi, L. (1974). The Hopkins Symptom Checklist (HSCL): A self-report symptom inventory. Behavioral Science, 19, 1 
-15 .

Diener, E., Emmons, R. A., Larsen, R. J., \& Griffin, S. (1985). The satisfaction with life scale. Journal of Personality Assessment, 49, 71-75.

Diener, E., Suh, E., \& Oishi, S. (1997). Recent findings on subjective well-being. Indian Journal of Clinical Psychology, 24, 25 - 41.

Duncan, K., \& Pozehl, B. Staying the course: The effects of an adherence facilitation intervention on home exercise participation. Progress in Cardiovascular Nursing, 21, 37 -38 .

Elavsky, S. (2005). Physical activity enhances long-term quality of life in older adults: Efficacy, esteem, and affective influences. Annals of Behavioral Medicine, 30, 138 - 145.

Emmons, R. A. (1996). Striving and feeling: Personal goals and subjective well-being. In P. M. Gollwitzer \& J. A. Bargh (Eds.), The psychology of action: Linking cognition and motivation to behavior (pp. 313 - 337). New York: Guildford Press.

Emmons, R.A.(1991). Personal strivings, daily life events, and psychological and physical wellbeing. Journal of Personality, 59, $453-472$.

Feldman, S., Downey, G., \& Shaffer-Neitz, R. (1999). Pain, negative mood, and perceived support in chronic pain patients: A daily diary study of people with relax sympathic dystrophy syndrome. Journal of Consulting and Clinical Psychology, 67, 776 - 785.

Ferraro, K. F., Thorpe, R. J., \& Wilkinson, J. A. (2003). The life-course of severe obesity: Does childhood overweight matter? Journals of Gerontology Series B: Psychological Sciences \& Social Sciences, 58B, S110-S119.

Fine, J. T., Colditz, G. A., Coakley, E. H., Moseley, G., Manson, J. E., Willett, W. C. et al. (1999). A prospective study of weight change and health-related quality of life in women. 
Journal of the American Medical Association, 282, 2136 - 2142.

Fisher, B. J., Day, M., \& Collier, C. E. (1992). Successful aging: Volunteerism and generativity in later life. In D. Redburn \& B. McNemara (Eds.), Social gerontology. Westport, CT: Greenwood.

Flegal, K. M., Carroll, M. D., Ogden, C. L., \& Johnson, C. L. (2002). Prevalence and trends in obesity among US adults, 1999-2000. Journal of the American Medical Association, 288, $1772-1773$.

Fontaine, K. R., Redden, D. T., Wang, C., Westfall, A. O., \& Allison, D. B. (2003). Years of life lost due to obesity. Journal American Medical Association, 289, 187 - 193.

Fremont, J., \& Craighead, L. W. (1987). Aerobic exercise and cognitive therapy in the treatment of dysphoric moods. Cognitive Therapy Research, 2, $241-251$.

Freund, A. M., \& Baltes, P. B. (1998). Selection, optimization, and compensation as strategies of life-management: Correlations with subjective indicators of successful aging. Psychology and Aging, 13, 531-543.

Freund, A. M., \& Riediger, M. (2003). Successful aging. In R. M. Lerner (Ed.), Handbook of psychology: Developmental psychology (Vol. 6, pp. 601-628). New York: John Wiley and Sons.

Freund, A. M, \& Baltes, P. B. (2003). Life-Management strategies of selection, optimization, and compensation: Measurement by self-report and construct validity. Journal of Personality and Social Psychology, 82, 642-662.

Fries, J. F. (2002). Successful aging: An emerging paradigm of gerontology. Clinics in Geriatric Medicine, 18, 371.

Gauvin, L., Rejeski, W. J., \& Reboussin, B. A. (2000). Contributions of acute bouts of vigorous 
physical activity to explaining diurnal variations in feeling states in active, middle-aged women. Health Psychology, 19, 365-375.

George, L. K. (2001). The social psychology of health. In R. H. Binstock (Ed.), Handbook of aging and the social sciences (5th ed., pp. 217-237). San Diego, CA: Academic Press.

Gingold, R. (1999). Successful aging. Oxford: Oxford University Press.Gingold, 1999;

Glanz, K., Murphy, S., Moylan, J., Evensen, D. \& Curb, J. D. (2006). Improving dietary selfmonitoring and adherence with hand-held computers: A pilot study. American Journal of Health Promotion, 20, $165-170$.

Glass, T. A., Seeman, T. E., Herzog, A. R., Kahn, R., \& Berkman, L. F. (1995). Change in productive activity in late adulthood. MacArthur Studies of Successful Aging. Journal of Gerontology, 50B, S65 - S76.

Godin, G., \& Gok, G. (1998). The theory of planned behavior: A review of its application to health-related behaviors. American Journal of Health Promotion, 11, 87 - 98.

Goedereis, E. A. (2005). Goal constructs in personality research: Are they unique? Unpublished master's thesis, Western Illinois University, Macomb.

Goldstein, D. J. (1992). Beneficial health effects of modest weight loss. International Journal of Obesity and Related Metabolic Disorders, 16, 397 - 415.

Golub, S. A., \& Langer, E. J. (2007). Challenging assumptions about adult development: Implications for the health of older adults. In C. M. Aldwin, C. L. Park, \& A. Spiro III (Eds.), Handbook of Health Psychology and Aging (pp. 9 - 29). New York, NY: Guilford.

Greenlee, R. T., Murray, T., Bolden, S., \& Wingo, P. A. (2000). Cancer statistics, 2000: CA. A Cancer Journal for Clinicians, 50, 7 - 33.

Grundy, E., \& Bowling, A. (1999). Enhancing the quality of extended life years. Identification of 
the oldest old with a very good and very poor quality of life. Aging and Mental Health, 3, 199-212.

Hagger, M. S., Chatziaratis, N. L., \&Biddle, S. J. (2002). A meta-analytic review of the theories of reasoned action and planned behavior in physical activity: Predictive validity and the contribution of additional variables. Journal of Sport and Exercise Psychology, 24, 3 32.

Hagger, M. S., \& Orbell, S. (2003). A meta-analytic review of the common-sense model of illness representations. Psychology and Health, 18, $141-184$.

Harris, T. B., Launer, L. J., Madans, J., \& Feldman, J. J. (1997). Cohort study of effect of being overweight and change in weight on risk of coronary heart disease in old age. British Medical Journal, 314, 1791 - 1794.

Haskell, W. L., Lee, I. M., Pate, R. R., Powell, K. E., Blair, S. N., Franklin, B. A. et al. (2007). Physical activity and public health: Updated recommendation for adults from the American College of Sports Medicine and the American Heart Association. Medicine \& Science in Sports \& Exercise, 39, 1423 - 1434.

Havinghurst, R. J. (1961). Successful aging. The Gerontologist, 1, 8 - 13.

Heckhausen, J., \& Schulz, R. (1995). A life-span theory of control. Psychological Review, 102, $284-305$

Hedley, A. A., Ogden, C. L., Johnson, C. L., Carroll, M. D., Curtin, L. R., \& Flegal, K. M. (2004). Prevalence of overweight and obesity among US children, adolescents, and adults, 1999-2002. Journal of the American Medical Association, 291, 2847 - 2850.

Henricksson, C. (1995). Living with continuous muscular pain: Patient perspectives. Scandinavian Journal of Caring Sciences, 9, 67 - 76. 
Hendricksson, C., Gundmark, I., Bengstsson, A., \& Ek., A. (1992). Living with fibromyalgia: Consequences for daily life. Clinical Journal of Pain, 8, 138 - 144.

Hillsdon, M., Brunner, E., Guralnik, J., \& Marmot, M. (2005). Prospective study of physical activity and physical function in early old age. American Journal of Preventive Medicine, $28,245-250$.

Hooker, K., \& Kaus, C. R. (1992). Possible selves and health behaviors in later life. Journal of Aging and Health, 4, $390-411$.

Hooker, K., \& Kaus, C. R. (1994). Health-related possible selves in young and middle adulthood. Psychology and Aging, 9, $126-133$.

Hubert, H. B., Block, D. A., \& Fries, J. F. (1993). Risk factors for physical disability in an aging cohort: The MHAMES I epidemiologic follow-up study. Journal of Rheumatology, 20, $480-488$.

Jacelon, C. S. (2007). Theoretical perspectives of perceived control in older adults: A selective review of the literature. Journal of Advanced Nursing, 59, 1 - 10.

Jenkins, K. R. (2004). Obesity's effects on the onset of functional impairment among older adults. The Gerontologist, 206-216.

Jensen, G. L., \& Friedmann, J. M. (2002). Obesity is associated with functional decline in community-dwelling rural older persons. Journal of the American Geriatrics Society, 50, $918-923$.

Johnson, M. F., Sallis, J. F., \& Hovell, M. F. (2000). Self-report assessment of walking: Effects of aided recall instructions and item order. Measurement in Physical Education and Exercise Science, 4, 141-155.

Kamarck, T., Shiffman, S., Smithline, L., Godie, J., Paty, J., Gnys, M., et al., (1998). Effects of 
task strain, social conflict, and emotional activation on ambulatory cardiovascular activity: Daily life consequences of recurring stress in a multiethnic adult sample. Health Psychology, 17, $17-29$.

Kenny, D., Kashy, D., \& Bolger, N. (1997). Data analysis in social psychology. In D. Gilbert, S. Fiske, \& G. Linzey (Eds.), Handbook of social psychology (4th ed., pp. $233-265)$. New York: McGraw-Hill.

Khatri,P., Blumenthal, J. A., Babyak, M. A., Craighead, W. E., Herman, S., Baldewicz, T. et al., (2001). Effects of exercise training on cognitive functioning among depressed older men and women. Journal of Aging and Physical Activity, 9, 43 - 57.

Kiecolt-Glaser, J. K., \& Newton, T. L. (2001). Marriage and health: His and hers. Psychological Bulletin, 127, 472-503.

King, A. C., Ahn, D. K., Oliveira, B. M., Atienza, A. A., Castro, C. M., \& Gardner, C. D. (2008). Promoting physical activity through hand-held computer technology. American Journal of Preventive Medicine, 34, 138 - 142.

King, A. C., Taylor, C. B., \& Haskell, W. L. (1993). Effects of differing intensities and formats of 12 months of exercise training on psychological outcomes in older adults. Health Psychology, 12, $292-300$.

King, A. C., Toobert, D., Ahn, D., Resnicow, K., Coday, M., Riebe, D. et al. (2006). Perceived environments as physical activity correlates and moderators of intervention in five studies. American Journal of Health Promotion, 21, 24 - 35.

Klein, D. A., Stone, W. J., Phillips, W. T., Gangi, J., \& Hartman, S. (2002). PNF training and physical function in assisted-living older adults. Journal of Aging and Physical Activity, $10,476-488$. 
Klinger, E. (1975). Consequences of commitment to and disengagement from incentives. Psychological Review, 82, 1-25.

Kramer, A. F., Hahn, S., \& McAuley, E. (2000). Influence of aerobic fitness on the neurocognitive function of older adults. Journal of Aging and Physical Activity, 8, 379 385.

Lachman, M. E. (2006). Perceived control over aging-related declines: Adaptive beliefs and behaviors. Current Directions in Psychological Science, 15, 282 - 286.

Lachman, M. E., \& Firth, K. M. (2004). The adaptive value of feeling in control during midlife. In O. G. Brim, C. D., Ryff, and R. C. Kessler (Eds.). How healthy are we? A national study of well-being at midlife (pp. 320 - 349). Chicago, IL: University of Chicago Press.

Lachman, M. E., \& James, J. B. (1997). Multiple paths of midlife development. Chicago, US: University of Chicago Press.

Lang, I. A., Guralnik, J. M., \& Melzer, D. (2007). Physical activity in middle-aged adults reduces risks of functional impairment independent of its effect on weight. Journal of the American Geriatrics Society, 55, 1836 - 1841.

Larsen R., \& Kasimatis, M. (1991). Day-to-day physical symptoms: Individual differences in the occurrence, duration, and emotional concomitants of minor daily illnesses. Journal of Personality, 59, 387-424.

Launer, L. J., Harris, T., Rumpel, C., \& Madans, J. (1994). Body mass index, weight change, and risk of mobility disability in middle-aged and older women. The epidemiologic follow-up study of NHANES I. Journal of the American Medical Association, 27, 1093 - 1098.

Lawton, M. P., Moss, M. S., Winter, L., \& Hoffman, C. (2002). Motivation in later life: Personal projects and well-being. Psychology and Aging, 17, $539-547$. 
Lazarus, R. S., \& DeLongis, A. (1983). Psychological stress and coping in aging. American Psychologist, 38, $254-254$.

Lean, M. E., J., Han, T. S., \& Seidell, J. C. (1998). Impairment of health and quality of life in men and women with a large waist. Lancet, 351, $853-856$.

Lee, P. H., Chang, W. Y., Liou, T. H., \& Chang, P. C. (2006). Stages of exercise and healthrelated quality of life among overweight and obese adults. Journal of Advanced Nursing, $53,295-303$.

LaPorte, R. E., Black-Sandler, R., Cauley, J. A., Link, M., Bayles, C., \& Marks, B. (1983). The assessment of physical activity in older women: Analysis of the interrelationship and reliability of activity monitoring, activity surveys, and caloric intake. Journals of Gerontology, 38, 394-397.

Lingyak, P. R., Suminski, R., \& Hortz, B. (2003). Predicting vigorous physical activity using social cognitive theory. American Journal of Health Behavior, 27, 301 - 311.

Lloyd-Jones, D. M., Larson, M. G., Beiser, A., \& Levy, D. (1999). Lifetime risk of developing coronary heart disease. Lancet, 353, 89 - 92.

Lucidi, F.,Grano, C., Barbaranelli, C. \& Violani, C. (2006). Social-cognitive determinants of physical activity attendance in older adults. Journal of Aging and Physical Activity,, $14,344-359$.

Lutz, R. S., Karoly, P. \& Okun, M.A. (2006). The why and how of goal pursuit: Selfdetermination, goal process cognition, and participation in physical exercise. Psychology of Sport and Exercise, 9, 559-575.

Marco, C. A., Neale, J. M., Schwartz, J. E., Shiffman, S., \& Stone, A. (1999). Coping with daily events and short-term mood changes: An unexpected failure to observe effects of coping. 
Journal of Consulting and Clinical Psychology, 67, 755 - 764.

Markus, H., \& Nurius, P. (1986). Possible selves. American Psychologist, 41, 954 - 969.

Masse, L. C., Ainsworth, B. E., Tortolero, S., Levin, S., Fulton, J. E., Henderson, K. A., et al. (1998). Measuring physical activity in midlife, older, and minority women: Issues from an expert panel Journal of Women's Health, 7, 57-67.

McNeil, J. K., LeBlanc, E. M., \& Joyner, M. (1991). The effect of exercise on depressive symptoms in the moderately depressed elderly. Psychology and Aging, 6, 487 - 488.

McTigue, K. M., Hess, R., \& Ziouras, J. (2006). Obesity in older adults: A systematic review of the evidence for diagnosis and treatment. Obesity, 14, 1485 - 1497.

Meegan, S. P., \& Goedereis, E. A. (2006). Life task appraisals, spouse involvement in strategies, and daily affect among short- and long-term married couples. Journal of Family Psychology, 20, $319-327$.

Mei, Z., Grummer-Strawn, L. M., Pietrobelli, A., Goulding, A., Goran, M. I., \& Dietz, W. H. (2002). Validity of body mass index compared with other body-composition screening indexes for the assessment of body fatness in children and adolescents. American Journal of Clinical Nutrition, $978-85$.

Milne, S., Orbell, S., \& Sheeran, P. (2002). Combining motivational and volitional interventions to promote exercise participation: Protection motivation theory and implementation intentions. British Journal of Health Psychology, 7, 163 - 184.

Must, A., Spadano, J., Coakley, E. H., Field, A. E., Colditz, G., \& Dietz, W. H. (1999). The disease burden associated with overweight and obesity. Journal of the American Medical Association, 282, $1523-1529$.

National Center for Health Statistics. (1999). Current estimates from the National Health 
Interview Survey, 1996 (Vital and Health Statistics, Series 10, No. 200). Atlanta, GA: Centers for Disease Control and Prevention.

National Center for Health Statistics, (2008, April). National Vital Statistics Reports, Deaths: Final Data for 2005, Vol. 56, No. 10. Retrieved October 28, 2008 from http://www.census.gov/compendia/statab/tables/09s0100.pdf

National Health Interview Survey, United States Department of Health and Human Services, (2002). Retrieved June 25, 2007 from ftp://ftp.cdc.gov/pub/Health_Statistics/NCHS/Survey_Questionnaires/NHIS/2005/Englis h/QADULT.pdf.

National Institutes of Health, National Heart, Lung, and Blood Institute (2002). Clinical guidelines on the identification, evaluation, and treatment of overweight and obesity in adults - The evidence report. Retrieved June 25, 2007 from www.nhlbi.nih.gov/guidelines/obesity/ob_gdlns.htm.

National Institute on Aging. (2006). Exercise: A guide from the National Institute on Aging. Bethesda, MD: National Institutes of Health. Retrieved June 25, 2007 from http://www.nia.nih.gov/HealthInformation/Publications/ExerciseGuide/.

National Vital Statistics System. (2000). Deaths: Final data for 1998. Atlanta, GA: Centers for Disease Control and Prevention.

Nelson, D. B., Sammel, M. D., Freeman, E. W., Lin, H., Gracia, C. R., \& Schmitz, K. H. (2008). Effect of physical activity on menopausal symptoms among urban women. Medicine and Science in Sports and Exercise, 40, 50 - 58.

Ory, M., \& Cox, D. M., (1994). Forging ahead: Linking health and behavior to improve quality of life in older people. Social Indicators Research, 33, 89-120. 
Paffenbarger, R. S, Wing, A. L., \& Hyde, R. T. (1978). Physical activity as an index of heart attack risk in college alumni. American Journal of Epidemiology, 108, 161-175.

Parker, S. J., Strath, S. J., \& Swarts, A. M. (2008). Physical activity measurement in older adults: Relationships with mental health. Journal of Aging and Physical Activity, 16, 369 - 380.

Peeters, A., Bonneux, L., Barendregt, J., \& Nusselder, W. (2003). Methods of estimating years of life lost due to obesity. Journal of the American Medical Association, 289, 2941.

Penninx, B.W., Nicklas, B. J., Newman, A. B., Harris, T. B., Goodpaster, B. H., Satterfield, S. et al. (2009). Metabolic syndrome and physical decline in older persons: Results from the health, aging and body composition study. The Journals of Gerontology. Series A, Biological and Mdical Sciences, 64, 96 - 102.

Perugini, M., \& Bagozzi, R. P. (2001). The role of desires and anticipated emotions in goaldirected behaviours: Broadening and deepening the theory of planned behavior. British Journal of Social Psychology, 40, 79 - 98. Pfeffer, R. I., Kurosaki, T. T., Harrah, C. H., Chance, J. M., \& Filos, S. (1982). Measurement of functional activities in older adults in the community. Journal of Gerontology, 37, 323-329.

Prochaska, J. O., \& DiClemente, C. C. (1983). Stages and processes of self-change in smoking: Toward an integrative model of change. Journal of Consulting and Clinical Psychology, $5,390-395$.

Rapkin, B. D., \& Fischer, K. (1992). Framing the construct of life satisfaction in terms of older adults' personal goals. Psychology and Aging, 7, 138 - 149.

Rhodes, R. E., Blanchard, C. M., \& Blacklock, R. E. (2008). Do physical activity beliefs differ by age and gender? Journal of Sport and Exercise Psychology, 30, 412 - 423. 
Rissanen, A., Heliovaara, M., Knekt, P., Reunanen, A., Aromaa, A., \& Maatela, J. (1990). Risk of disability and mortality due to overweight in a Finnish population. British Medical Journal, 301, 835-837.

Rowe, J.W.,\&Kahn, R. L. (1987).Human aging: Usual and successful. Science, 237, 143-149.

Rowe, J. W., \& Kahn, R. L. (1997). Successful aging. The Gerontologist, 37, 433-441.

Rowe, J. W., \& Kahn, R. L. (1998). Successful aging. New York: Pantheon Books.

Rumpel, C., Ingram, D. D., Harris, T. B., \& Madans, J. (1994). The association between weight change and psychological well-being in women. International Journal of Obesity, 18, $179-183$.

Salmon, J., Owen, N., Crawford, D., Bauman, A., \& Sallis, J. F. (2003). Physical activity and sedentary behavior: A population-based study of barriers, enjoyment, and preference. Health Psychology, 22, $178-188$.

Sarafino, E. P. (1994). Health psychology: Biopsychosocial interactions. New York: Wiley.

Schnor, P., Kristensen, T. S., Prescott, E., \& Scharling, H. (2005). Stress and life dissatisfaction are inversely associated with jogging and other types of physical activity in leisure time The Copenhagen City Heart Study. Scandanavian Journal of Medicine and Science in Sports, 15, $107-112$.

Scholz, U., Knoll, N., Sniehotta, F. F., \& Schwarzer, R. (2006). Physical activity and depressive symptoms in cardiac rehabilitation: Long-term effects of a self-management intervention. Social Science \& Medicine, 62, $3109-3120$.

Schulz, R., \& Heckhausen, J. (1996). A life span model of successful aging. American Psychologist, 51, 702-714.

Seeman T. E., Unger J. B., McAvay G., Mendes de Leon C. F. M. (1999). Self-efficacy beliefs 
and perceived declines in functional ability: MacArthur studies of successful aging. Journal of Gerontology: Psychological Sciences, 54B, P214-P222.

Shiffman, S., \& Stone, A. (1998). Introduction to the special edition: Ecological momentary assessment in health psychology. Health Psychology, 17, 3 - 5.

Shilts, M.K., Horowitz, M. \& Townsend, M.S. (2004) Goal setting as a strategy for dietary and physical activity behavior change: A review of the literature. American Journal of Health Promotion, 19, $81-93$.

Siegel, P. Z., Brackbill, R. M., \& Heath, G. W. (1995) The epidemiology of walking for exercise: Implications for promoting activity among sedentary groups. American Journal of Public Health, 85, 706-710.

Singh-Manoux, A., Hillsdon, M., Brunner, E., \& Marmot, M. (2005). Effects of physical activity on cognitive functioning in middle age: Evidence from the Whitehall II Prospective Cohort Study. American Journal of Public Health, 95, 2252 - 2258.

Smith, J., Borchelt, M., Maier, H., \& Jopp, D. (2002). Health and well-being in the young old and oldest old. Journal of Social Issues, 58, 715 - 732.

Spielberger, C. D., Gorsuch, R. L., \& Lushene, R. E. (1970). Manual for the State-Trait Anxiety Inventory. Palo Alto, CA: Consulting Psychology Press.

Spiro, A. III. (2001). Health in midlife: Toward a lifespan view. In M. E. Lachman (Ed.), Handbook of midlife development (pp. 156 - 187). New York: Wiley.

Stamler, J., Stamler, R., Neaton, J. D., Wentworth, D., Daviglus, M. L., Garside, D. et al. (1999). Low risk-factor profile and long-term cardiovascular and noncardiovascular mortality and life expectancy: Findings for 5 large cohorts of young adult and middle-aged men and women. Journal of the American Medical Association, 282, 2012 - 2018. 
Stathi, A., Fox, K. R., \& McKenna, J. (2002). Physical activity and dimensions of subjective well-being in older adults. Journal of Aging and Physical Activity, 10, 76-92.

Steele, J. C. (2004). Intraindividual variability and relations between daily affect and physical activity among community-dwelling older women. Unpublished doctoral dissertation. West Virginia University, West Virginia.

Stephens, T. (1988). Physical activity and mental health in the United States and Canada: Evidence from four population surveys. Preventative Medicine, 17, 35 - 47.

Steiger, H., Gauvin, L., Jabalpurwala, S., Seguin, J. R., \& Stotland, S. (1999). Hypersensitivity to social interaction in bulimic syndromes: Relationship to binge eating. Journal of Consulting and Clinical Psychology,67, 765-775.

Stevens, S. J., Cai, J. Evenson, K. R., \& Thomas, R. (2002). Fitness and fatness as predictors of mortality from all causes and from cardiovascular disease in men and women in the lipid research clinics study. American Journal of Epidemiology, 156, 832 - 41.

Stevens, J., Cai, J., Pamuk, E. R., Williason, D. F., Thun, M. J., \& Wood, J. L. (1998). The effect of age on the association between body-mass index and mortality. New England Journal of Medicine, 338, 1 - 7 .

Stewart, A. L., Verboncoeur, C. J., McLellan, B. Y., Gillis, D. E., Rush, S., Mills, K. M. et al., (2001). Physical activity outcomes of CHAMPS II: A physical activity promotion program for older adults. Journal of Gerontology: Medical Sciences, 56A, M465 - M470.

Stone, A., Schwartz, J., Neale, S., Shiffman, S., Marco, C., Hickcox, M., Paty, J., Porter, L., \& Cruise, L. (1998). A comparison of coping assessed by ecological momentary assessment and retrospective recall. Journal of Personality and Social Psychology, 74, 1670 - 1680.

Stephens, T. (1988). Physical activity and mental health in the United States and Canada: 
Evidence from four population surveys. Preventative Medicine, 17, 35 - 47.

Strawbridge, W. J., Cohen, R. D., Shema, S. J., \& Kaplan, G. K. (1996). Successful aging:

Predictors and associated activities. American Journal of Epidemiology, 144, 135-141.

Symons Downs, D. \& Hausenblas, H. A. (2005) The theories of reasoned action and planned behavior applied to exercise: A meta-analytic update. Journal of Physical Activity and Health, 2, $76-97$.

Taylor, L., Whittington, F., Hollingsworth, C., Ball, M., King, S., Patterson, V. et al., (2003). Assessing the effectiveness of a walking program on physical function of residents living in an assisted living facility. Journal of Community Health Nursing, 20, 15 - 26.

Tennen, H., \& Affleck, G. (1996). Daily processes in coping with chronic pain: Methods and analytic strategies. In M. Zeldner and N. Endler (Eds.), Handbook of Coping (pp. 151 180). New York: Wiley.

Tennen, H., Affleck, G., Armeli, S. \& Carney, M.A. (2000). A daily process approach to coping: linking theory, research, and practice. American Psychologist, 55, 626 - 636.

Tennen, H., Affleck, G., \& Armeli, S. (2003). Daily processes in health and illness. In J. Suls \& K. A. Wallston (Eds.). Social Psychological Foundations of Health and Illness (pp. 495 529). Malden, MA: Blackwell.

U.S. Census Bureau (2005). American Factfinder, 2005-2007 American Community Survey. Retrieved March 1, 2009 from http://factfinder.census.gov/servlet/STTable? bm=y\&geo_id=01000US\&-qr_name=ACS_2007_3YR_G00_S0101\&ds_name=ACS_2007_3YR_G00.

U.S. Department of Health and Human Services (2008). Physical activity and health: a report of the Surgeon General. Atlanta, GA: U.S. Department of Health and Human Services, 
Centers for Disease Control and Prevention National Center for Chronic Disease Prevention and Health Promotion. Retrieved June 2, 2007, from http://www.cdc.gov/nccdphp/sgr/intro.htm.

Vaillant, G. E. (2002). Aging well: Surprising guideposts to a happier life from the Landmark Harvard Study of Adult Development. Boston: Little, Brown.

Vaillant, G. E. (1990). Avoiding negative life outcomes: Evidence from a forty five year study. In P. B. Baltes \& M. M. Baltes (Eds.), Successful aging. Perspectives from the social sciences. New York: Cambridge University Press.

Vansteelandt, K., Rijmen, F., Pieters, G., Probst, M., \& Vanderlinden, J. (2007). Drive for thinness, affect regulation and physical activity in eating disorders: A daily life study. Behaviour Research and Therapy, 45, 1717 - 1734.

Vendrig, A. A., \& Lousberg, R. (1997). Within-person relationships among pain intensity, mood physical activity in chronic pain: A naturalistic approach. Pain, 73, 71-76.

Villareal, D. T., Banks, M., Sinacore, D. R., Siener, C., \& Klein, S. (2006). Effect of weigh tloss and exercise on frailty in obese older adults. Archives of Internal Medicine, 166, $860-$ 866.

Villareal, D. T., Apovian, C. M., Kushner, R. F., \& Klein, S. (2005). Obesity in older adults: Technical review and position statement of the American Society for Nutrition and NAASO, The Obesity Society. American Journal of Clinical Nutrition, 82, 923 - 934.

Visscher, T. L., Rissanen, A., Seidell, J. C., Heliovaara, M., Knekt, P., Reunanen, A., \& Aromaa, A. (2004). Obesity and unhealthy life-years in adult Finns. Archives of Internal Medicine, 164, 1413 - 1420.

Wadden, T. A., Womble, L. G., Stunkard, L. G., \& Anderson, D. A. (2002). Psychosocial 
consequences of obesity and weight loss. In T. A. Wadden and A. J. Stunkard (Eds.). Handbook of obesity treatment. New York: Guilford Press.

Wang, Y., Beyodoun, M.A, Liang, L., Caballero, B. \& Kumanyika, S.K. (2008). Will all Americans become overweight or obese? Estimating the progression and cost of the US obesity epidemic. Obesity, 16, $2323-2330$.

Washburn, R. A., Smith, K. W., Godfield, S. R., \& McKinlay, J. R. (1991). Reliability and physiologic correlates of the Harvard Alumni Activity Survey in a general population. Journal of Clinical Epidemiology, 44, 1319 - 1326.

Watson, D., Clark, L. A., \& Tellegen, A. (1988). Development and validation of brief measures of positive and negative affect: The PANAS scales. Journal of Personality and Social Psychology, 54(6), $1063-1070$.

West, S. G., \& Hepworth, J. T. (1991). Statistical issues in the study of temporal data: Daily experiences. Journal of Personality, 59, $609-662$.

Wethington, E. (2003). Turning points as opportunities for psychological growth. In Flourishing: The positive person and the life well-lived, C. L. Keyes and J. Haidt (Eds), 37 - 53. Washington, D.C.: American Psychological Association.

Whitman, T. L. (1999). Conceptual frameworks for viewing health and illness. In T. L. Whitman, T. V. Merluzzi, \& R. D. White (Eds.), Life-span perspectives on health and illness (pp. 3-22). Mahwah, NJ: Lawrence Erlbaum Associates.

Willcox, B. J., He, Q., Chen, R., Yano, K., Masaki, K. H., Grove, J. S., et al. (2008). Midlife risk factors and healthy survival in men. Journal of the American Medical Association, 296, $2343-2350$.

Willett, W. C., Dietz, W. H., \& Colditz, G. A. (1999). Guidelines for healthy weight. New 
England Journal of Medicine, 341, 427 - 434.

Wing, R. R, Epstein, L. H. \& Marcus, M. D. (1984). Intermittent low-calorie regimen and booster sessions in the treatment of obesity. Behaviour Research and Therapy, 22, 445449.

World Health Organization (2008). Ageing and the lifecourse [on-line]. Retrieved December 18, 2008 from http://www.who.int/ageing/en/

World Health Organization (2005). Global InfoBase, BMI estimates. Retrieved September 17, 2007, from http://www.who.int/infobase/report.aspx?rid=112\&ind=BMI\&goButton=Go.

World Health Organization (1946). The constitution of the World Health Organization. WHO Chronicle, 1, 21.

Yan, L. L., Daviglus, M. L., Liu, K., Stamler, J., Wang, R., Pirzada, A., Garside, D. B., Dyer, A.R., Horn, L.V., Liao, Y., Fries, J.F. \& Greenland, P. (2006). Midlife body mass index and hospitalization and mortality in older age. Journal of American Medical Association, $295,190-198$.

Zamboni, M., Mazzali, G., Zoico, E., Harris, T. B., Meigs, J. B., Di Franceso, V. et al. (2005). Health consequences of obesity in the elderly: A review of four unresolved questions. International Journal of Obesity, 29, 1011-1029. 
Table 1

Sample Characteristics for Total Sample, and Women and Men

\begin{tabular}{|c|c|c|c|c|c|c|}
\hline \multirow[t]{2}{*}{ Variable } & \multicolumn{2}{|c|}{$\operatorname{Total}(N=35)$} & \multicolumn{2}{|c|}{ Women $(N=31)$} & \multicolumn{2}{|c|}{$\operatorname{Men}(N=4)$} \\
\hline & $M$ & $S D$ & $M$ & $S D$ & $M$ & $S D$ \\
\hline Age (years) & 48.97 & 7.76 & 49.68 & 7.47 & 43.50 & 8.96 \\
\hline Education (years) & 15.65 & 2.56 & 15.39 & 2.45 & 18.33 & 2.52 \\
\hline $\begin{array}{l}\text { Length of } \\
\text { marriage (years) }\end{array}$ & 24.33 & 11.14 & 25.13 & 10.94 & 18.00 & 13.00 \\
\hline Height (inches) & 64.81 & 2.60 & 64.37 & 2.37 & 68.25 & 1.50 \\
\hline Weight (pounds) & 202.19 & 38.81 & 200.44 & 38.39 & 215.75 & 6.32 \\
\hline $\begin{array}{l}\text { Body Mass Index } \\
\text { (BMI) }\end{array}$ & 33.95 & 6.94 & 34.13 & 7.10 & 32.58 & 6.32 \\
\hline $\begin{array}{l}\text { IADL } \\
\text { Impairments }\end{array}$ & 0.31 & 0.72 & 0.26 & 0.68 & 0.75 & 0.96 \\
\hline $\begin{array}{l}\text { Self-rated } \\
\text { Physical Health }\end{array}$ & 4.54 & 0.85 & 2.45 & 0.89 & 4.50 & 0.58 \\
\hline $\begin{array}{l}\text { Self-rated Mental } \\
\text { Health }\end{array}$ & 5.00 & .97 & 1.97 & 1.02 & 4.75 & 0.50 \\
\hline Income & $N$ & $\%$ & $N$ & $\%$ & $N$ & $\%$ \\
\hline Under $\$ 21,999$ & 2 & 5.7 & 2 & 6.5 & - & - \\
\hline$\$ 24,000-25,999$ & 2 & 5.7 & 2 & 6.5 & - & - \\
\hline$\$ 28,000-29,999$ & 2 & 5.7 & 2 & 6.5 & - & - \\
\hline$\$ 30,000-50,000$ & 8 & 22.9 & 6 & 19.4 & 2 & 50 \\
\hline Over $\$ 50,000$ & 21 & 60.0 & 19 & 61.3 & 2 & 50 \\
\hline Ethnicity & & & & & & \\
\hline White & 33 & 94.3 & 30 & 96.8 & 3 & 75 \\
\hline $\begin{array}{l}\text { African } \\
\text { American }\end{array}$ & 1 & 2.9 & 1 & 3.2 & - & - \\
\hline $\begin{array}{l}\text { Asian/Pacific } \\
\text { Islander }\end{array}$ & 1 & 2.9 & - & - & 1 & 25 \\
\hline
\end{tabular}


Table 2

Intercorrelations among Participant Characteristics, Baseline Goal Appraisals, Individual-level Subjective Well-being and Physical Activity

\begin{tabular}{|c|c|c|c|c|c|c|c|c|c|}
\hline Variable & 1 & 2 & 3 & 4 & 5 & 6 & 7 & 8 & 9 \\
\hline \multicolumn{10}{|c|}{ Participant characteristics } \\
\hline \multicolumn{10}{|c|}{ 1. Age } \\
\hline 2. Years of marriage & .57 & & & & & & & & \\
\hline 3. BMI & -.14 & .38 & & & & & & & \\
\hline 4. Impairments & -.28 & -.16 & .21 & & & & & & \\
\hline $\begin{array}{l}\text { 5. Self-rated physical } \\
\text { health }\end{array}$ & .35 & .32 & $-.40 *$ & .14 & & & & & \\
\hline $\begin{array}{l}\text { 6. Self-rated mental } \\
\text { health }\end{array}$ & .25 & .31 & -.23 & $-.46 * *$ & $.43 *$ & & & & \\
\hline \multicolumn{10}{|c|}{ Goal screening appraisals } \\
\hline 7. Control & .05 & .38 & -.40 & -.11 & -.01 & .25 & & & \\
\hline 8. Effort & .29 & $.56 * *$ & -.27 & .16 & .30 & .31 & .33 & & \\
\hline 9. Progress & $.46^{* *}$ & $.58 * *$ & -.28 & -.10 & .35 & .41 & .40 & $.80 * *$ & \\
\hline 10. Difficulty & $.57 * *$ & .59 & -.23 & -.46 & .28 & .37 & .22 & .38 & .53 \\
\hline 11. Value & -.20 & $.45^{*}$ & -.40 & -.04 & .03 & .28 & .40 & .26 & .11 \\
\hline 12. Useful & .07 & .22 & .13 & $-.57 * *$ & .22 & .32 & -.02 & .15 & .08 \\
\hline 13. Beneficial & -.13 & .09 & -.23 & -.15 & $.48 * *$ & .17 & -.09 & -.09 & -.02 \\
\hline 14. Importance & -.07 & .38 & -.24 & -.11 & -.01 & .30 & $.56 * *$ & .25 & .18 \\
\hline 15. Spouse support & .17 & .08 & -.02 & -.15 & -.18 & .09 & .11 & -.07 & -.08 \\
\hline $\begin{array}{l}\text { 16. Desire to please } \\
\text { significant other }\end{array}$ & .16 & -.06 & .13 & -.38 & -.07 & .16 & .04 & -.10 & -.05 \\
\hline \multicolumn{10}{|l|}{ Subjective well-being } \\
\hline 17. Positive affect & .07 & $.41 *$ & -.23 & .25 & .21 & .14 & .20 & .33 & $.37 *$ \\
\hline 18. Negative affect & -.06 & -.08 & .17 & .03 & $-.39 *$ & $-.47 * *$ & -.27 & -.28 & -.32 \\
\hline 19. Life satisfaction & -.01 & .27 & -.25 & -.18 & $.45 * *$ & $.46^{* *}$ & .29 & .31 & .31 \\
\hline \multicolumn{10}{|l|}{ Physical activity } \\
\hline $\begin{array}{l}20 \text {. Daily physical } \\
\text { activity (minutes) }\end{array}$ & .15 & .37 & $-.40 *$ & .08 & .34 & .28 & .20 & $.35^{*}$ & .27 \\
\hline
\end{tabular}


Table 2 (continued)

\begin{tabular}{|c|c|c|c|c|c|c|c|c|c|c|c|}
\hline Variable & 10 & 11 & 12 & 13 & 14 & 15 & 16 & 17 & 18 & 19 & 20 \\
\hline \multicolumn{12}{|l|}{ Goal appraisals } \\
\hline \multicolumn{12}{|l|}{ 10. Difficulty } \\
\hline 11. Value & 20 & & & & & & & & & & \\
\hline 12. Useful & .27 & .36 & & & & & & & & & \\
\hline 13. Beneficial & -.04 & .17 & .25 & & & & & & & & \\
\hline 14. Importance & .24 & $.77 * *$ & .31 & .20 & & & & & & & \\
\hline 15. Spouse support & .34 & .26 & -.06 & -.18 & $.53 * *$ & & & & & & \\
\hline $\begin{array}{l}\text { 16. Desire to please } \\
\text { significant other }\end{array}$ & .28 & .05 & .20 & -.12 & .30 & $.62 * *$ & & & & & \\
\hline \multicolumn{12}{|l|}{ Subjective well-being } \\
\hline 17. Positive affect & -.04 & .26 & -.13 & .26 & .32 & .01 & -.31 & & & & \\
\hline 18. Negative affect & -.18 & -.01 & .06 & -.25 & -.09 & .18 & .15 & .00 & & & \\
\hline 19. Life satisfaction & .12 & .25 & .14 & .28 & .18 & -.21 & -.30 & $44 * *$ & $-.47 * *$ & & \\
\hline Physical activity & & & & & & & & & & & \\
\hline $\begin{array}{l}\text { 20. Daily physical } \\
\text { activity (minutes) }\end{array}$ & .20 & .08 & -.37 & .13 & .17 & .14 & -.06 & .46 & -.21 & .37 & \\
\hline
\end{tabular}


Table 3

Summary of Constructs and Measures

\begin{tabular}{ll}
\hline Construct Assessed & Measure \\
\hline Physical activity & $\begin{array}{l}\text { CHAMPS Physical Activity Questionnaire (Stewart, Mills, King } \\
\text { et al., 2001) }\end{array}$ \\
Physical activity & $\begin{array}{l}\text { Paffenbarger Activity Questionnaire (PAQ; Paffenbarger, Wing, \& } \\
\text { Hyde, 1978) }\end{array}$
\end{tabular}

Physical activity

Select National Health Interview Survey items (USDHHS, 2005)

Subjective well-being (positive and negative affect)

Subjective well-being (life satisfaction)

Goal screening

Goal processes
Positive and Negative Affect Scales (PANAS; Watson, Clark, \& Tellegen, 1988)

Satisfaction with Life Scale (SWLS; Diener, Emmons, Larsen, \& Griffin, 1985)

Current concerns (based on Klinger, 1975)

Daily Goal Process Journal (Goedereis, 2005) 
Table 4

Physical Activity Goals and Corresponding Strategies Nominated by Study Participant $(N=35)$

\begin{tabular}{lll}
\hline Participant & Participant's physical activity goal & Strategy for working toward goal \\
\hline 101 & To achieve 30 min of intentional exercise a day. & Home gym, tapes. \\
102 & To lose 10 lbs. & $\begin{array}{l}\text { Nutri System, Walk } 6 \text { times per week for } \\
\text { at least } 45 \text { min. }\end{array}$ \\
103 & Cardio and weight training 3-4 times per week. & Local gym group workouts. \\
106 & Exercise 3-4 times per week for 45-60 min. & $\begin{array}{l}\text { Go to Stansbury loft; member 3-4 times } \\
\text { per week. }\end{array}$ \\
107 & Line dance 3 times per week. & $\begin{array}{l}\text { Take and teach classes, belongs to many } \\
\text { organizations (line dancing). }\end{array}$ \\
& & Participating in PEIA weight loss program: \\
& To work towards becoming physically active. & $\begin{array}{l}\text { go to gym 3 times per week, HealthWorks, } \\
\text { food log, used to do WW, counts fat, } \\
\text { grams, fruits. }\end{array}$ \\
& & $\begin{array}{l}\text { Wearing pedometer; counting WW pts; } \\
\text { plans to do resistance training every other } \\
\text { day(routine); plans to engage in another } \\
\text { activity (activity w/ family member, } \\
\text { treadmill) after work. }\end{array}$ \\
& &
\end{tabular}

(table continues) 
Table 4 (continued)

202 To lose weight, increase energy.

204 starting "cold turkey."

\section{Walking daily 1-2 miles.} I'm wanting to participate in. healthy.

To be more physically fit.
To engage in a minimum of 30 minutes of activity (100BPR+) each day,

To exercise at least 4 times per week for $>30$ minutes, reduce intake of fats to $<30 \%$ of calories, lose weight over the next 30 days.

Reach my pre-pregnancy weight through diet and exercise.

I would like to get back to exercising for at least a half hour per day. Activities such as walking, using an elliptical, and free weights are those

To reduce my weight by $10 \mathrm{~kg}$. To control my cholesterol and to be

To exercise 7 days a week-being consistent, using both cardio and strength training for one hour per day.
Watching diet, climbing stairs instead of elevators, walking more.

Morning walks.

Go to the gym mornings before work, trying for 5 days per week, trying to diet.

Walk during lunch/work, elliptical

Treadmill; 1 time per week now, wants to do more.

Take walks and play basketball daily.

Try to go to the rec 2 times. Try to walk around house 1 hour per day.

Exercise 3-4 days per week.

Joined HMR (2 months ago), Wellness gym, walk at home, fit TV, Hip Hop Abs. 
Table 4 (continued)

301 To incorporate physical activity, primarily walking, into my daily routine.

Exercise 1-1.5hrs daily, 6 days/week. It can be 1 time or 2 times per day.

Increase cardiovascular workouts. Walk 3 miles per day, but only 3 days per week (currently).

Getting more daily activity. Walk and use the stairs while at work.

I want to get back to running/walking 1 hour each morning before work. I want to work up to this gradually to avoid injury.

Get more regular exercise.

To get in at least 3 days a week of exercise of 30 minutes or more.

To have 20-30 minutes of physical activity 5 days a week.

Cardio/aerobic-30 min/day, 5 times/week; strength training 3 times/week.

Increase activity (walking or exercise bike) to 30-40 minutes, 6 days per week.

To exercise 30 minutes a day.
Use weight watchers, walks with my husband in mornings.

Go to SRC.

Involved with physical activities with family members.

Walking, using stairs while at work.

Walking intermittently, stretching, lifting weights.

Walk 2 miles in the morning, noon. Stretches 15 minutes per day. 100 crunches per day.

Go to curves, swim in pool.

Walk 3 nights/week, Zumba 2 nights/week, and weight watchers.

30 min walking at lunch 5 times/week.

Walk during work.

Walk at lunch, go to Wellness Center, walk at home, mow grass. (table continues) 
Table 4 (continued)

$402 \quad$ Walk at least 1 mile and/or 30 minutes at least 5 days a week.

At this time my goal is to get 10,000 or more steps on my pedometer every day. I also work in my vegetable garden when weather allows and exercise in my pool at home.

To be lean, toned, strong, sharp and quick (cognitively).
Walking with coworkers, mow lawn, chase grandkids, pull weeds.

Walk as much as possible during work, lunch.

Taking body boot camp, personal fitness trainer who put her on a program to use once boot camp ends; monitor weight and other physical levels weekly.

Currently started working out for $20 \min 3 x$ week at wellness center. I want to start walking at least 3 days a week in addition to the wellness center. I would like to reach a healthy weight.

408 My goal is to increase physical activity to improve physical and mental health in order to enjoy more activities.

409 My physical activity goal is to exercise more and on a more regular basis to help reduce my weight so I look and feel healthier.

Would like to engage in 30 minutes of exercise at least 5 days per week with a mixture of cardio and weight bearing exercise.
Go to wellness center $3 \mathrm{x}$ week during lunch.

Walking, making effort to have better nutrition.

Social support w/ co-workers to exercise during lunch.

Walking during lunch, begin Zumba, Enroll (return) to Curves.

Starts personal training Monday August 4, 2008, walking more.
My goal is to lose weight so I feel more comfortable. I am trying to increase cardiovascular exercises. 
Table 5

CHAMPS (Physical Activity) and Baseline Goal Appraisals for Total Sample

\begin{tabular}{lrr}
\hline Variable & $M$ & \\
\hline CHAMPS & & \\
\hline All Activities & & \\
$\quad$ Frequency/week & 21.17 & 10.46 \\
$\quad$ Caloric expenditure/week & 4441.58 & 2459.44 \\
Moderate Intensity Activities & & \\
$\quad$ Frequency/week & 10.39 & 6.78 \\
$\quad$ Caloric expenditure/week & 2899.85 & 2220.57 \\
& & \\
Goal Appraisals & & \\
Perceived Control & 8.77 & 2.73 \\
Effort & 6.54 & 2.37 \\
Progress & 6.17 & 2.48 \\
Ease (difficulty) & 5.89 & 1.42 \\
Good (bad) & 9.57 & 1.16 \\
Useful (useless) & 9.56 & 1.95 \\
Beneficial (Harmful) & 9.35 & 1.01 \\
Important & 9.43 & 1.50 \\
Support from Significant Other & 8.63 & 3.03 \\
\hline Desire to Please Significant Other & 5.97 &
\end{tabular}


Table 6

CHAMPS and Baseline Goal Appraisals for Total Sample and Low and High Missing Data

\begin{tabular}{llllllll}
\hline Variable & \multicolumn{3}{c}{ Low Missing } & \multicolumn{3}{c}{ High Missing } & \multicolumn{3}{c}{ Difference Test } \\
\cline { 2 - 8 } & $M$ & $S D$ & $M$ & $S D$ & $F$ & $d f$ & $p$ \\
\hline Age (years) & 48.72 & 8.20 & 49.24 & 7.52 & 0.34 & 1,33 & .85 \\
Education (years) & 15.12 & 2.40 & 16.18 & 2.68 & 1.48 & 1,32 & .23 \\
$\begin{array}{l}\text { Length of marriage } \\
\text { (years) }\end{array}$ & 24.60 & 9.97 & 24.0 & 12.91 & 0.02 & 1,25 & .89 \\
Body Mass Index & 33.79 & 5.98 & 34.12 & 8.03 & 0.20 & 1,33 & .89 \\
(BMI) & & & & & & & \\
IADL Impairments & 0.22 & 0.55 & 0.41 & 0.87 & 0.60 & 1,33 & .44 \\
Self-rated Physical & 4.50 & 0.99 & 4.59 & 0.71 & 0.09 & 1,33 & .76 \\
Health & & & & & & & \\
Self-rated Mental & 5.17 & 0.99 & 4.82 & 0.95 & 1.10 & 1,33 & .30 \\
Health & & & & & & & \\
& 8.83 & 1.69 & 8.71 & 1.83 & 0.05 & 1,33 & .83 \\
Perceived Control & 6.67 & 2.11 & 6.41 & 2.06 & 0.13 & 1,33 & .72 \\
Effort & 6.33 & 2.30 & 6.00 & 2.50 & 0.17 & 1,33 & .68 \\
Progress & 6.79 & 2.16 & 4.94 & 2.15 & 5.41 & 1,33 & $.03 *$ \\
$\begin{array}{l}\text { Ease (difficulty) } \\
\text { Good (bad) }\end{array}$ & 9.94 & 0.24 & 9.18 & 1.98 & 2.68 & 1,33 & .11 \\
Useful (useless) & 9.94 & 0.25 & 9.19 & 1.16 & 3.61 & 1,30 & .07 \\
Beneficial & 9.06 & 2.66 & 9.65 & 0.79 & 0.77 & 1,32 & .39 \\
(Harmful) & & & & & & & \\
$\begin{array}{l}\text { Important } \\
\text { Support from }\end{array}$ & 9.61 & 0.61 & 9.24 & 1.30 & 1.22 & 1,33 & .28 \\
$\begin{array}{l}\text { Significant Other } \\
\text { Desire to Please }\end{array}$ & 8.87 & 1.60 & 8.40 & 1.40 & 0.72 & 1,28 & .40 \\
Significant Other & 6.60 & 3.14 & 5.33 & 2.90 & 1.32 & 1,28 & .26 \\
\hline & & & & & & & \\
\hline
\end{tabular}

Note. Low missing refers to participants who missed between 0 and 2 sessions. High missing refers to all other values of missing data. 
Table 7

Standardized Regression Coefficients for Within-person Predictors and Final Model Fit

\begin{tabular}{|c|c|c|c|c|c|c|}
\hline & $\begin{array}{l}\text { Outcome } \\
\text { Variable }\end{array}$ & Predictor Variable & B & $t$ & $\Delta R^{2}$ & Model $R^{2}$ \\
\hline \multirow[t]{2}{*}{ Research Objective I } & Effort & Perceived Control & 0.23 & 3.78 & $0.02 *$ & $0.50 *$ \\
\hline & Progress & Perceived Control & 0.24 & 4.68 & $0.02 *$ & $0.66^{*}$ \\
\hline Research Objective II & Physical Activity & $\begin{array}{l}\text { Perceived Control } \\
\text { Effort } \\
\text { Progress }\end{array}$ & $\begin{array}{l}0.07 \\
0.21 \\
0.25\end{array}$ & $\begin{array}{l}0.98 \\
4.16 \\
4.09\end{array}$ & $\begin{array}{l}0.001 \\
0.02 * \\
0.02 *\end{array}$ & $\begin{array}{l}0.37^{*} \\
0.39^{*} \\
0.39^{*}\end{array}$ \\
\hline \multirow[t]{3}{*}{ Research Objective III } & Positive Affect & $\begin{array}{l}\text { Perceived Control } \\
\text { Effort } \\
\text { Progress }\end{array}$ & $\begin{array}{l}0.25 \\
0.08 \\
0.22\end{array}$ & $\begin{array}{l}5.60 \\
2.25 \\
5.52\end{array}$ & $\begin{array}{l}0.02 * \\
0.03 * \\
0.02 *\end{array}$ & $\begin{array}{l}0.73^{*} \\
0.72^{*} \\
0.73^{*}\end{array}$ \\
\hline & Negative Affect & $\begin{array}{l}\text { Perceived Control } \\
\text { Effort } \\
\text { Progress }\end{array}$ & $\begin{array}{l}-0.30 \\
-0.05 \\
-0.15\end{array}$ & $\begin{array}{l}-4.90 \\
-0.95 \\
-2.77\end{array}$ & $\begin{array}{l}0.03^{*} \\
0.001 \\
0.01 *\end{array}$ & $\begin{array}{l}0.50 * \\
0.47 * \\
0.48 *\end{array}$ \\
\hline & Life Satisfaction & $\begin{array}{l}\text { Perceived Control } \\
\text { Effort } \\
\text { Progress }\end{array}$ & $\begin{array}{l}0.13 \\
0.04 \\
0.07\end{array}$ & $\begin{array}{l}4.72 \\
1.78 \\
2.83\end{array}$ & $\begin{array}{c}0.01 * \\
0.001 \\
0.002 *\end{array}$ & $\begin{array}{l}0.91^{*} \\
0.90^{*} \\
0.90^{*}\end{array}$ \\
\hline \multirow[t]{3}{*}{ Research Objective IV } & Positive Affect & Physical Activity & 0.10 & 3.12 & $0.01 *$ & $0.72 *$ \\
\hline & Negative Affect & Physical Activity & 0.07 & 1.62 & 0.003 & $0.47^{*}$ \\
\hline & Life Satisfaction & Physical Activity & 0.02 & 0.94 & $<0.001$ & $0.90 *$ \\
\hline
\end{tabular}

Note. For sake of clarity, standardized coefficients for the dummy coded subject variables are not presented. $\Delta R^{2}$ refers to the variance that is attributable to the independent variable after accounting for the variance attributable to the dummy coded subject variables. Model $R^{2}$ refers to total variance accounted for by the dummy coded subject variables (i.e., the between-subject variability) and the predictor variable of interest.

$* p<.05$ 
Table 8

Sample-level Weighted Correlation Coefficients Among Goal Processes

\begin{tabular}{llll}
\hline & Perceived Control & $t(N=35)$ & $p$ (two-tailed) \\
\hline Goal effort & $0.44^{*}$ & 2.81 & .01 \\
Goal progress & $0.46^{*}$ & 2.97 & .01 \\
\hline
\end{tabular}


Table 9

Sample-level Weighted Correlation Coefficients Among Goal Processes and Physical Activity

\begin{tabular}{llll}
\hline & Physical Activity & $t(N=35)$ & $p$ (two-tailed) \\
\hline Perceived control & 0.05 & 0.29 & .77 \\
Goal effort & $0.40^{*}$ & 2.52 & .02 \\
Goal progress & $0.37^{*}$ & 2.26 & .03 \\
\hline
\end{tabular}


Table 10

Sample-level Weighted Correlation Coefficients for Goal Processes and Subjective Well-being Indices

\begin{tabular}{lllllll}
\hline & \multicolumn{2}{c}{ Positive Affect } & \multicolumn{2}{c}{ Negative Affect } & \multicolumn{2}{c}{ Life Satisfaction } \\
\cline { 2 - 7 } & $r$ & $t(N=35)$ & $r$ & $t(N=35)$ & $r$ & $t(N=35)$ \\
\hline Perceived & $0.37^{*}$ & 2.32 & -0.03 & -0.16 & 0.23 & 1.38 \\
control & & & & & & \\
Goal effort & $0.62^{* *}$ & 4.54 & -0.18 & -1.07 & 0.31 & 2.86 \\
Goal progress & $0.65^{* *}$ & 4.86 & -0.20 & -1.15 & $0.41^{*}$ & 2.57 \\
\hline$* p<.05$ & & & & & &
\end{tabular}




\section{Table 11}

Sample-level Weighted Correlation Coefficients for Physical Activity and Subjective Well-being Indices

\begin{tabular}{lccl}
\hline & Physical Activity & $t(N=35)$ & $p$ (two-tailed) \\
\hline Positive Affect & $0.48^{*}$ & 3.12 & .01 \\
Negative Affect & -0.21 & -1.23 & .23 \\
Life Satisfaction & $0.36^{*}$ & 2.25 & .03 \\
\hline
\end{tabular}


Table 12

Summary of Within-person and Sample-level Findings

\begin{tabular}{|c|c|c|c|}
\hline $\begin{array}{l}\text { Research } \\
\text { Objective }\end{array}$ & General Hypothesis & $\begin{array}{l}\text { Significant } \\
\text { Within- } \\
\text { person }\end{array}$ & $\begin{array}{c}\text { Significant } \\
\text { Sample- } \\
\text { level }\end{array}$ \\
\hline \multicolumn{4}{|c|}{ Goal processes } \\
\hline & $\begin{array}{l}\text { H1. It was expected that there would be a significant and positive association } \\
\text { between perceived control and daily goal effort toward physical activity goals. }\end{array}$ & $\mathrm{X}$ & $\mathrm{X}$ \\
\hline & $\begin{array}{l}\text { H2. It was expected that there will be a significant and positive association between } \\
\text { perceived control and daily goal progress toward physical activity goals. }\end{array}$ & $\mathrm{X}$ & $\mathrm{X}$ \\
\hline \multicolumn{4}{|c|}{$\begin{array}{l}\text { Goal processes } \\
\text { and physical activity }\end{array}$} \\
\hline \multicolumn{4}{|c|}{$\begin{array}{l}\text { H3. It was expected that there would be a significant and positive assoc } \\
\text { between perceived control and total daily minutes of physical activity. }\end{array}$} \\
\hline & $\begin{array}{l}\text { H4. It was expected that there would be a significant and positive association } \\
\text { between daily effort and total daily minutes of physical activity. }\end{array}$ & $\mathrm{X}$ & $\mathrm{X}$ \\
\hline & $\begin{array}{l}\text { H5. It was expected that there would be a significant and positive association } \\
\text { between daily progress and total daily minutes of physical activity. }\end{array}$ & $\mathrm{X}$ & $\mathrm{X}$ \\
\hline \multicolumn{4}{|c|}{$\begin{array}{l}\text { Goal processes } \\
\text { and subjective well-being }\end{array}$} \\
\hline & $\begin{array}{l}\text { H6. It was expected that there would be a significant and positive association } \\
\text { between perceived control and daily positive affect. }\end{array}$ & $\mathrm{X}$ & $\mathrm{X}$ \\
\hline & $\begin{array}{l}\text { H7. It was expected that there would be a significant and positive association } \\
\text { between goal effort and daily positive affect. }\end{array}$ & $\mathrm{X}$ & $X$ \\
\hline & $\begin{array}{l}\text { H8. It was expected that there would be a significant and positive association } \\
\text { between goal progress and daily positive affect. }\end{array}$ & $\mathrm{X}$ & \\
\hline
\end{tabular}

(table continues) 
Table 12

(continued)

H9. It was expected that there would be a significant and negative association

$\mathrm{X}$ between perceived control and daily negative affect.

H10. It was expected that there would be a significant and negative association between goal effort and daily negative affect.

H11. It was expected that there would be a significant and negative association between goal progress daily negative affect.

H12. It was expected that there would be a significant and positive association between perceived control and daily life satisfaction.

H13. It was expected that there would be a significant and positive association between goal effort and daily life satisfaction.

H14. It was expected that there would be a significant and positive association between goal progress and daily life satisfaction.

Physical activity

and subjective well-being

H15. It was expected that there would be a significant and positive association between physical activity and positive affect.

H16. It was expected that there would be a significant and negative association between physical activity and daily negative affect.

H17. It was expected that there would be a significant and positive association between physical activity and life satisfaction.
X

X

X

$\mathrm{X}$

X 
Overview of Appendices

\begin{tabular}{llll}
\hline Measure & Construct Assessed & Location & Delivery \\
\hline Intake Form & Eligibility, tracking & Appendix A & Intake - interview \\
Personal Data Form & Participant characteristics & Appendix B & Intake - self-report \\
$\begin{array}{l}\text { CHAMPS Physical } \\
\text { Activity } \\
\text { Questionnaire }\end{array}$ & Physical activity & Appendix C & Intake - self-report \\
$\begin{array}{l}\text { Paffenbarger Activity } \\
\text { Questionnaire }\end{array}$ & Physical activity & \\
Select NHIS items & Physical activity & Appendix D & Daily - Palm \\
PANAS & $\begin{array}{l}\text { Subjective well-being (positive } \\
\text { and negative affect) }\end{array}$ & Appendix F & Daily - Palm \\
SWLS & $\begin{array}{l}\text { Subjective well-being } \\
\text { (life satisfaction) }\end{array}$ & Appendix G & Daily - Palm \\
$\begin{array}{l}\text { Goal Screening and } \\
\text { Daily Goal Process } \\
\text { Journal }\end{array}$ & Goal processes & Appendix H & Daily - Palm \\
Daily Log & $\begin{array}{l}\text { Mechanical issues, missed } \\
\text { trials }\end{array}$ & Appendix I & Daily - self-report \\
\hline
\end{tabular}


Appendix A

Daily Goal Processes in Physical Activity \& Mood During Midlife: Intake Form

Participant Name:

Palm ID:

\begin{tabular}{|l|l|l|}
\hline Task & Status ( X when complete) & Initial \\
\hline Informed Consent & & \\
\hline HIPAA & & \\
\hline Personal Data & & \\
\hline Goal Screening & & \\
\hline Palm Training & & \\
\hline CHAMPS & & \\
\hline PSQI & & \\
\hline Morning/Eveningness & & \\
\hline Assign Palm & & \\
\hline Instructions & & \\
\hline Daily Log & & \\
\hline
\end{tabular}

1. Does the participant have a physical activity goal?

2. If yes, list.

$$
Y \quad N
$$

3. What is the participant doing to work towards his or her physical activity goal? (e.g., "I joined HMR," "I attend exercise classes 2x/week and use Weight Watchers points.")

4. How did the participant hear about the study?

5. Has the participant ever been diagnosed with any chronic health conditions?

$$
\text { Y N }
$$

6. If yes, list.

7. Has the participant ever been diagnosed with sleep apnea?

$$
Y N
$$

8. Has the participant ever been diagnosed with any other sleep disorders?

9. If yes, list.

$$
\mathrm{Y} \quad \mathrm{N}
$$

10. Are there any other physical or medical considerations to note?

$$
\mathrm{Y} \quad \mathrm{N}
$$

11. If yes, list. 


\section{Appendix B}

Personal Data Form

1. Birthdate: Month

Day

Year

\section{Current Age:}

2. Date of Marriage: Month

Day Year

3. I believe my physical health to be: (Circle one):

\begin{tabular}{llllll}
1 & 2 & 3 & 4 & 5 & 6 \\
\hline Very good & Good & Moderately & Moderately & Poor & Very Poor \\
& & Good & Poor & &
\end{tabular}

4. I believe my mental health to be: (Circle one):

$\begin{array}{llllll}1 & 2 & 3 & 4 & 5 & 6\end{array}$

\begin{tabular}{|c|c|c|c|c|c|}
\hline Very good & Good & Moderately & Moderately & Poor & Very Poor \\
\hline
\end{tabular}

5. Circle the highest level of education you have completed:

Grade School/

High School:

Trade, Business or

Technical School

College:

Graduate School

\begin{tabular}{|c|c|c|c|c|}
\hline $1^{\mathrm{st}}$ & $2^{\text {nd }}$ & $3^{\mathrm{rd}}$ & $4^{\text {th }}$ & $5^{\text {th }}$ \\
\hline $7^{\text {th }}$ & $8^{\text {th }}$ & $9^{\text {th }}$ & $10^{\text {th }}$ & $11^{\text {th }}$ \\
\hline
\end{tabular}


6. Sex: (Circle one): Male Female

7. I believe my life to be: (Circle one)

\begin{tabular}{lllllll}
1 & 2 & 3 & 4 & 5 & 6 & 7 \\
\hline Extremely & Very & Somewhat & Average & Somewhat & Very & Extremely \\
Happy & Happy & Happy & & Unhappy & Unhappy & Unhappy
\end{tabular}

8. How many people, including yourself, live in your home?

9. How many living children do you currently have?

10. How many of your children live within a $\underline{60 \text {-minute drive? }}$

11. Total yearly family income: (Circle one)
a. Under $\$ 4,000$
i. $\$ 18,000$ to $\$ 19,999$
b. $\$ 4,000$ to $\$ 5,999$
j. $\$ 20,000$ to $\$ 21,999$
c. $\$ 6,000$ to $\$ 7,999$
k. $\$ 22,000$ to $\$ 23,999$
d. $\$ 8,000$ to $\$ 9,999$
1. $\$ 24,000$ to $\$ 25,999$
e. $\$ 10,000$ to $\$ 11,999$
m. $\$ 26,000$ to $\$ 27,999$
f. $\$ 12,000$ to $\$ 13,999$
n. $\$ 28,000$ to $\$ 29,999$
g. $\$ 14,000$ to $\$ 15,999$
o. $\$ 30,000$ to $\$ 50,000$
h. $\$ 16,000$ to $\$ 17,999$
p. Over $\$ 50,000$

12. I believe my eyesight to be: (Circle one)

\begin{tabular}{llllll}
1 & 2 & 3 & 4 & 5 & 6 \\
\hline Very good & Good & Moderately & Moderately & Poor & Very Poor \\
& & Good & Poor & &
\end{tabular}


13. I believe my hearing to be: (Circle one)

\begin{tabular}{llllll}
1 & 2 & 3 & 4 & 5 & 6 \\
\hline Very good & Good & Moderately & Moderately & Poor & Very Poor \\
& & Good & Poor & &
\end{tabular}

14. Do you wear a hearing aid? (Circle one) Yes No

15. Do you use a walker or wheel chair? Yes No

16. Do you use other assistive devices? Yes No

If yes, specify

17. Approximately how many times have you seen a doctor in the last $\underline{\underline{\text { ix months }}}$ ?__ times

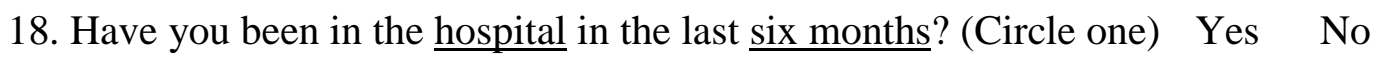

If yes, for how many days? days

19. What is your height? feet and inches

20. What is your weight? pounds

21. How far can you walk without needing to take a break (without stopping)? Cannot walk

A few steps 10-99 yards $100-499$ yards 500 yards -1 mile 1-3 miles more than 3 miles 
The next eighteen (18) questions ask you about activities that you do everyday. For each of the following categories, please circle the ONE answer you feel best applies to you. PLEASE ANSWER EVERY QUESTION.

22. ABILITY TO USE THE TELEPHONE (Circle one)

a. I use the telephone without assistance (I look up and dial number, etc.).

b. I dial a few memorized numbers.

c. I answer the telephone, but don't dial out.

d. I don't use the telephone at all.

23. SHOPPING (Circle one)

a. I shop alone and return home independently with purchases.

b. When I shop, somebody must provide transportation.

c. When I shop, I need somebody's help.

d. I am completely unable to shop.

\section{FOOOD PREPARATION (Circle one)}

a. I plan, prepare, and serve good meals independently.

b. I can prepare my own meals if supplied with the ingredients.

c. I can heat and serve prepared meals.

d. I need to have meals prepared and served.

25. HOUSEKEEPING (Circle one)

a. I maintain my home alone or I need occasional help (e.g., heavy work, domestic help)

b. I perform light daily tasks such as dishwashing and bed making.

c. I perform most light daily tasks, and I keep it very clean and tidy. 
d. I need help with all home maintenance tasks.

e. I don't participate in any housekeeping tasks.

26. LAUNDRY (Circle one)

a. I do all of my laundry.

b. I only launder small items - rinse socks, stockings, etc.

c. All of my laundry is done by others.

27. TRANSPORTATION (Circle one)

a. I drive my own car for long-distance and short trips.

b. I drive my own car for local (short) shorts only.

c. I depend on someone else to help me get around (relative, friend, taxi driver).

d. I am not able to travel by car.

28. RESPONSIBILITY FOR OWN MEDICATION (Circle one)

a. I am responsible for taking my own medication in the correct dosage at the correct time

b. I am responsible for taking my own medication, but someone needs to prepare it (e.g., load syringe, open pill bottle).

c. Someone gives me my medication (e.g., gives me a shot, reminds me when to take medication, brings me my pills).

29. ABILITY TO HANDLE FINANCES (Circle one)

a. I manage my financial matters independently (budgets, banking, write checks, pay rent, bills), collect and keep track of income.

b. I manage day-to-day purchases, but need help with banking, major purchases, etc.

c. Someone must help me with all of my finances. 
30. When it comes to writing checks, paying bills, and keeping financial records:
a. I never did the task, and would have difficulty now.
b. I never did the task, and could do it now.
c. I have no difficulty performing the task by myself.
d. I do have difficulty, but I perform the task myself.
e. I require some assistance to get the task done.
f. I require total assistance; someone must do the task for me.

31. When it comes to assembling tax records and making out business and insurance papers:
a. I never did the task, and would have difficulty now.
b. I never did the task, but could do it now.
c. I have no difficulty performing the task by myself.
d. I do have difficulty, but I perform the task myself.
e. I require some assistance to get the task done.
f. I require total assistance; someone must do the task for me.

32. When it comes to shopping alone for clothes, household necessities, and groceries:
a. I never did the task, and would have difficulty now.
b. I never did the task, but could do it now.
c. I have no difficulty performing the task by myself.
d. I do have difficulty, but I perform the task myself.
e. I require some assistance to get the task done.
f. I require total assistance; someone must do the task for me. 
33. When it comes to playing a game of skill such as bridge, other card games, or chess:
a. I never did the task, and would have difficulty now.
b. I never did the task, but could do it now.
c. I have no difficulty performing the task by myself.
d. I do have difficulty, but I perform the task myself.
e. I require some assistance to get the task done.
f. I require total assistance; someone must do the task for me.

34. When it comes to heating water for coffee or tea and turning off the stove:
a. I never did the task, and would have difficulty now.
b. I never did the task, but could do it now.
c. I have no difficulty performing the task by myself.
d. I do have difficulty, but I perform the task myself.
e. I require some assistance to get the task done.
f. I require total assistance; someone must do the task for me.

35. When it comes to preparing a balanced meal:
a. I never did the task, and would have difficulty now.
b. I never did the task, but could do it now.
c. I have no difficulty performing the task by myself.
d. I do have difficulty, but I perform the task myself.
e. I require some assistance to get the task done.
f. I require total assistance; someone must do the task for me. 
36. When it comes to keeping track of current events:
a. I never did the task, and would have difficulty now.
b. I never did the task, but could do it now.
c. I have no difficulty performing the task by myself.
d. I do have difficulty, but I perform the task myself.
e. I require some assistance to get the task done.
f. I require total assistance; someone must do the task for me.

37. When is comes to paying attention to, and understanding, a TV program, book, or magazine:
a. I never did the task, and would have difficulty now.
b. I never did the task, but could do it now.
c. I have no difficulty performing the task by myself.
d. I do have difficulty, but I perform the task myself.
e. I require some assistance to get the task done.
f. I require total assistance; someone must do the task for me.

38. When it comes to remembering appointments, family occasions, and medications:
a. I never did the task, and would have difficulty now.
b. I never did the task, but could do it now.
c. I have no difficulty performing the task by myself.
d. I do have difficulty, but I perform the task myself.
e. I require some assistance to get the task done.
f. I require total assistance; someone must do the task for me. 
39. When it comes to traveling outside my neighborhood:
a. I never did the task, and would have difficulty now.
b. I never did the task, but could do it now.
c. I have no difficulty performing the task by myself.
d. I do have difficulty, but I perform the task myself.
e. I require some assistance to get the task done.
f. I require total assistance; someone must do the task for me.

40. What kind of work have you done most of your life?

a. For what kind of business, company, or agency is that?
41. Are you currently employed?
Yes No
42. Are you current retired?
Yes No

43. How many hours in a typical week do you spend in paid work? Hours

44. How many hours in a typical week do you spend in unpaid volunteer work? Hours 45. How much financial difficulty do you have paying your bills? Would you say: (Circle one)

\begin{tabular}{|l|l|l|l|l|}
\hline 1 & 2 & 3 & 4 & 5 \\
\hline A great deal of & Some difficulty & A little difficulty & No difficulty & Does not apply \\
\hline difficulty & & & & \\
\hline
\end{tabular}


46. Which of the following best describes your living situation? (Check all that apply) Urban House

Rural Apartment

Assisted living facility

Other

47. For descriptive purposes, could you please check the ethnicity category to which you most belong:

African American/Black

American Indian/Alaskan Native

Asian/Pacific Islander

Caucasian/White

Latino/Hispanic

Other: Please indicate

48. Please indicate how you heard about this study (e.g., "I attend Health Management Resources (HMR) and noticed a flyer."). 


\title{
Appendix C
}

\section{The CHAMPS Questionnaire}

\author{
This questionnaire is about activities that you may have done in the past 4 weeks. The questions on the \\ following pages are similar to the example shown below. \\ INSTRUCTIONS \\ If you DID the activity in the past 4 weeks: \\ Step \#1 Check the YES box. \\ Step \#2 Think about how many TIMES a week you usually did it, and write your response in the \\ space provided. \\ Step \#3 Circle how many TOTAL HOURS in a typical week you did the activity.
}

Here is an example of how Mrs. Jones would answer question \#1: Mrs. Jones usually visits her friends Maria and Olga twice a week. She usually spends one hour on Monday with Maria and two hours on Wednesday with Olga. Therefore, the total hours a week that she visits with friends is $\underline{3}$ hours a week.

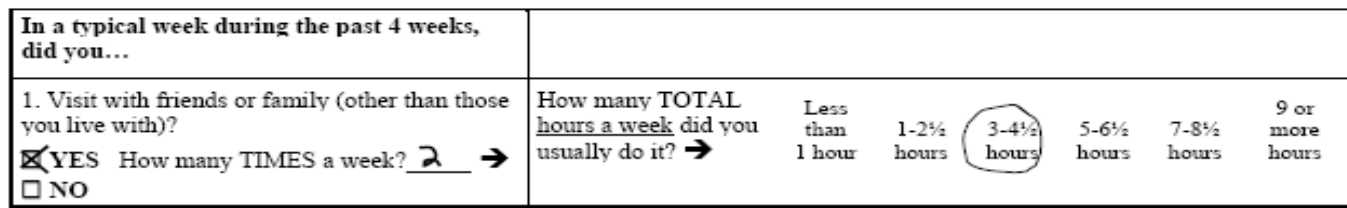

If you DID NOT do the activity:

- Check the NO box and move to the next question

\begin{tabular}{|c|c|c|c|c|c|c|c|}
\hline $\begin{array}{l}\text { In a typical week during the past } \\
4 \text { weeks, did you ... }\end{array}$ & & & & & & & \\
\hline $\begin{array}{l}\text { 1. Visit with friends or family (other than those } \\
\text { you live with)? } \\
\text { YES How many TIMES a week? } \\
\text { NO }\end{array}$ & $\begin{array}{l}\text { How many TOTAL } \\
\text { hours a week did you } \\
\text { usually do it? } \rightarrow\end{array}$ & $\begin{array}{l}\text { Less } \\
\text { than } \\
1 \text { hour }\end{array}$ & $\begin{array}{l}1-2 \% / 2 \\
\text { hours }\end{array}$ & $\begin{array}{l}3-4 \frac{1}{2} \\
\text { hours }\end{array}$ & $\begin{array}{l}5-6^{1 / 2} / 2 \\
\text { hours }\end{array}$ & $\begin{array}{l}7-81 / 2 \\
\text { hours }\end{array}$ & $\begin{array}{l}9 \text { or } \\
\text { more } \\
\text { hours }\end{array}$ \\
\hline $\begin{array}{l}\text { 2. Go to the senior center? } \\
\text { YES How many TIMES a week? } \\
\text { NO }\end{array}$ & $\begin{array}{l}\text { How many TOTAL } \\
\text { hours a week did you } \\
\text { usually do it? } \rightarrow\end{array}$ & $\begin{array}{l}\text { Less } \\
\text { than } \\
1 \text { hour }\end{array}$ & $\begin{array}{l}1-2 \% / 2 \\
\text { hours }\end{array}$ & $\begin{array}{l}3-4 \frac{1}{2} \\
\text { hours }\end{array}$ & $\begin{array}{l}5-6^{1 / 2} \\
\text { hours }\end{array}$ & $\begin{array}{l}7-81 / 2 \\
\text { hours }\end{array}$ & $\begin{array}{l}9 \text { or } \\
\text { more } \\
\text { hours }\end{array}$ \\
\hline $\begin{array}{l}\text { 3. Do volunteer work? } \\
\text { YES How many TIMES a week? } \\
\text { NO }\end{array}$ & $\begin{array}{l}\text { How many TOTAL } \\
\text { hours a week did you } \\
\text { usually do it? } \rightarrow\end{array}$ & $\begin{array}{l}\text { Less } \\
\text { than } \\
1 \text { hour }\end{array}$ & $\begin{array}{l}1-2 \frac{1}{2} \\
\text { hours }\end{array}$ & $\begin{array}{l}3-4 \frac{1}{2} 2 \\
\text { hours }\end{array}$ & $\begin{array}{l}5-61 / 2 \\
\text { hours }\end{array}$ & $\begin{array}{l}7-81 / 2 \\
\text { hours }\end{array}$ & $\begin{array}{l}9 \text { or } \\
\text { more } \\
\text { hours }\end{array}$ \\
\hline $\begin{array}{l}\text { 4. Attend church or take part in church } \\
\text { activities? } \\
\text { YES How many TIMES a week? } \\
\text { NO }\end{array}$ & $\begin{array}{l}\text { How many TOTAL } \\
\text { hours a week did you } \\
\text { usually do it? } \rightarrow\end{array}$ & $\begin{array}{l}\text { Less } \\
\text { than } \\
1 \text { hour }\end{array}$ & $\begin{array}{l}1-2 \frac{1}{2} \\
\text { hours }\end{array}$ & $\begin{array}{l}3-4 \frac{1}{2} \\
\text { hours }\end{array}$ & $\begin{array}{l}5-61 / 2 \\
\text { hours }\end{array}$ & $\begin{array}{l}7-81 / 2 \\
\text { hours }\end{array}$ & $\begin{array}{l}9 \text { or } \\
\text { more } \\
\text { hours }\end{array}$ \\
\hline $\begin{array}{l}\text { 5. Attend other club or group meetings? } \\
\text { YES How many TIMES a week? } \\
\text { NO }\end{array}$ & $\begin{array}{l}\text { How many TOTAL } \\
\text { hours a week did you } \\
\text { usually do it? } \rightarrow\end{array}$ & $\begin{array}{l}\text { Less } \\
\text { than } \\
1 \text { hour }\end{array}$ & $\begin{array}{l}1-2 \% / 2 \\
\text { hours }\end{array}$ & $\begin{array}{l}3-4 \frac{1}{2} \\
\text { hours }\end{array}$ & $\begin{array}{l}5-6^{1 / 2} \\
\text { hours }\end{array}$ & $\begin{array}{l}7-81 / 2 \\
\text { hours }\end{array}$ & $\begin{array}{l}9 \text { or } \\
\text { more } \\
\text { hours }\end{array}$ \\
\hline $\begin{array}{l}\text { 6. Use a computer? } \\
\text { YES How many TIMES a week? } \\
\text { NO }\end{array}$ & $\begin{array}{l}\text { How many TOTAL } \\
\text { hours a week did you } \\
\text { usually do it? } \rightarrow\end{array}$ & $\begin{array}{l}\text { Less } \\
\text { than } \\
1 \text { hour }\end{array}$ & $\begin{array}{l}1-2 \% / 2 \\
\text { hours }\end{array}$ & $\begin{array}{l}3-4 \frac{1}{2} \\
\text { hours }\end{array}$ & $\begin{array}{l}5-6^{1 / 2} \\
\text { hours }\end{array}$ & $\begin{array}{l}7-81 / 2 \\
\text { hours }\end{array}$ & $\begin{array}{l}9 \text { or } \\
\text { more } \\
\text { hours }\end{array}$ \\
\hline
\end{tabular}




\begin{tabular}{|c|c|c|c|c|c|c|c|}
\hline $\begin{array}{l}\text { In a typical week during the past } \\
4 \text { weeks, did you ... }\end{array}$ & & & & & & & \\
\hline $\begin{array}{l}\text { 7. Dance (such as square, folk, line, ballroom) } \\
\text { (do not count aerobic dance here)? } \\
\text { YES How many TIMES a week? } \\
\text { NO }\end{array}$ & $\begin{array}{l}\text { How many TOTAL } \\
\text { hours a week did you } \\
\text { usually do it? } \rightarrow\end{array}$ & $\begin{array}{l}\text { Less } \\
\text { than } \\
1 \text { hour }\end{array}$ & $\begin{array}{l}1-2 \% / 2 \\
\text { hours }\end{array}$ & $\begin{array}{l}3-4 \frac{1}{2} / 2 \\
\text { hours }\end{array}$ & $\begin{array}{l}5-6^{1 / 2} \\
\text { hours }\end{array}$ & $\begin{array}{l}7-81 / 2 \\
\text { hours }\end{array}$ & $\begin{array}{l}9 \text { or } \\
\text { more } \\
\text { hours }\end{array}$ \\
\hline $\begin{array}{l}\text { 8. Do woodworking, needlework, drawing, or } \\
\text { other arts or crafts? } \\
\text { YES How many TIMES a week? } \\
\text { NO }\end{array}$ & $\begin{array}{l}\text { How many TOTAL } \\
\text { hours a week did you } \\
\text { usually do it? } \rightarrow\end{array}$ & $\begin{array}{l}\text { Less } \\
\text { than } \\
1 \text { hour }\end{array}$ & $\begin{array}{l}1-2 \frac{1}{2} \\
\text { hours }\end{array}$ & $\begin{array}{l}3-4 \frac{1}{2} \\
\text { hours }\end{array}$ & $\begin{array}{l}5-61 / 2 \\
\text { hours }\end{array}$ & $\begin{array}{l}7-81 / 2 \\
\text { hours }\end{array}$ & $\begin{array}{l}9 \text { or } \\
\text { more } \\
\text { hours }\end{array}$ \\
\hline $\begin{array}{l}\text { 9. Play golf, carrying or pulling your equipment } \\
\text { (count walking time only)? } \\
\text { YES How many TIMES a week? } \\
\text { NO }\end{array}$ & $\begin{array}{l}\text { How many TOTAL } \\
\text { hours a week did you } \\
\text { usually do it? } \rightarrow\end{array}$ & $\begin{array}{l}\text { Less } \\
\text { than } \\
1 \text { hour }\end{array}$ & $\begin{array}{l}1-2 \frac{1}{2} \\
\text { hours }\end{array}$ & $\begin{array}{l}3-4 \frac{4}{2} \\
\text { hours }\end{array}$ & $\begin{array}{l}5-6^{1 / 2} \\
\text { hours }\end{array}$ & $\begin{array}{l}7-81 / 2 \\
\text { hours }\end{array}$ & $\begin{array}{l}9 \text { or } \\
\text { more } \\
\text { hours }\end{array}$ \\
\hline $\begin{array}{l}\text { 10. Play golf, riding a cart (count walking time } \\
\text { only)? } \\
\text { YES How many TIMES a week? } \\
\text { NO }\end{array}$ & $\begin{array}{l}\text { How many TOTAL } \\
\text { hours a week did you } \\
\text { usually do it? } \rightarrow\end{array}$ & $\begin{array}{l}\text { Less } \\
\text { than } \\
1 \text { hour }\end{array}$ & $\begin{array}{l}1-2 \frac{t}{2} \\
\text { hours }\end{array}$ & $\begin{array}{l}3-4 \frac{1}{2} \\
\text { hours }\end{array}$ & $\begin{array}{l}5-6^{1 / 2} \\
\text { hours }\end{array}$ & $\begin{array}{l}7-81 / 2 \\
\text { hours }\end{array}$ & $\begin{array}{l}9 \text { or } \\
\text { more } \\
\text { hours }\end{array}$ \\
\hline $\begin{array}{l}\text { 11. Attend a concert, movie, lecture, or sport } \\
\text { event? } \\
\text { YES How many TIMES a week? } \\
\text { NO }\end{array}$ & $\begin{array}{l}\text { How many TOTAL } \\
\text { hours a week did you } \\
\text { usually do it? } \rightarrow\end{array}$ & $\begin{array}{l}\text { Less } \\
\text { than } \\
1 \text { hour }\end{array}$ & $\begin{array}{l}1-2 t / 2 \\
\text { hours }\end{array}$ & $\begin{array}{l}3-4 \frac{1}{2} \\
\text { hours }\end{array}$ & $\begin{array}{l}5-61 / 2 \\
\text { hours }\end{array}$ & $\begin{array}{l}7-81 / 2 \\
\text { hours }\end{array}$ & $\begin{array}{l}9 \text { or } \\
\text { more } \\
\text { hours }\end{array}$ \\
\hline $\begin{array}{l}\text { 12. Play cards, bingo, or board } \\
\text { games with other people? } \\
\text { YES How many TIMES a week? } \\
\text { NO }\end{array}$ & $\begin{array}{l}\text { How many TOTAL } \\
\text { hours a week did you } \\
\text { usually do it? } \rightarrow\end{array}$ & $\begin{array}{l}\text { Less } \\
\text { than } \\
1 \text { hour }\end{array}$ & $\begin{array}{l}1-2 \frac{1}{2} \\
\text { hours }\end{array}$ & $\begin{array}{l}3-4 \frac{1}{2} \\
\text { hours }\end{array}$ & $\begin{array}{l}5-61 / 2 \\
\text { hours }\end{array}$ & $\begin{array}{l}7-81 / 2 \\
\text { hours }\end{array}$ & $\begin{array}{l}9 \text { or } \\
\text { more } \\
\text { hours }\end{array}$ \\
\hline
\end{tabular}

\begin{tabular}{|c|c|c|c|c|c|c|c|}
\hline $\begin{array}{l}\text { In a typical week during the past } \\
4 \text { weeks, did you ... }\end{array}$ & & & & & & & \\
\hline $\begin{array}{l}\text { 13. Shoot pool or billiards? } \\
\text { YES How many TIMES a week? } \\
\text { NO }\end{array}$ & $\begin{array}{l}\text { How many TOTAL } \\
\text { hours a week did you } \\
\text { usually do it? } \rightarrow\end{array}$ & $\begin{array}{l}\text { Less } \\
\text { than } \\
1 \text { hour }\end{array}$ & $\begin{array}{l}1-2 \% / 2 \\
\text { hours }\end{array}$ & $\begin{array}{l}3-4 \frac{1}{2} \\
\text { hours }\end{array}$ & $\begin{array}{l}5-6^{1 / 2} \\
\text { hours }\end{array}$ & $\begin{array}{l}7-81 / 2 \\
\text { hours }\end{array}$ & $\begin{array}{l}9 \text { or } \\
\text { more } \\
\text { hours }\end{array}$ \\
\hline $\begin{array}{l}\text { 14. Play singles tennis (do not count doubles)? } \\
\text { YES How many TIMES a week? } \\
\text { NO }\end{array}$ & $\begin{array}{l}\text { How many TOTAL } \\
\text { hours a week did you } \\
\text { usually do it? } \rightarrow\end{array}$ & $\begin{array}{l}\text { Less } \\
\text { than } \\
1 \text { hour }\end{array}$ & $\begin{array}{l}1-2 \frac{1}{2} \\
\text { hours }\end{array}$ & $\begin{array}{l}3-4^{4 / 2} \\
\text { hours }\end{array}$ & $\begin{array}{l}5-6^{1 / 2} \\
\text { hours }\end{array}$ & $\begin{array}{l}7-81 / 2 \\
\text { hours }\end{array}$ & $\begin{array}{l}9 \text { or } \\
\text { more } \\
\text { hours }\end{array}$ \\
\hline $\begin{array}{l}\text { 15. Play doubles temis (do not count singles)? } \\
\text { YES How many TIMES a week? } \\
\text { NO }\end{array}$ & $\begin{array}{l}\text { How many TOTAL } \\
\text { hours a week did you } \\
\text { usually do it? } \rightarrow\end{array}$ & $\begin{array}{l}\text { Less } \\
\text { than } \\
1 \text { hour }\end{array}$ & $\begin{array}{l}1-2 \frac{1}{2} \\
\text { hours }\end{array}$ & $\begin{array}{l}3-4 \frac{1}{2} \\
\text { hours }\end{array}$ & $\begin{array}{l}5-61 / 2 \\
\text { hours }\end{array}$ & $\begin{array}{l}7-81 / 2 \\
\text { hours }\end{array}$ & $\begin{array}{l}9 \text { or } \\
\text { more } \\
\text { hours }\end{array}$ \\
\hline $\begin{array}{l}\text { 16. Skate (ice, roller, in-line)? } \\
\text { YES How many TIMES a week? } \\
\text { NO }\end{array}$ & $\begin{array}{l}\text { How many TOTAL } \\
\text { hours a week did you } \\
\text { usually do it? } \rightarrow\end{array}$ & $\begin{array}{l}\text { Less } \\
\text { than } \\
1 \text { hour }\end{array}$ & $\begin{array}{l}1-2 \frac{1}{2} \\
\text { hours }\end{array}$ & $\begin{array}{l}3-4 \frac{1}{2} \\
\text { hours }\end{array}$ & $\begin{array}{l}5-6^{1 / 2} \\
\text { hours }\end{array}$ & $\begin{array}{l}7-81 / 2 \\
\text { hours }\end{array}$ & $\begin{array}{l}9 \text { or } \\
\text { more } \\
\text { hours }\end{array}$ \\
\hline $\begin{array}{l}\text { 17. Play a musical instrument? } \\
\text { YES How many TIMES a week? } \\
\text { NO }\end{array}$ & $\begin{array}{l}\text { How many TOTAL } \\
\text { hours a week did you } \\
\text { usually do it? } \rightarrow\end{array}$ & $\begin{array}{c}\text { Less } \\
\text { than } \\
1 \text { hour }\end{array}$ & $\begin{array}{l}1-2 \% / 2 \\
\text { hours }\end{array}$ & $\begin{array}{l}3-4^{4 / 2} \\
\text { hours }\end{array}$ & $\begin{array}{l}5-61 / 2 \\
\text { hours }\end{array}$ & $\begin{array}{l}7-81 / 2 \\
\text { hours }\end{array}$ & $\begin{array}{l}9 \text { or } \\
\text { more } \\
\text { hours }\end{array}$ \\
\hline $\begin{array}{l}\text { 18. Read? } \\
\text { YES How many TIMES a week? } \\
\text { NO }\end{array}$ & $\begin{array}{l}\text { How many TOTAL } \\
\text { hours a week did you } \\
\text { usually do it? } \rightarrow\end{array}$ & $\begin{array}{l}\text { Less } \\
\text { than } \\
1 \text { hour }\end{array}$ & $\begin{array}{l}1-2 \% / 2 \\
\text { hours }\end{array}$ & $\begin{array}{l}3-4^{4 / 2} \\
\text { hours }\end{array}$ & $\begin{array}{l}5-61 / 2 \\
\text { hours }\end{array}$ & $\begin{array}{l}7-81 / 2 \\
\text { hours }\end{array}$ & $\begin{array}{l}9 \text { or } \\
\text { more } \\
\text { hours }\end{array}$ \\
\hline $\begin{array}{l}\text { 19. Do heavy work around the house (such as } \\
\text { washing windows, cleaning gutters)? } \\
\text { YES How many TIMES a week? } \\
\text { NO }\end{array}$ & $\begin{array}{l}\text { How many TOTAL } \\
\text { hours a week did you } \\
\text { usually do it? } \rightarrow\end{array}$ & $\begin{array}{l}\text { Less } \\
\text { than } \\
1 \text { hour }\end{array}$ & $\begin{array}{l}1-2 \% / 2 \\
\text { hours }\end{array}$ & $\begin{array}{l}3-4 \frac{1}{2} \\
\text { hours }\end{array}$ & $\begin{array}{l}5-61 / 2 \\
\text { hours }\end{array}$ & $\begin{array}{l}7-8^{1 / 2} \\
\text { hours }\end{array}$ & $\begin{array}{l}9 \text { or } \\
\text { more } \\
\text { hours }\end{array}$ \\
\hline
\end{tabular}




\begin{tabular}{|c|c|c|c|c|c|c|c|}
\hline $\begin{array}{l}\text { In a typical week during the past } \\
4 \text { weeks, did you ... }\end{array}$ & & & & & & & \\
\hline $\begin{array}{l}\text { 20. Do light work around the house (such as } \\
\text { sweeping or vacuuming)? } \\
\text { YES How many TIMES a week? } \\
\text { NO }\end{array}$ & $\begin{array}{l}\text { How many TOTAL } \\
\text { hours a week did you } \\
\text { usually do it? } \rightarrow\end{array}$ & $\begin{array}{l}\text { Less } \\
\text { than } \\
1 \text { hour }\end{array}$ & $\begin{array}{l}1-2 \frac{1}{2} \\
\text { hours }\end{array}$ & $\begin{array}{l}3-4^{4} / 2 \\
\text { hours }\end{array}$ & $\begin{array}{l}5-61 / 2 \\
\text { hours }\end{array}$ & $\begin{array}{r}7-81 / 2 \\
\text { hours }\end{array}$ & $\begin{array}{l}9 \text { or } \\
\text { more } \\
\text { hours }\end{array}$ \\
\hline $\begin{array}{l}\text { 21. Do heavy gardening (such as spading, } \\
\text { raking)? } \\
\text { YES How many TIMES a week? } \\
\text { NO }\end{array}$ & $\begin{array}{l}\text { How many TOTAL } \\
\text { hours a week did you } \\
\text { usually do it? } \rightarrow\end{array}$ & $\begin{array}{l}\text { Less } \\
\text { than } \\
1 \text { hour }\end{array}$ & $\begin{array}{l}1-2 \% / 2 \\
\text { hours }\end{array}$ & $\begin{array}{l}3-4^{1 / 2} / 2 \\
\text { hours }\end{array}$ & $\begin{array}{l}5-61 / 2 \\
\text { hours }\end{array}$ & $\begin{array}{r}7-81 / 2 \\
\text { hours }\end{array}$ & $\begin{array}{l}9 \text { or } \\
\text { more } \\
\text { hours }\end{array}$ \\
\hline $\begin{array}{l}\text { 22. Do light gardening (such as watering } \\
\text { plants)? } \\
\text { YES How many TIMES a week? } \\
\text { NO }\end{array}$ & $\begin{array}{l}\text { How many TOTAL } \\
\text { hours a week did you } \\
\text { usually do it? } \rightarrow\end{array}$ & $\begin{array}{l}\text { Less } \\
\text { than } \\
1 \text { hour }\end{array}$ & $\begin{array}{l}1-2 \% / 2 \\
\text { hours }\end{array}$ & $\begin{array}{l}3-4 \frac{1}{2} \\
\text { hours }\end{array}$ & $\begin{array}{l}5-6^{1 / 2} \\
\text { hours }\end{array}$ & $\begin{array}{r}7-81 / 2 \\
\text { hours }\end{array}$ & $\begin{array}{l}9 \text { or } \\
\text { more } \\
\text { hours }\end{array}$ \\
\hline $\begin{array}{l}\text { 23. Work on your car, truck, lawn mower, or } \\
\text { other machinery? } \\
\text { YES How many TIMES a week? } \\
\text { NO }\end{array}$ & $\begin{array}{l}\text { How many TOTAL } \\
\text { hours a week did you } \\
\text { usually do it? } \rightarrow\end{array}$ & $\begin{array}{l}\text { Less } \\
\text { than } \\
1 \text { hour }\end{array}$ & $\begin{array}{l}1-2 \% / 2 \\
\text { hours }\end{array}$ & $\begin{array}{l}3-4^{1 / 2} \\
\text { hours }\end{array}$ & $\begin{array}{l}5-6 \frac{1}{2} \\
\text { hours }\end{array}$ & $\begin{array}{r}7-81 / 2 \\
\text { hours }\end{array}$ & $\begin{array}{l}9 \text { or } \\
\text { more } \\
\text { hours }\end{array}$ \\
\hline \multicolumn{8}{|c|}{${ }^{* *}$ Please note: For the following questions about running and walking, include use of a treadmill. } \\
\hline $\begin{array}{l}\text { 24. Jog or run? } \\
\text { YES How many TIMES a week? } \\
\text { NO }\end{array}$ & $\begin{array}{l}\text { How many TOTAL } \\
\text { hours a week did you } \\
\text { usually do it? } \rightarrow\end{array}$ & $\begin{array}{c}\text { Less } \\
\text { than } \\
1 \text { hour }\end{array}$ & $\begin{array}{l}1-2 \% / 2 \\
\text { hours }\end{array}$ & $\begin{array}{l}3-4 \frac{1}{2} \\
\text { hours }\end{array}$ & $\begin{array}{l}5-61 / 2 \\
\text { hours }\end{array}$ & $\begin{array}{r}7-81 / 2 \\
\text { hours }\end{array}$ & $\begin{array}{l}9 \text { or } \\
\text { more } \\
\text { hours }\end{array}$ \\
\hline $\begin{array}{l}\text { 25. Walk uphill or hike uphill (count only uphill } \\
\text { part)? } \\
\text { YES How many TIMES a week? } \\
\text { NO }\end{array}$ & $\begin{array}{l}\text { How many TOTAL } \\
\text { hours a week did you } \\
\text { usually do it? } \rightarrow\end{array}$ & $\begin{array}{l}\text { Less } \\
\text { than } \\
1 \text { hour }\end{array}$ & $\begin{array}{l}1-2 \frac{1}{2} \\
\text { hours }\end{array}$ & $\begin{array}{l}3-4 \frac{1}{2} \\
\text { hours }\end{array}$ & $\begin{array}{r}5-6^{1 / 2} \\
\text { hours }\end{array}$ & $\begin{array}{r}7-81 / 2 \\
\text { hours }\end{array}$ & $\begin{array}{l}9 \text { or } \\
\text { more } \\
\text { hours }\end{array}$ \\
\hline $\begin{array}{l}\text { In a typical week during the past } \\
4 \text { weeks, did you ... }\end{array}$ & & & & & & & \\
\hline $\begin{array}{l}\text { 26. Walk fast or briskly for exercise (do not } \\
\text { count walking leisurely or uphill)? } \\
\text { YES How many TIMES a week? } \\
\text { NO }\end{array}$ & $\begin{array}{l}\text { How many TOTAL } \\
\text { hours a week did you } \\
\text { usually do it? } \rightarrow\end{array}$ & $\begin{array}{l}\text { Less } \\
\text { than } \\
1 \text { hour }\end{array}$ & $\begin{array}{l}1-2 \% / 2 \\
\text { hours }\end{array}$ & $\begin{array}{l}3-4 \frac{1}{2} \\
\text { hours }\end{array}$ & $\begin{array}{l}5-6^{1 / 2} \\
\text { hours }\end{array}$ & $\begin{array}{r}7-81 / 2 \\
\text { hours }\end{array}$ & $\begin{array}{l}9 \text { or } \\
\text { more } \\
\text { hours }\end{array}$ \\
\hline $\begin{array}{l}\text { 27. Walk to do errands (such as to/from a store } \\
\text { or to take children to school (count walk time } \\
\text { onlv)? } \\
\text { YES How many TIMES a week? } \\
\text { NO }\end{array}$ & $\begin{array}{l}\text { How many TOTAL } \\
\text { hours a week did you } \\
\text { usually do it? } \rightarrow\end{array}$ & $\begin{array}{l}\text { Less } \\
\text { than } \\
1 \text { hour }\end{array}$ & $\begin{array}{l}1-2 \% / 2 \\
\text { hours }\end{array}$ & $\begin{array}{l}3-4 \frac{1}{2} \\
\text { hours }\end{array}$ & $\begin{array}{l}5-6^{1 / 2} \\
\text { hours }\end{array}$ & $\begin{array}{r}7-81 / 2 \\
\text { hours }\end{array}$ & $\begin{array}{l}9 \text { or } \\
\text { more } \\
\text { hours }\end{array}$ \\
\hline $\begin{array}{l}\text { 28. Walk leisurely for exercise or pleasure? } \\
\text { YES How many TIMES a week? } \\
\text { NO }\end{array}$ & $\begin{array}{l}\text { How many TOTAL } \\
\text { hours a week did you } \\
\text { usually do it? } \rightarrow\end{array}$ & $\begin{array}{l}\text { Less } \\
\text { than } \\
1 \text { hour }\end{array}$ & $\begin{array}{l}1-2 \% / 2 \\
\text { hours }\end{array}$ & $\begin{array}{l}3-4 \frac{1}{2} \\
\text { hours }\end{array}$ & $\begin{array}{l}5-6^{1 / 2} \\
\text { hours }\end{array}$ & $\begin{array}{r}7-81 / 2 \\
\text { hours }\end{array}$ & $\begin{array}{l}9 \text { or } \\
\text { more } \\
\text { hours }\end{array}$ \\
\hline $\begin{array}{l}\text { 29. Ride a bicycle or stationary cycle? } \\
\text { YES How many TIMES a week? } \\
\text { NO }\end{array}$ & $\begin{array}{l}\text { How many TOTAL } \\
\text { hours a week did you } \\
\text { usually do it? } \rightarrow\end{array}$ & $\begin{array}{l}\text { Less } \\
\text { than } \\
1 \text { hour }\end{array}$ & $\begin{array}{l}1-2 \% / 2 \\
\text { hours }\end{array}$ & $\begin{array}{l}3-4 \frac{1}{2} \\
\text { hours }\end{array}$ & $\begin{array}{l}5-6^{1 / 2} \\
\text { hours }\end{array}$ & $\begin{array}{r}7-81 / 2 \\
\text { hours } \\
\end{array}$ & $\begin{array}{l}9 \text { or } \\
\text { more } \\
\text { hours }\end{array}$ \\
\hline $\begin{array}{l}\text { 30. Do other aerobic machines such as rowing, } \\
\text { or step machines (do not count treadmill or } \\
\text { stationary cycle)? } \\
\text { YES How many TIMES a week? } \\
\text { NO }\end{array}$ & $\begin{array}{l}\text { How many TOTAL } \\
\text { hours a week did you } \\
\text { usually do it? } \rightarrow\end{array}$ & $\begin{array}{l}\text { Less } \\
\text { than } \\
1 \text { hour }\end{array}$ & $\begin{array}{l}1-2 \% / 2 \\
\text { hours }\end{array}$ & $\begin{array}{l}3-4 \frac{1}{2} \\
\text { hours }\end{array}$ & $\begin{array}{l}5-6^{1 / 2} \\
\text { hours }\end{array}$ & $\begin{array}{l}7-81 / 2 \\
\text { hours }\end{array}$ & $\begin{array}{l}9 \text { or } \\
\text { more } \\
\text { hours }\end{array}$ \\
\hline $\begin{array}{l}\text { 31. Do water exercises (do not count other } \\
\text { swimming)? } \\
\text { YES How many TIMES a week? } \\
\text { NO }\end{array}$ & $\begin{array}{l}\text { How many TOTAL } \\
\text { hours a week did you } \\
\text { usually do it? } \rightarrow\end{array}$ & $\begin{array}{l}\text { Less } \\
\text { than } \\
1 \text { hour }\end{array}$ & $\begin{array}{l}1-2 \% / 2 \\
\text { hours }\end{array}$ & $\begin{array}{l}3-4 \frac{1}{2} \\
\text { hours }\end{array}$ & $\begin{array}{l}5-6^{1 / 2} \\
\text { hours }\end{array}$ & $\begin{array}{r}7-81 / 2 \\
\text { hours }\end{array}$ & $\begin{array}{l}9 \text { or } \\
\text { more } \\
\text { hours }\end{array}$ \\
\hline
\end{tabular}




\begin{tabular}{|c|c|c|c|c|c|c|c|}
\hline $\begin{array}{l}\text { In a typical week during the past } \\
4 \text { weeks, did you ... }\end{array}$ & & & & & & & \\
\hline $\begin{array}{l}\text { 32. Swim moderately or fast? } \\
\text { YES How many TIMES a week? } \\
\text { NO }\end{array}$ & $\begin{array}{l}\text { How many TOTAL } \\
\text { hours a week did you } \\
\text { usually do it? } \rightarrow\end{array}$ & $\begin{array}{l}\text { Less } \\
\text { than } \\
1 \text { hour }\end{array}$ & $\begin{array}{l}1-2 \frac{1}{2} \\
\text { hours }\end{array}$ & $\begin{array}{l}3-4 \frac{1}{2} \\
\text { hours }\end{array}$ & $\begin{array}{l}5-6^{1 / 2} \\
\text { hours }\end{array}$ & $\begin{array}{l}7-81 / 2 \\
\text { hours }\end{array}$ & $\begin{array}{l}9 \text { or } \\
\text { more } \\
\text { hours }\end{array}$ \\
\hline $\begin{array}{l}\text { 33. Swim gently? } \\
\text { YES How many TIMES a week? } \\
\text { NO }\end{array}$ & $\begin{array}{l}\text { How many TOTAL } \\
\text { hours a week did you } \\
\text { usually do it? } \rightarrow\end{array}$ & $\begin{array}{l}\text { Less } \\
\text { than } \\
1 \text { hour }\end{array}$ & $\begin{array}{l}1-2 \% / 2 \\
\text { hours }\end{array}$ & $\begin{array}{l}3-4 \% / 2 \\
\text { hours }\end{array}$ & $\begin{array}{l}5-6^{1 / 2} \\
\text { hours }\end{array}$ & $\begin{array}{l}7-8^{1 / 2} \\
\text { hours }\end{array}$ & $\begin{array}{l}9 \text { or } \\
\text { more } \\
\text { hours }\end{array}$ \\
\hline $\begin{array}{l}\text { 34. Do stretching or flexibility exercises (do not } \\
\text { count yoga or Tai-chi)? } \\
\text { YES How many TIMES a week? } \\
\text { NO }\end{array}$ & $\begin{array}{l}\text { How many TOTAL } \\
\text { hours a week did you } \\
\text { usually do it? } \rightarrow\end{array}$ & $\begin{array}{l}\text { Less } \\
\text { than } \\
1 \text { hour }\end{array}$ & $\begin{array}{l}1-2 \frac{1}{2} \\
\text { hours }\end{array}$ & $\begin{array}{l}3-4 \frac{1}{2} \\
\text { hours }\end{array}$ & $\begin{array}{l}5-6^{1 / 2} \\
\text { hours }\end{array}$ & $\begin{array}{r}7-81 / 2 \\
\text { hours }\end{array}$ & $\begin{array}{l}9 \text { or } \\
\text { more } \\
\text { hours }\end{array}$ \\
\hline $\begin{array}{l}\text { 35. Do yoga or Tai-chi? } \\
\text { YES How many TIMES a week? } \\
\text { NO }\end{array}$ & $\begin{array}{l}\text { How many TOTAL } \\
\text { hours a week did you } \\
\text { usually do it? } \rightarrow\end{array}$ & $\begin{array}{l}\text { Less } \\
\text { than } \\
1 \text { hour }\end{array}$ & $\begin{array}{l}1-2 \frac{1}{2} \\
\text { hours }\end{array}$ & $\begin{array}{l}3-4 \frac{1}{2} \\
\text { hours }\end{array}$ & $\begin{array}{l}5-6^{1 / 2} \\
\text { hours }\end{array}$ & $\begin{array}{l}7-81 / 2 \\
\text { hours }\end{array}$ & $\begin{array}{l}9 \text { or } \\
\text { more } \\
\text { hours }\end{array}$ \\
\hline $\begin{array}{l}\text { 36. Do aerobics or aerobic dancing? } \\
\text { YES How many TIMES a week? } \\
\text { NO }\end{array}$ & $\begin{array}{l}\text { How many TOTAL } \\
\text { hours a week did you } \\
\text { usually do it? } \rightarrow\end{array}$ & $\begin{array}{l}\text { Less } \\
\text { than } \\
1 \text { hour }\end{array}$ & $\begin{array}{l}1-2 \% / 2 \\
\text { hours }\end{array}$ & $\begin{array}{l}3-4 \% / 2 \\
\text { hours }\end{array}$ & $\begin{array}{l}5-6^{1 / 2} \\
\text { hours }\end{array}$ & $\begin{array}{l}7-8^{1 / 2} \\
\text { hours }\end{array}$ & $\begin{array}{l}9 \text { or } \\
\text { more } \\
\text { hours }\end{array}$ \\
\hline $\begin{array}{l}\text { 37. Do moderate to heavy strength training } \\
\text { (such as hand-held weights of more than } 5 \mathrm{lbs} \text {., } \\
\text { weight machines, or push-ups)? } \\
\text { YES How many TIMES a week? } \\
\text { NO }\end{array}$ & $\begin{array}{l}\text { How many TOTAL } \\
\text { hours a week did you } \\
\text { usually do it? } \rightarrow\end{array}$ & $\begin{array}{l}\text { Less } \\
\text { than } \\
1 \text { hour }\end{array}$ & $\begin{array}{l}1-2 \frac{1}{2} \\
\text { hours }\end{array}$ & $\begin{array}{l}3-4 \frac{1}{2} \\
\text { hours }\end{array}$ & $\begin{array}{l}5-6^{1 / 2} \\
\text { hours }\end{array}$ & $\begin{array}{r}7-81 / 2 \\
\text { hours }\end{array}$ & $\begin{array}{l}9 \text { or } \\
\text { more } \\
\text { hours }\end{array}$ \\
\hline
\end{tabular}

\begin{tabular}{|c|c|c|c|c|c|c|c|}
\hline $\begin{array}{l}\text { In a typical week during the past } \\
4 \text { weeks, did you .... }\end{array}$ & & & & & & & \\
\hline $\begin{array}{l}\text { 38. Do light strength training (such as hand-held } \\
\text { weights of } 5 \text { lbs. or less or elastic bands)? } \\
\text { YES How many TIMES a week? } \\
\text { NO }\end{array}$ & $\begin{array}{l}\text { How many TOTAL } \\
\text { hours a week did you } \\
\text { usually do it? } \rightarrow\end{array}$ & $\begin{array}{c}\text { Less } \\
\text { than } \\
1 \text { hour }\end{array}$ & $\begin{array}{l}1-2 \% / 2 \\
\text { hours }\end{array}$ & $\begin{array}{l}3-4 \% / 2 \\
\text { hours }\end{array}$ & $\begin{array}{l}5-61 / 2 \\
\text { hours }\end{array}$ & $\begin{array}{l}7-81 / 2 \\
\text { hours }\end{array}$ & $\begin{array}{l}9 \text { or } \\
\text { more } \\
\text { hours }\end{array}$ \\
\hline $\begin{array}{l}\text { 39. Do general conditioning exercises, such as } \\
\text { light calisthenics or chair exercises (do not } \\
\text { count strength training)? } \\
\text { YES How many TIMES a week? } \\
\text { NO }\end{array}$ & $\begin{array}{l}\text { How many TOTAL } \\
\text { hours a week did you } \\
\text { usually do it? } \rightarrow\end{array}$ & $\begin{array}{l}\text { Less } \\
\text { than } \\
1 \text { hour }\end{array}$ & $\begin{array}{l}1-2 \frac{1}{2} \\
\text { hours }\end{array}$ & $\begin{array}{l}3.4 \% 2 \\
\text { hours }\end{array}$ & $\begin{array}{l}5-61 / 2 \\
\text { hours }\end{array}$ & $\begin{array}{l}7-81 / 2 \\
\text { hours }\end{array}$ & $\begin{array}{l}9 \text { or } \\
\text { more } \\
\text { hours }\end{array}$ \\
\hline $\begin{array}{l}\text { 40. Play basketball, soccer, or racquetball (do } \\
\text { not count time on sidelines)? } \\
\text { YES How many TIMES a week? } \\
\text { NO }\end{array}$ & $\begin{array}{l}\text { How many TOTAL } \\
\text { hours a week did you } \\
\text { usually do it? } \rightarrow\end{array}$ & $\begin{array}{l}\text { Less } \\
\text { than } \\
1 \text { hour }\end{array}$ & $\begin{array}{l}1-2 \% / 2 \\
\text { hours }\end{array}$ & $\begin{array}{l}3-4 \% / 2 \\
\text { hours }\end{array}$ & $\begin{array}{l}5-61 / 2 \\
\text { hours }\end{array}$ & $\begin{array}{l}7-81 / 2 \\
\text { hours }\end{array}$ & $\begin{array}{l}9 \text { or } \\
\text { more } \\
\text { hours }\end{array}$ \\
\hline $\begin{array}{l}\text { 41. Do other types of physical activity not } \\
\text { previously mentioned (please specify)? } \\
\text { YES How many TIMES a week? } \\
\text { NO }\end{array}$ & $\begin{array}{l}\text { How many TOTAL } \\
\text { hours a week did you } \\
\text { usually do it? } \rightarrow\end{array}$ & $\begin{array}{l}\text { Less } \\
\text { than } \\
1 \text { hour }\end{array}$ & $\begin{array}{l}1-2 \% / 2 \\
\text { hours }\end{array}$ & $\begin{array}{l}3-4 \% / 2 \\
\text { hours }\end{array}$ & $\begin{array}{l}5-61 / 2 \\
\text { hours }\end{array}$ & $\begin{array}{l}7-81 / 2 \\
\text { hours }\end{array}$ & $\begin{array}{l}9 \text { or } \\
\text { more } \\
\text { hours }\end{array}$ \\
\hline
\end{tabular}

\section{Thank You}




\section{Appendix D}

The Paffenbarger Activity Questionnaire

Please answer the following questions based on your activity since the last testing session.

1. How many stairs did you climb since the last testing session

a. stairs (1 flight or floor $=10$ stairs)

2. How many city blocks or their equivalent did you walk since the last testing session?

a. _ blocks (12 blocks $=1$ mile)

3. List any sports, leisure, or recreational activities you have participated in since the last testing session. Additionally, please enter the approximate duration of these sessions.

Sport or Recreation

1.

2.

3.

4.

5.

6.
.

.
Time per Episode

$\underline{\text { Hours } \quad \text { Minutes }}$

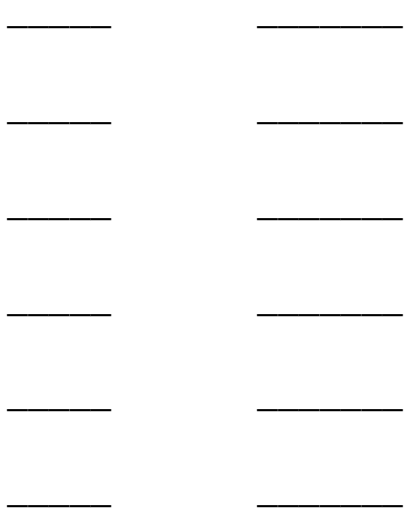




\section{Appendix E}

Select National Health Interview Survey Items

The next questions are about physical activities (exercise, sports, physically active hobbies) that you may have done in your leisure time since your last testing session.

Since your last testing session:

1. Have you engaged in any VIGOROUS leisure-time physical activities for AT LEAST 10 MINUTES that cause HEAVY sweating or LARGE increases in breathing or heart rate?

No

Yes

If yes, how for how long? hours minutes

2. Have you engaged in any LIGHT OR MODERATE leisure-time physical activities for AT LEAST 10 MINUTES that cause ONLY LIGHT sweating or SLIGHT TO MODERATE increase in breathing or heart rate?

No

Yes

If yes, how for how long? hours minutes 


\section{Appendix F}

The PANAS

This scale consists of a number of words that describe different feelings and emotions. Read each item and then mark the appropriate answer in the space next to that word. Indicate to what extent each word describes how you have felt since the last time of measurement. Use the following scale to record your answers.

\section{very slightly or not at all}

1

$\begin{array}{ll}\text { _ interested } & \text { _irritable } \\ \text { _ distressed } & \text { _alert } \\ \text { _ excited } & \text { - ashamed } \\ \text { _upset } & \text { _inspired } \\ \text { _strong } & \text {-nervous } \\ \text {-guilty } & \text { _determined } \\ \text { - scared } & \text {-attentive } \\ \text { - hostile } & \text { _jittery } \\ \text { - enthusiastic } & \text {-active } \\ \text { - proud } & \text { _afraid }\end{array}$

a little

(1)

3 moderately quite a bit extremely 


\section{Appendix G}

\section{The SWLS}

Below are five statements with which you may agree or disagree. Using the $1-7$ scale below, indicate your agreement with each item by placing the appropriate number on the line preceding that item. Please be open and honest in your responding.

$\begin{array}{ccccccc}1 & 2 & 3 & 4 & 5 & 6 & 7 \\ \text { strongly } & \text { disagree } & \begin{array}{l}\text { slightly } \\ \text { disagree }\end{array} & \begin{array}{l}\text { neither agree slightly } \\ \text { nor disagree }\end{array} & \text { agree } & \text { agree } & \begin{array}{c}\text { strongly } \\ \text { disagree }\end{array}\end{array}$

1. In most ways my life is close to my ideal.

2. The conditions of my life are excellent.

3. I am satisfied with my life.

4. So far I have gotten the important things I want in life.

5. If I could live my life over, I would change almost nothing. 


\section{Appendix $\mathrm{H}$ \\ Goal Screening and Daily Goal Process Journal}

Prior to participation, participants will be asked the following:

One way to define goal-directed behavior is to examine current concerns. Current concerns are conceptualized as "The state of having become committed to a particular goal." Examples of current concerns include "exercising daily," "finding a job that better suits my interests and skills," "growing closer to my grown children and their children," and "finding new activities to occupy my free time." As you can see, the concept of current concerns can include a wide variety of goals. You also may have any number of current concerns. However, the purpose of this study is to learn about the daily pursuit of short-term physical activity goals. Please tell us about one personal physical activity goal you're trying to accomplish. You may or may not be able to completely achieve this goal during the course of this study. We will eventually ask you questions about your physical activity goal. Thus, the goal that you nominate should be one that you reasonably expect will be on your mind for the duration of the study.

1. How much control do you have over working toward your physical activity goal?

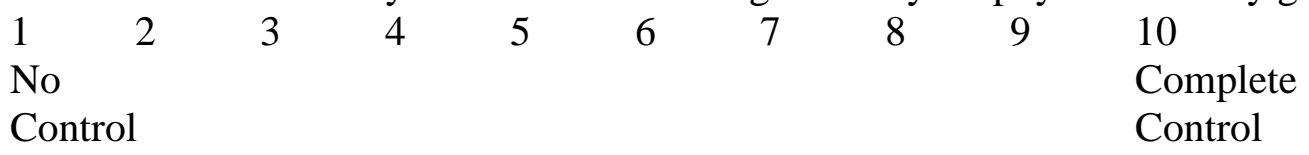

2. How much effort have you put forth toward your physical activity goal?

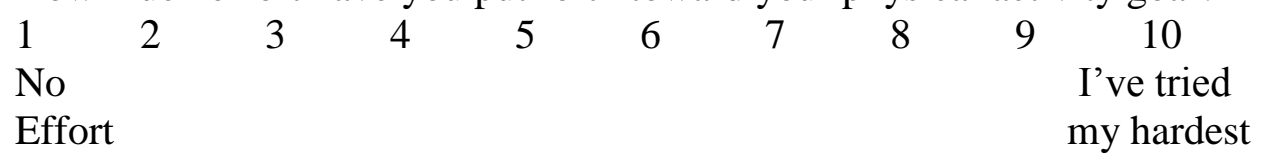

3. How much progress toward your physical activity goal do you feel you have made?
No
Progress
45
$6 \quad 7$
8
$9 \quad 10$
Complete
Progress

4. How difficult will it be to work toward your physical activity goal?

$\begin{array}{llllllllll}1 & 2 & 3 & 4 & 5 & 6 & 7 & 8 & 9 & 10 \\ \text { Very } & & & & & & & & & \text { Very easy } \\ \text { Difficult } & & & & & & & & & \end{array}$

5. Working toward my physical activity goal would be

$\begin{array}{llllllllll}\text { A. } \quad 1 & 2 & 3 & 4 & 5 & 6 & 7 & 8 & 9 & 10 \\ \text { Very bad } & & & & & & & & & \text { Very good } \\ \text { B. } \quad 1 & 2 & 3 & 4 & 5 & 6 & 7 & 8 & 9 & 10 \\ \text { Very useless } & & & & & & & & & \text { Very useful }\end{array}$


$\begin{array}{lllllllllll}\text { C. } & 1 & 2 & 3 & 4 & 5 & 6 & 7 & 8 & 9 & 10\end{array}$ Very harmful Very beneficial

6. How important is it that you work toward your attaining your physical activity goal?

$\begin{array}{llllllllll}1 & 2 & 3 & 4 & 5 & 6 & 7 & 8 & 9 & 10\end{array}$
Not at all

Important

Very

Important

7. My significant other thinks it is important that I should work toward my physical activity goal.

$\begin{array}{lllllllll}1 \quad 2 & 3 & 4 & 5 & 6 & 7 & 8 & 9 & 10 \\ \begin{array}{l}\text { Disagree very } \\ \text { much }\end{array} & & & & & & & \text { Agree very much } \\ \end{array}$

8. When it comes to working toward my physical activity goal, I want to do what this person thinks I should do.

$\begin{array}{lllllllll}1 \quad 2 & 3 & 4 & 5 & 6 & 7 & 8 & 9 & 10 \\ \begin{array}{l}\text { Disagree very } \\ \text { much }\end{array} & & & & & & & \text { Agree very much }\end{array}$


Appendix I

Daily Goal Processes in Physical Activity \& Mood During Midlife: Daily Log

Thank you for participating in this study. This sheet is your Daily Log. In the table below, please indicate the time you went to bed the previous night, the time you awoke each day and your quality of sleep on each given night. In addition, please note any issues related to the Palm operation. Finally, if you have any general comments or impressions on a given day, please include them in the "Comments" section. If you have any problems or questions, please call me at (304) 906-8394.

\begin{tabular}{|c|c|c|}
\hline \multicolumn{3}{|l|}{$\begin{array}{l}\text { DAY 1: MONDAY } \\
\text { DATE: }\end{array}$} \\
\hline $\begin{array}{l}\text { Went to bed the previous } \\
\text { night at... }\end{array}$ & Awoke today at.... & $\begin{array}{l}\text { How would you rate your sleep } \\
\text { quality on this night? }(0-3 \text {, } \\
\text { where } 0 \text { = very bad; } 3=\text { very } \\
\text { good) }\end{array}$ \\
\hline \multicolumn{3}{|l|}{$\begin{array}{l}\text { Any issues } \\
\text { with the } \\
\text { Palm } \\
\text { operation? }\end{array}$} \\
\hline \multicolumn{3}{|l|}{ Comments } \\
\hline \multicolumn{3}{|l|}{$\begin{array}{l}\text { DAY 2: TUESDAY } \\
\text { DATE: }\end{array}$} \\
\hline $\begin{array}{l}\text { Went to bed the previous } \\
\text { night at... }\end{array}$ & Awoke today at.... & $\begin{array}{l}\text { How would you rate your sleep } \\
\text { quality on this night? }(0-3 \text {, } \\
\text { where } 0 \text { = very bad; } 3=\text { very } \\
\text { good) }\end{array}$ \\
\hline & & \\
\hline
\end{tabular}




\begin{tabular}{|c|c|c|}
\hline \multicolumn{3}{|l|}{$\begin{array}{l}\text { Any issues } \\
\text { with the } \\
\text { Palm } \\
\text { operation? }\end{array}$} \\
\hline \multicolumn{3}{|l|}{ Comments } \\
\hline \multicolumn{3}{|c|}{$\begin{array}{l}\text { DAY 3: WEDNESDAY } \\
\text { DATE: }\end{array}$} \\
\hline $\begin{array}{l}\text { Went to bed the previous } \\
\text { night at... }\end{array}$ & Awoke today at.... & $\begin{array}{l}\text { How would you rate your sleep } \\
\text { quality on this night? }(0-3 \text {, } \\
\text { where } 0=\text { very bad; } 3=\text { very } \\
\text { good) }\end{array}$ \\
\hline \multicolumn{3}{|l|}{$\begin{array}{l}\text { Any issues } \\
\text { with the } \\
\text { Palm } \\
\text { operation? }\end{array}$} \\
\hline \multicolumn{3}{|l|}{ Comments } \\
\hline \multicolumn{3}{|c|}{$\begin{array}{l}\text { DAY 4: THURSDAY } \\
\text { DATE: }\end{array}$} \\
\hline $\begin{array}{l}\text { Went to bed the previous } \\
\text { night at... }\end{array}$ & Awoke today at.... & $\begin{array}{l}\text { How would you rate your sleep } \\
\text { quality on this night? }(0-3 \text {, } \\
\text { where } 0=\text { very bad; } 3=\text { very } \\
\text { good) }\end{array}$ \\
\hline
\end{tabular}




\begin{tabular}{|c|c|c|}
\hline \multicolumn{3}{|l|}{$\begin{array}{l}\text { Any issues } \\
\text { with the } \\
\text { Palm } \\
\text { operation? }\end{array}$} \\
\hline \multicolumn{3}{|l|}{ Comments } \\
\hline \multicolumn{3}{|c|}{$\begin{array}{l}\text { DAY 5: FRIDAY } \\
\text { DATE: }\end{array}$} \\
\hline $\begin{array}{l}\text { Went to bed the previous } \\
\text { night at... }\end{array}$ & Awoke today at.... & $\begin{array}{l}\text { How would you rate your sleep } \\
\text { quality on this night? }(0-3 \text {, } \\
\text { where } 0=\text { very bad; } 3=\text { very } \\
\text { good) }\end{array}$ \\
\hline \multicolumn{3}{|l|}{$\begin{array}{l}\text { Any issues } \\
\text { with the } \\
\text { Palm } \\
\text { operation? }\end{array}$} \\
\hline \multicolumn{3}{|l|}{ Comments } \\
\hline \multicolumn{3}{|c|}{$\begin{array}{l}\text { DAY 6: SATURDAY } \\
\text { DATE: }\end{array}$} \\
\hline $\begin{array}{l}\text { Went to bed the previous } \\
\text { night at... }\end{array}$ & Awoke today at.... & $\begin{array}{l}\text { How would you rate your sleep } \\
\text { quality on this night? }(0-3 \text {, } \\
\text { where } 0=\text { very bad; } 3=\text { very } \\
\text { good) }\end{array}$ \\
\hline
\end{tabular}




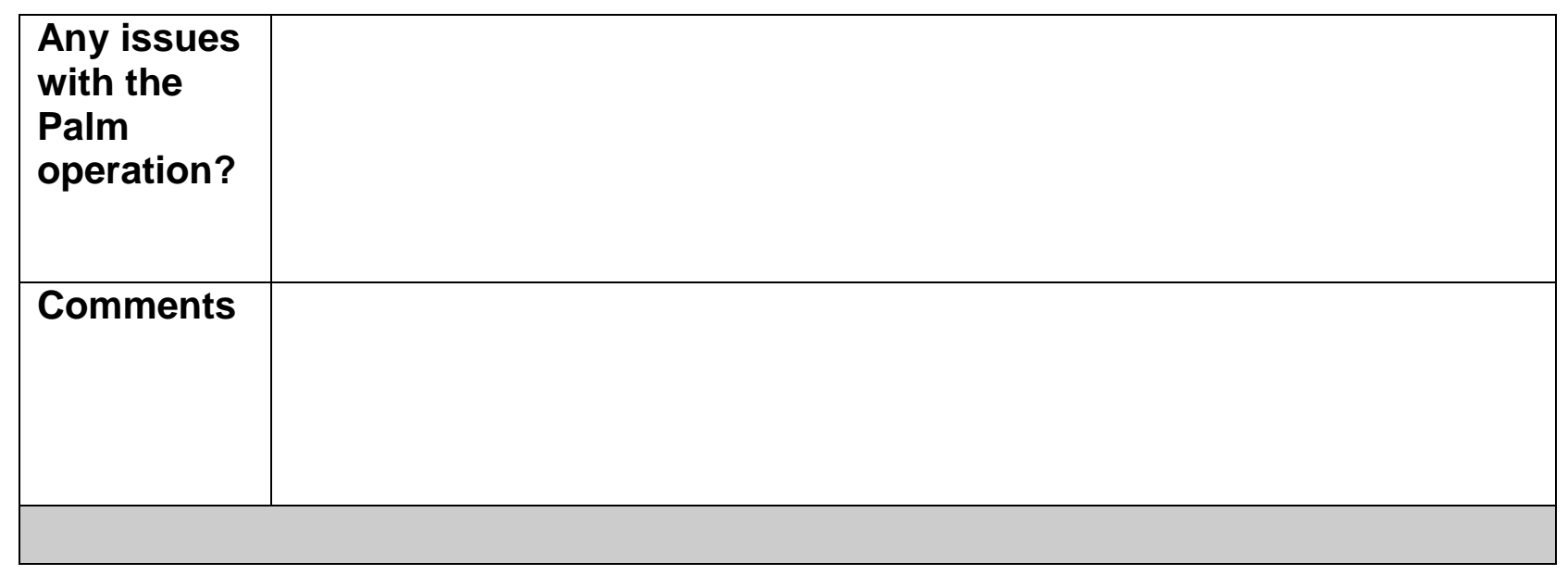

Please contact me when you are finished so that I can retrieve the Palm and compensate you for your time and participation. Call (304) 906-8394 or email Eric.Goedereis@mail.wvu.edu.

\section{THANK YOU FOR PARTICIPATING!}

